
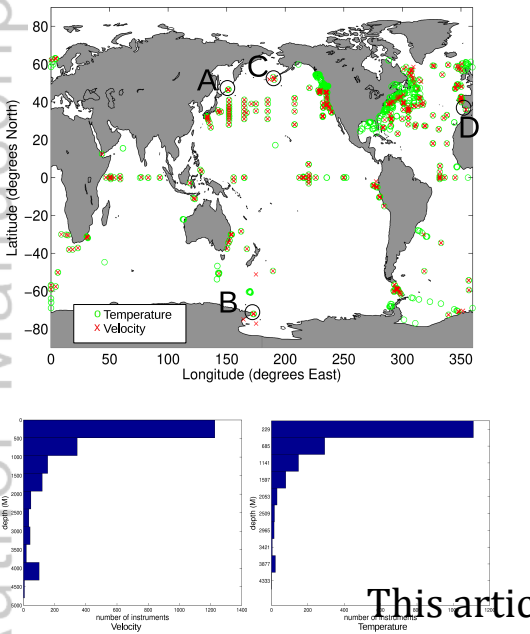
Figure 2.
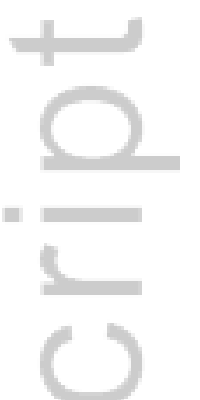

$\infty$
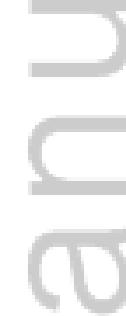

This article is protected by copyright. All rights reserved. 
Temperature Spectra at $236^{\circ} \mathrm{E}, 39^{\circ} \mathrm{N}$

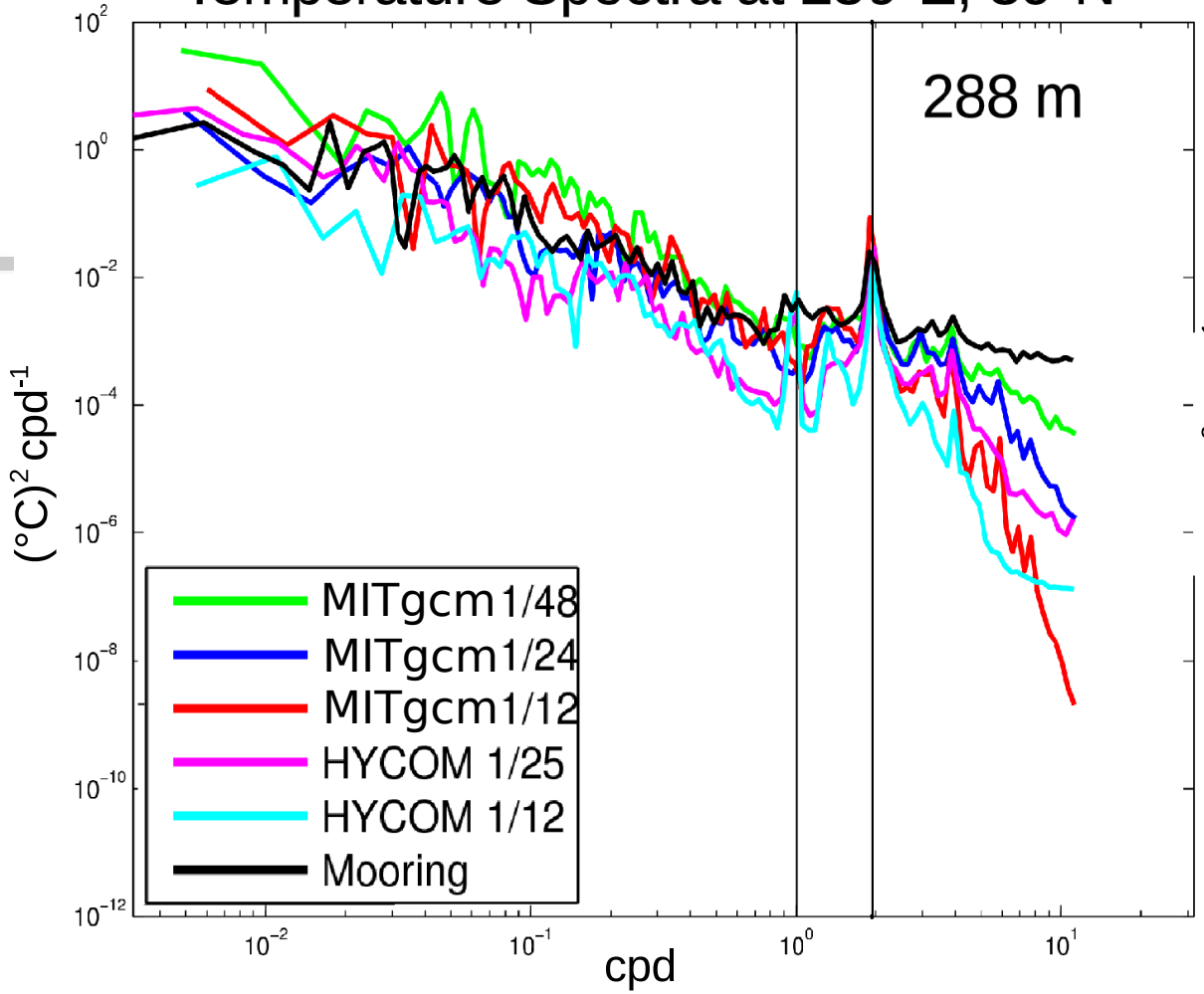

Temperature Spectra at $232^{\circ} \mathrm{E}, 39^{\circ} \mathrm{N}$

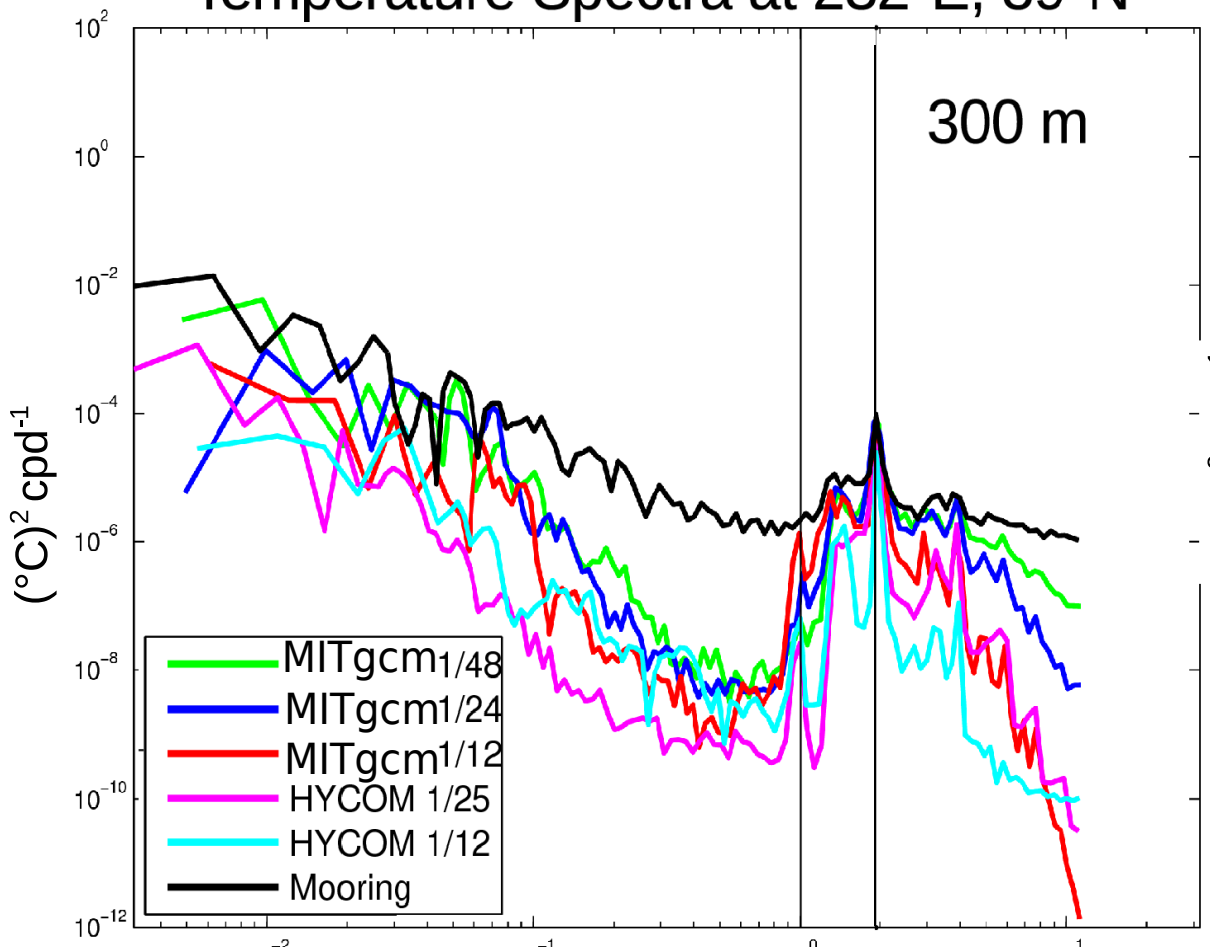

$\mathrm{KE}$ Spectra at $298^{\circ} \mathrm{E}, 43^{\circ} \mathrm{N}$

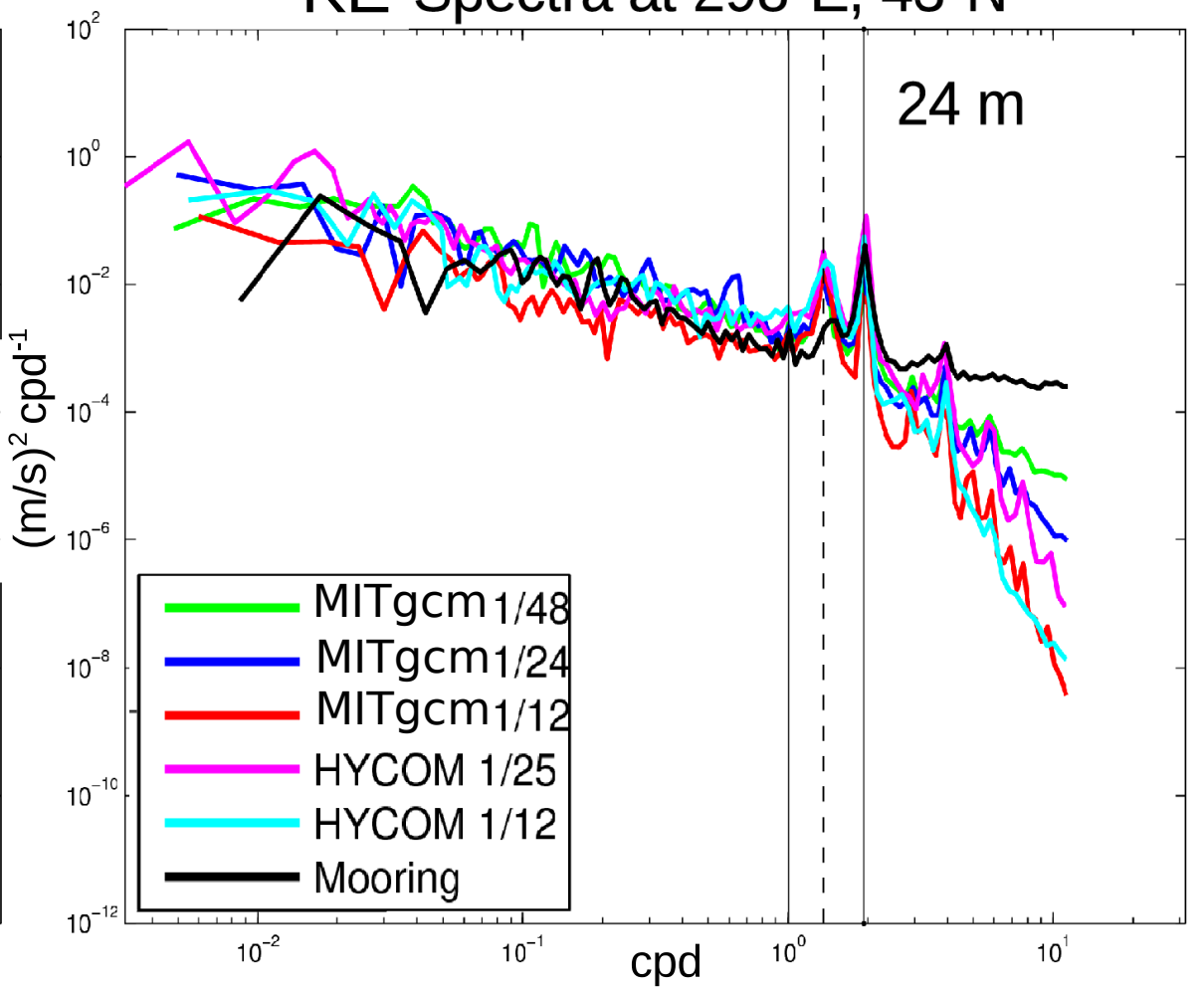

KE Spectra at $288^{\circ} \mathrm{E}, 39^{\circ} \mathrm{N}$

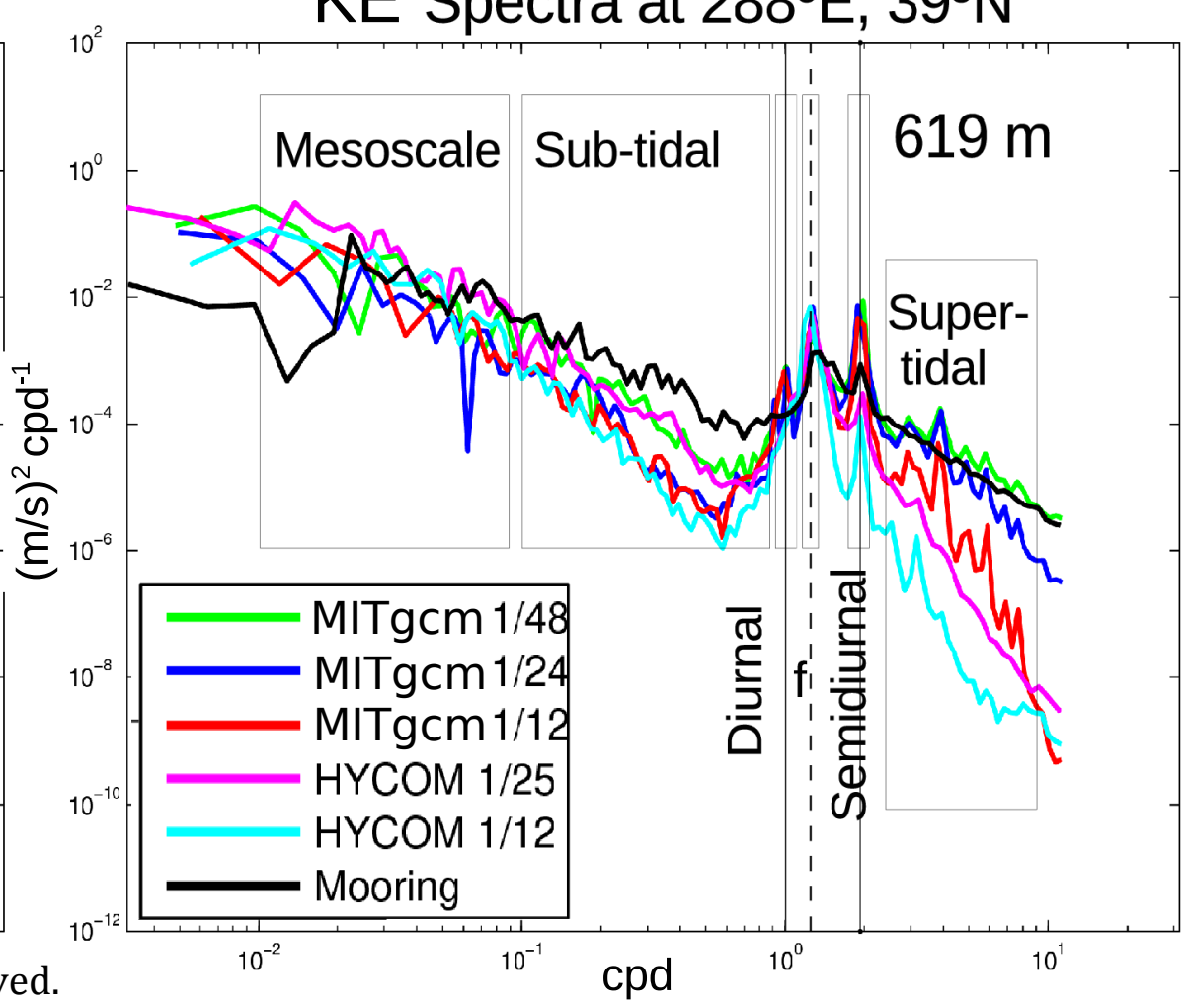




\section{Mean KE by Frequency Band}
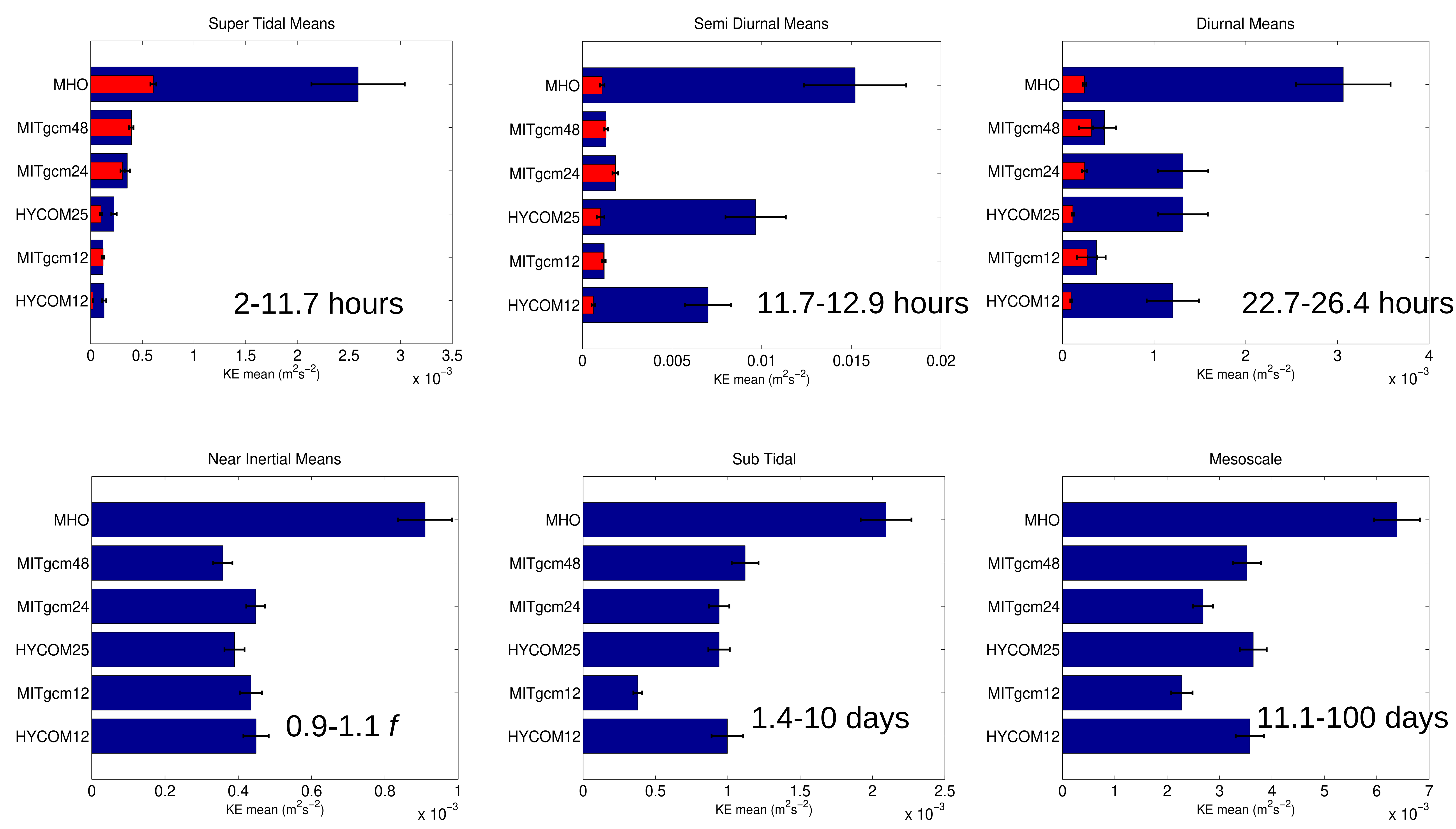

\section{Mean Temperature Variance by Frequency Band}
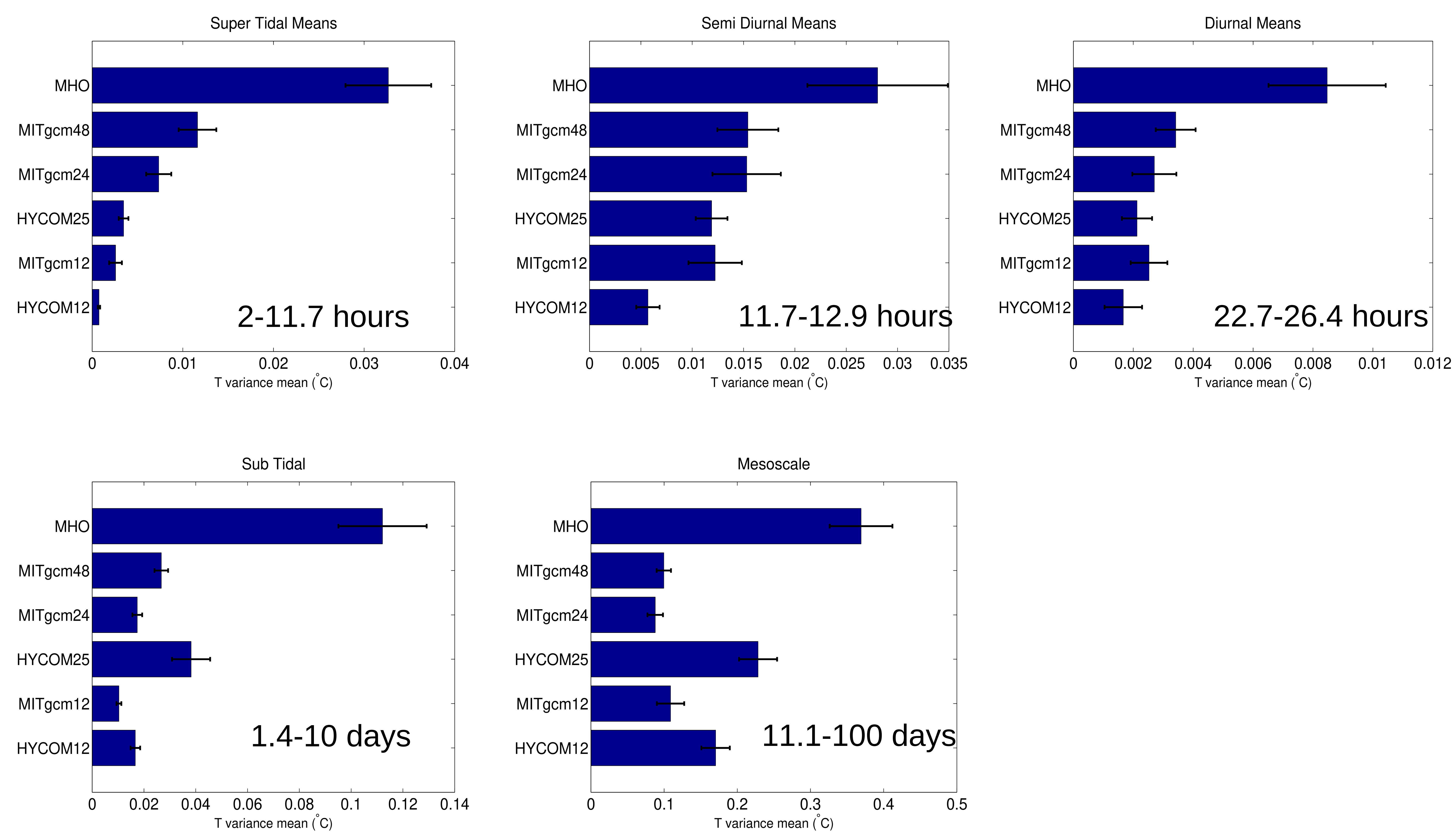
KE comparison metrics
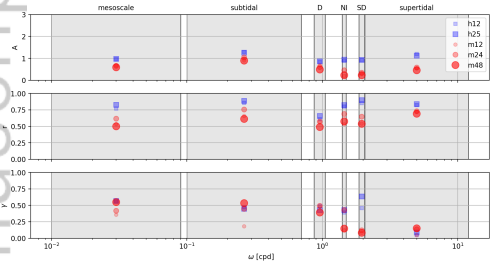

mesoscale

subtidal

D

5D

supertidal

temperature variance comparison metrics
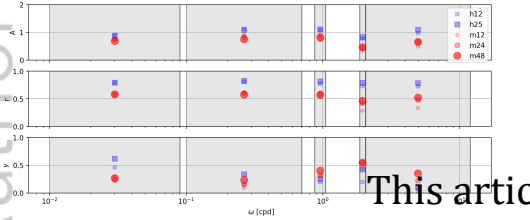
Figure 5.
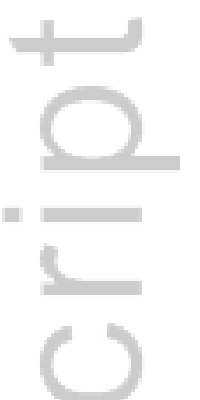

$\infty$
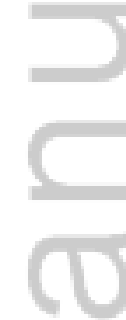

This article is protected by copyright. All rights reserved. 
MITgcm12 Super Tidal KE

MHO mean $=2.59 \mathrm{e}-03$

MITgcm mean $=1.19 \mathrm{e}-04$

$A=0.55, b=-2.51 * A=0.97, b=-1.01$

$\begin{array}{ll}A=0.05 & { }^{*} \gamma=0.20 \\ \gamma=0.72 & { }^{*} r_{s}=0.75\end{array}$

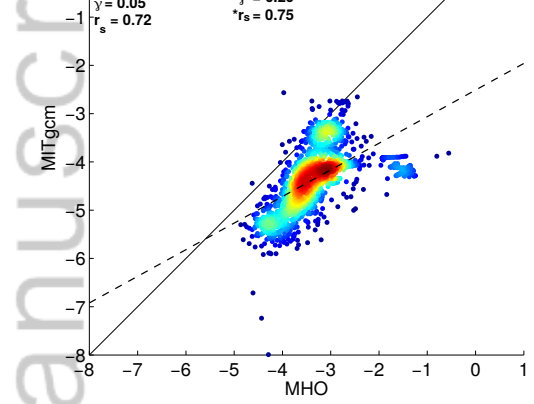

HYCOM12 Super Tidal KE

MHO mean $=2.59 \mathrm{e}-03$

HYCOM mean $=1.30 \mathrm{e}-04$

O $A=1.20, b=-1.04 * A=1.20, b=-1.06$

$\begin{array}{lll}A=0.05 & { }^{*} A=0.04 \\ \gamma & \gamma=0.83 & { }^{*} r_{s}=0.78\end{array}$
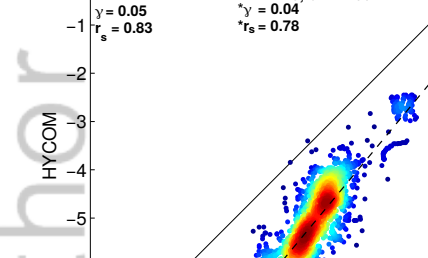

-5
-6

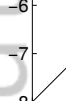

$-8$

then

(3)

$-5 \quad-4 \mathrm{MHO}^{-3}$
MITgcm24 Super Tidal KE

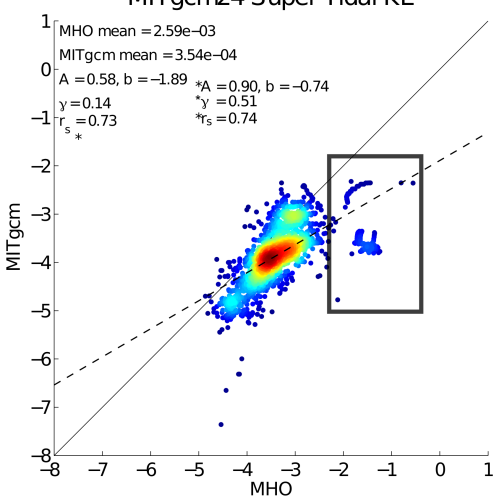

HYCOM25 Super Tidal KE

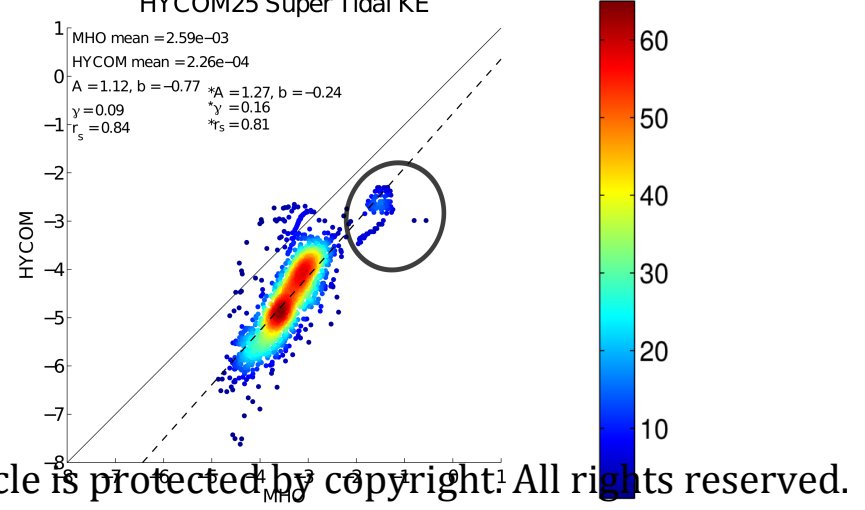

60

50

$-40$

$-30$

$-20$

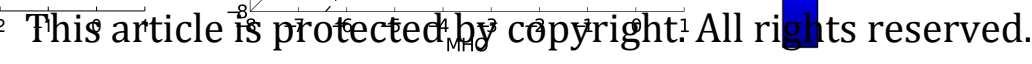

MITgcm48 Super Tidal KE

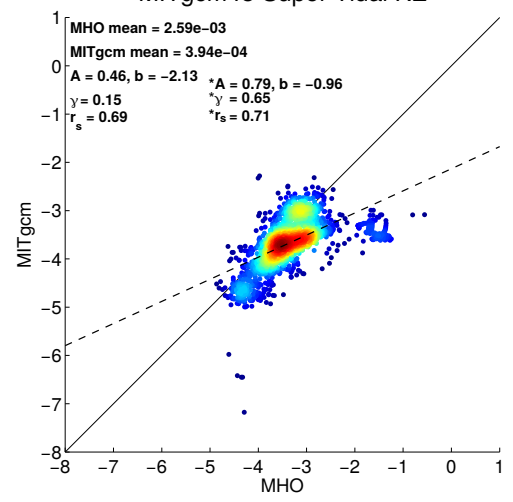


MITgcm12 Super Tidal temperature

MHO mean $=3.27 \mathrm{e}-02$

MITgcm mean $=2.57 \mathrm{e}-03$

$A=0.49, b=-2.84$

$\gamma=0.08$

$-1 \frac{\gamma=0.08}{r_{s}=0.34}$

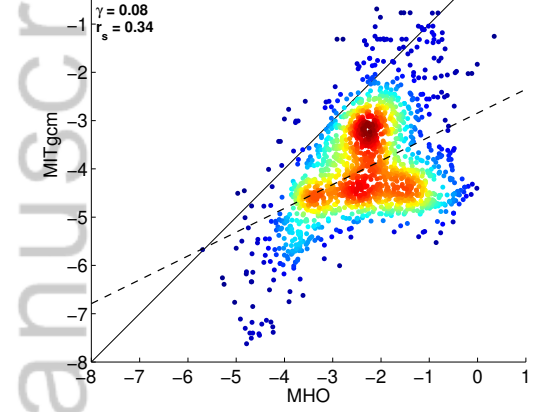

HYCOM12 Super Tidal temperature

MHO mean $=3.27 \mathrm{e}-02$

HYCOM mean $=7.47 \mathrm{e}-04$

$A=0.98, b=-2.08$

$-1 \mid \begin{aligned} & \gamma=0.02 \\ & r_{s}=0.73\end{aligned}$

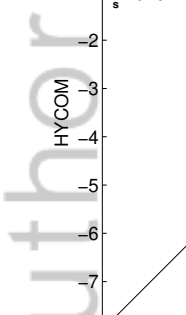

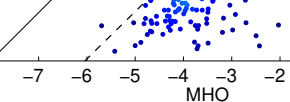

MITgcm24 Super Tidal temperature

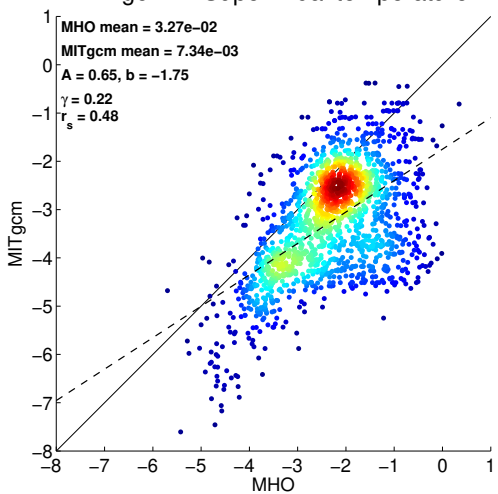

HYCOM25 Super Tidal temperature

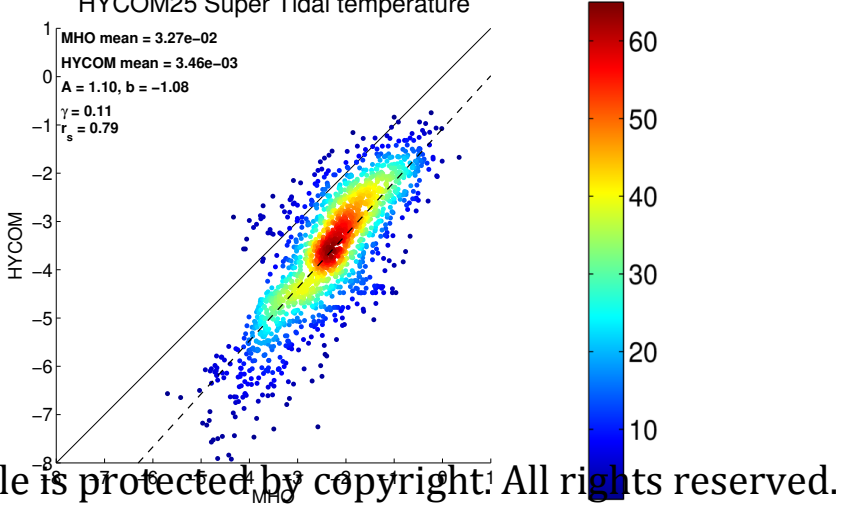

MITgcm48 Super Tidal temperature

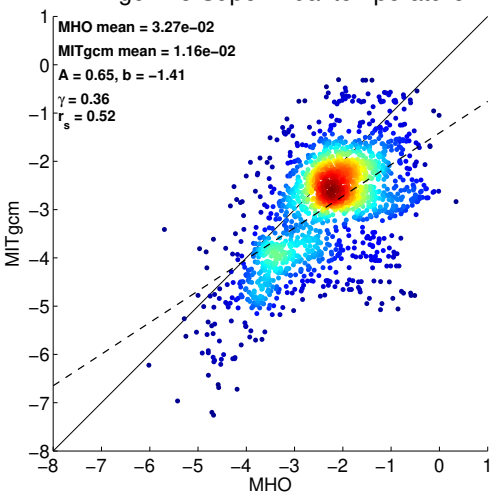

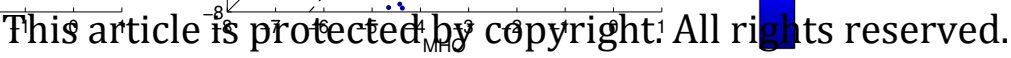


MITgcm12 Semi-Diurnal KE

MHO mean $=1.52 \mathrm{e}-02$

MITgcm mean $=1.22 \mathrm{e}-03$

$A=0.28, b=-2.27 * A=0.43, b=-1.77$

$\begin{array}{ll}\gamma=0.08 & { }^{*} \gamma=1.08 \\ r_{s}=0.54 & { }^{*} r_{s}=0.51\end{array}$

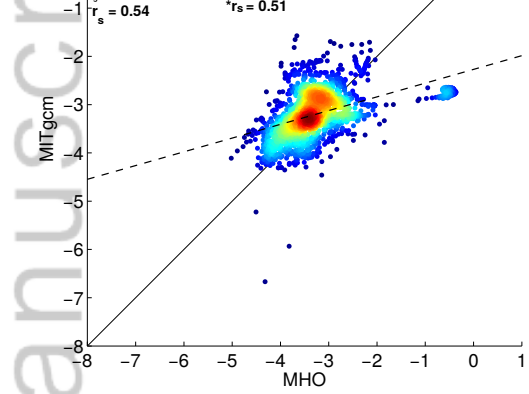

HYCOM12 Semi-Diurnal KE

MHO mean $=1.52 \mathrm{e}-02$

HYCOM mean $=7.01 \mathrm{e}-03$

$\mathrm{A}=0.92, \mathrm{~b}=-0.52 \times \mathrm{A}=0.86, \mathrm{~b}=-0.72$

\begin{tabular}{l|ll} 
& & \\
$\gamma=0.46$ & & \\
& ${ }^{*} \gamma=0.56$ \\
$r_{s}=0.85$ & ${ }^{*} r_{s}=0.83$
\end{tabular}

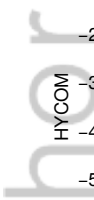

MITgcm24 Semi-Diurnal KE

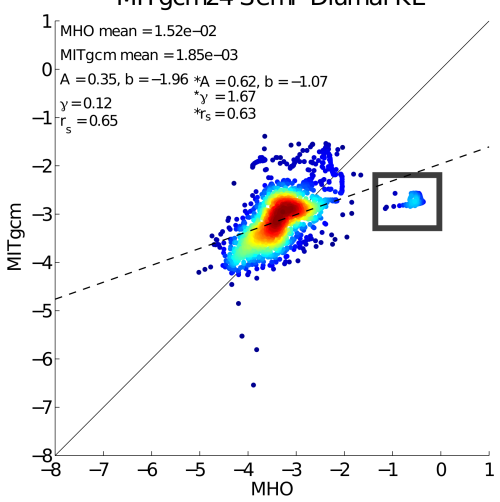

HYCOM25 Semi-Diurnal KE

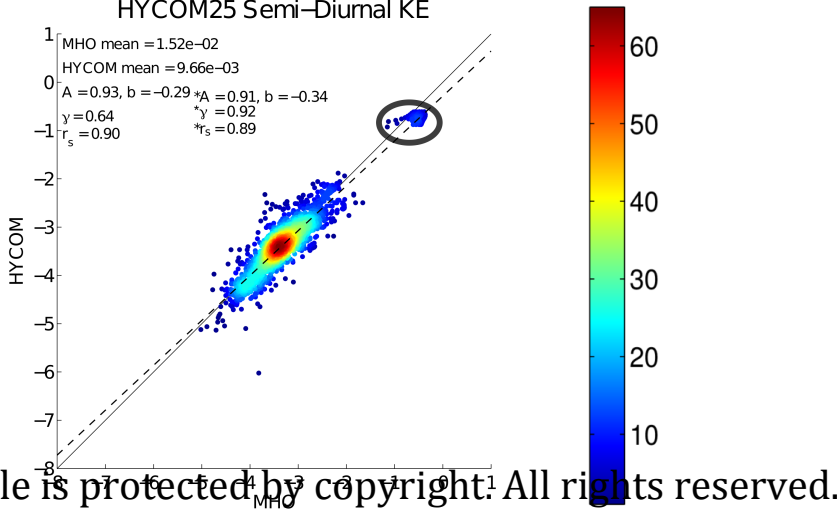

\section{MITgcm48 Semi-Diurnal KE}

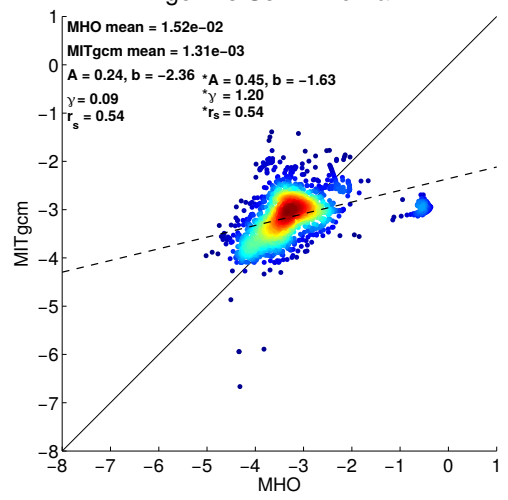

ts reserved. 
MITgcm12 Semi-Diurnal temperature

MHO mean $=2.81 \mathrm{e}-02$

MITgcm mean $=1.22 \mathrm{e}-02$

$A=0.34, b=-2.38$

$\gamma=0.44$

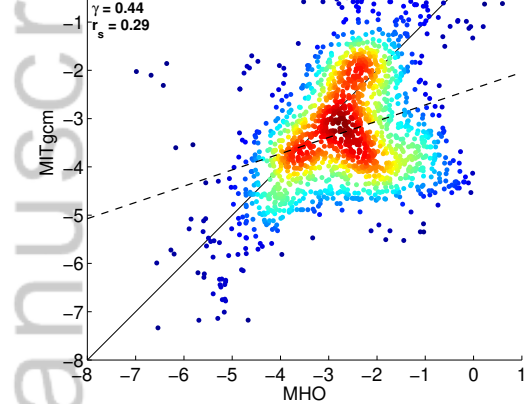

HYCOM12 Semi-Diurnal temperature

MHO mean $=2.81 \mathrm{e}-02$

HYCOM mean $=5.68 \mathrm{e}-03$

$A=0.77, b=-1.44$

$\gamma=0.20$
$\gamma=0.73$

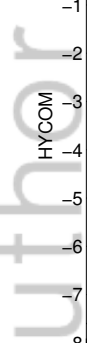
$-8$

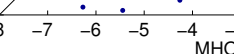

$\therefore$

$\therefore$

西

$\therefore$

or $\because \therefore$

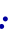

$\therefore$.

\section{T}

MITgcm24 Semi-Diurnal temperature

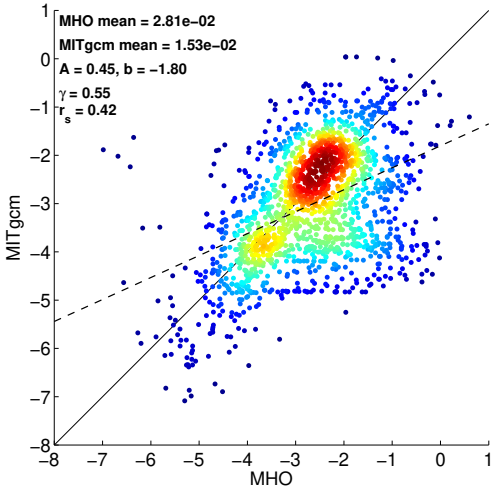

HYCOM25 Semi-Diurnal temperature

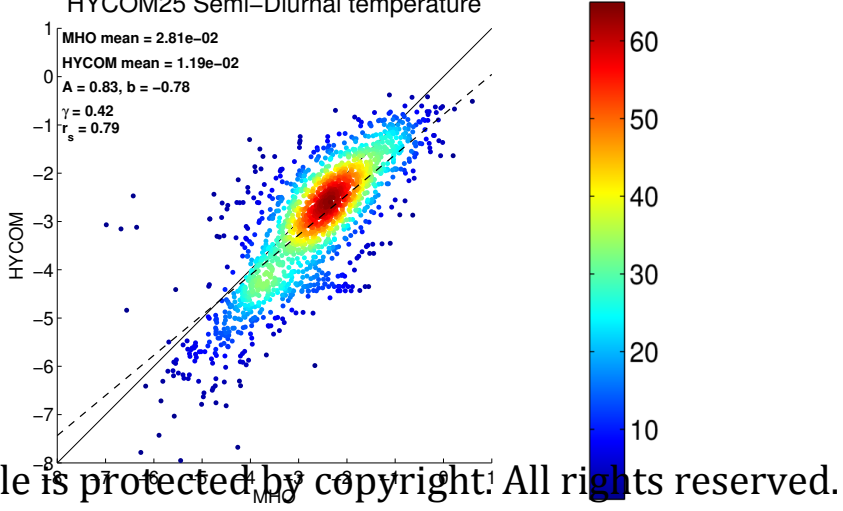

60

50
MITgcm48 Semi-Diurnal temperature

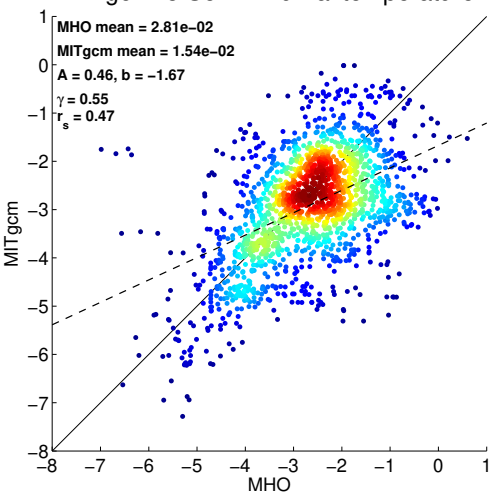

$\because \cdots$

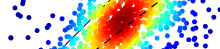

- $\therefore$,

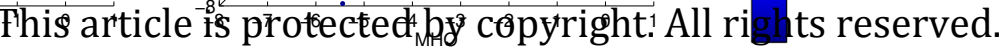


Figure 9.
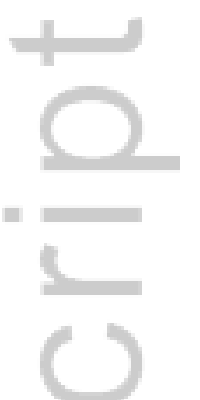

$\infty$
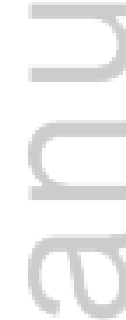

This article is protected by copyright. All rights reserved. 
MITgcm12 Diurnal KE

MHO mean $=3.06 \mathrm{e}-03$

MITgcm mean $=3.71 \mathrm{e}-04$

$A=0.20, b=-3.26 * A=0.57, b=-1.79$

$\begin{array}{ll}\gamma=0.12 & { }^{*} \gamma=1.10 \\ r_{s}=0.53 & { }^{*} r_{s}=0.66\end{array}$

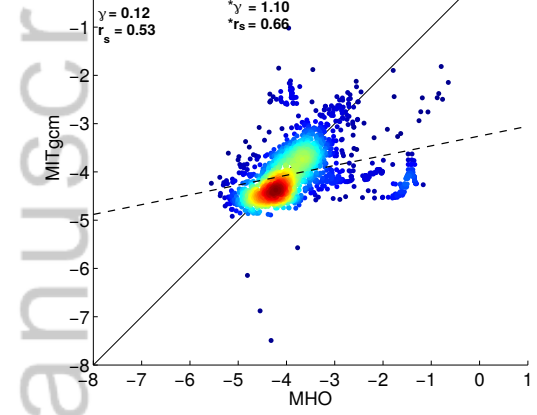

HYCOM12 Diurnal KE

MHO mean $=3.06 \mathrm{e}-03$

HYCOM mean $=1.20 \mathrm{e}-03$

0 $A=0.90, b=-0.91 * A=0.91, b=-0.84$

$-1 \quad \begin{array}{ll}A=0.39 & { }^{*} \gamma=0.41 \\ \gamma=0.80 & { }^{*} r_{s}=0.79\end{array}$
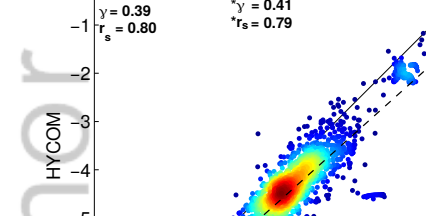

की

a

artastis.

, w.

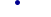

MITgcm24 Diumal KE

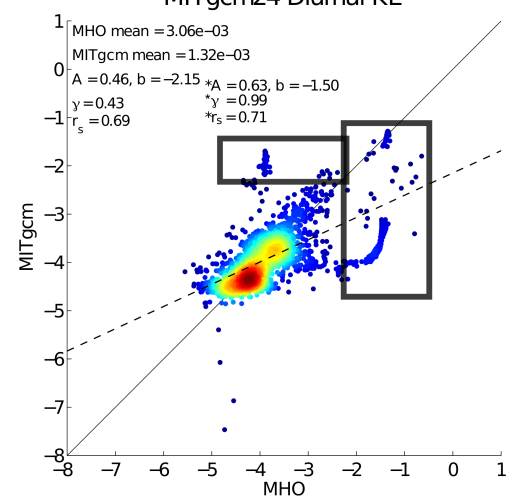

HYCOM25 Diurnal KE

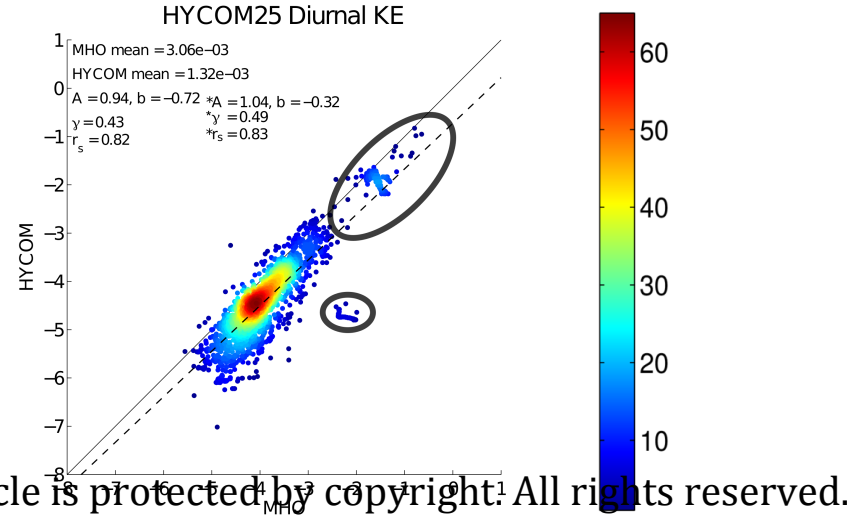


MITgcm12 Diurnal temperature

MHO mean $=8.47 \mathrm{e}-03$

MITgcm mean $=2.52 \mathrm{e}-03$

$A=0.75, b=-1.93$

\begin{tabular}{l|l}
$\gamma$ & $\gamma=0.30$ \\
$-r_{s}=0.53$
\end{tabular}

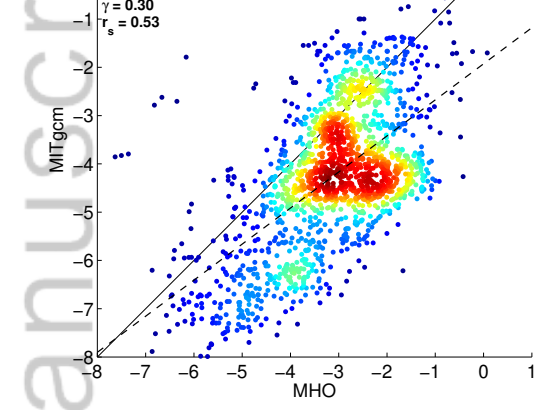

HYCOM12 Diurnal temperature

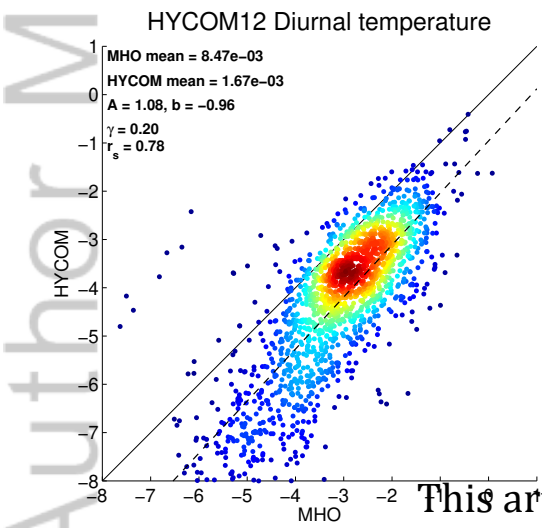

MITgcm24 Diurnal temperature

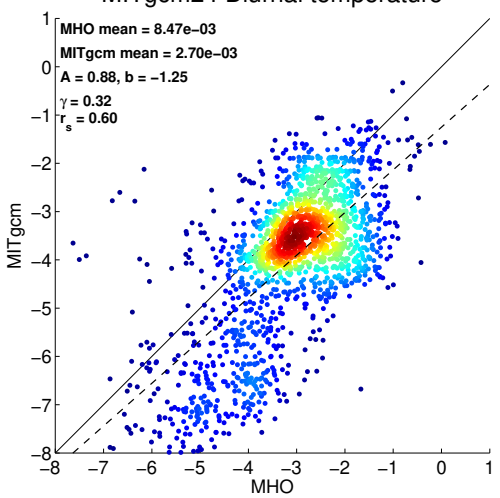

HYCOM25 Diurnal temperature

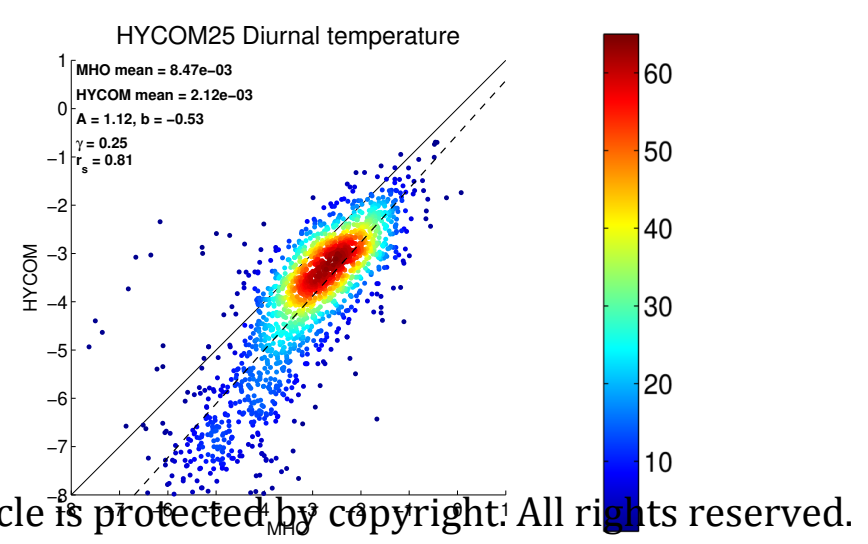

MITgcm48 Diurnal temperature

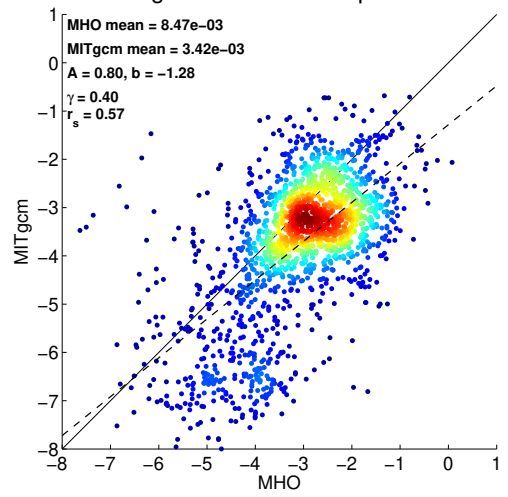


Figure 12.
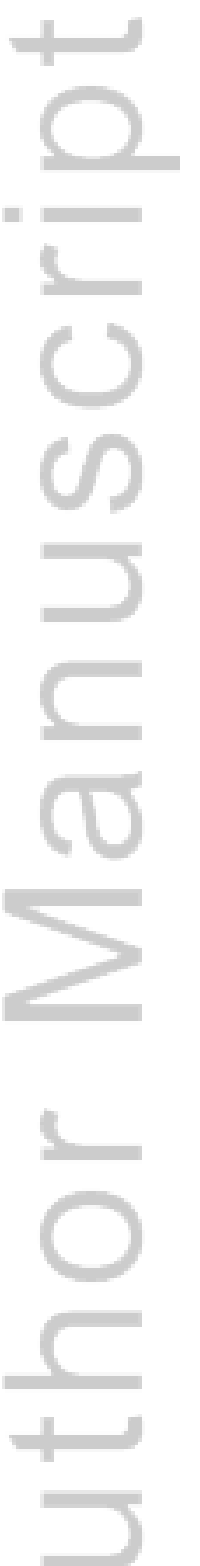

This article is protected by copyright. All rights reserved. 
MITgcm12 Sub Tidal temperature

MHO mean $=1.12 \mathrm{e}-01$

MITgcm mean $=1.03 \mathrm{e}-02$

$A=0.92, b=-1.39$

$-1 \mid \begin{aligned} & \gamma=0.09 \\ & \gamma-r_{s}=0.61\end{aligned}$

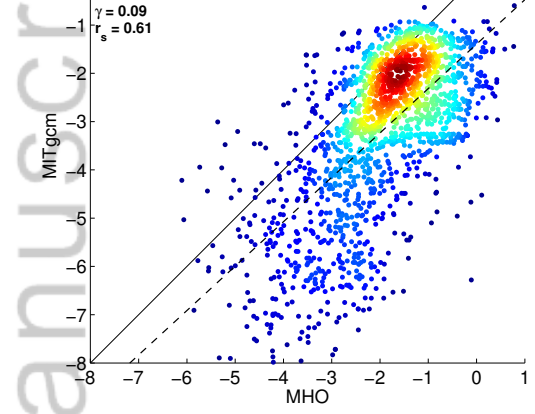

HYCOM12 Sub Tidal temperature

MHO mean $=1.12 \mathrm{e}-01$

HYCOM mean $=1.67 \mathrm{e}-02$

$A=1.12, b=-0.84$

$\gamma=0.15$

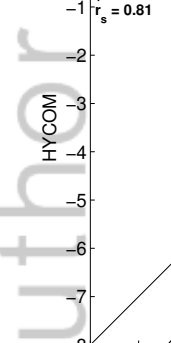

$-8$

$\begin{array}{lll}-8 & -7 & -6\end{array}$
MITgcm24 Sub Tidal temperature

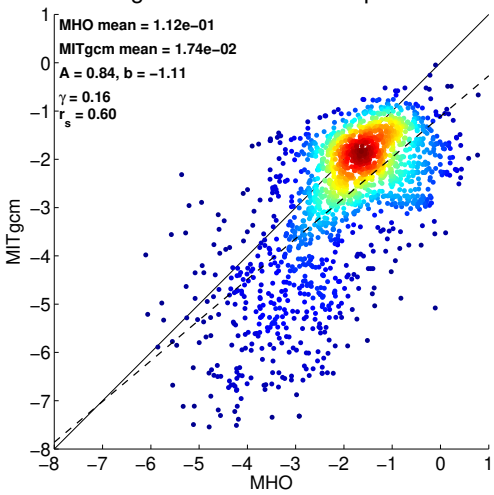

HYCOM25 Sub Tidal temperature

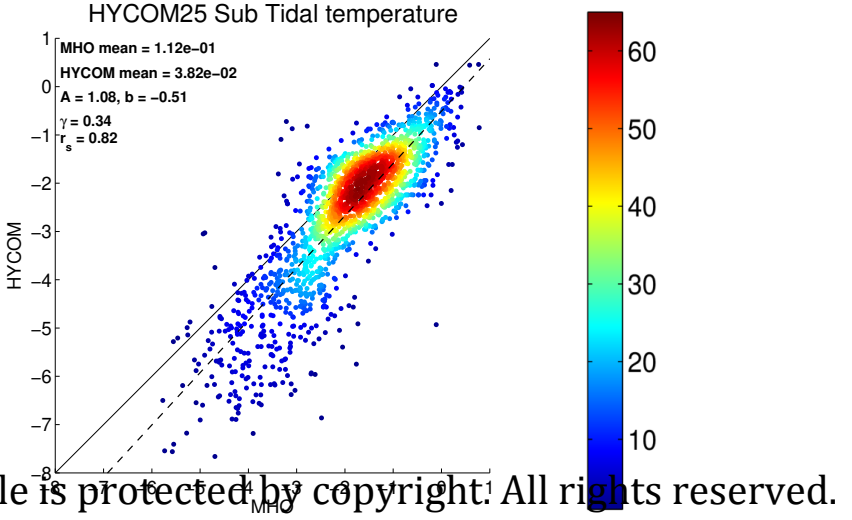

MITgcm48 Sub Tidal temperature

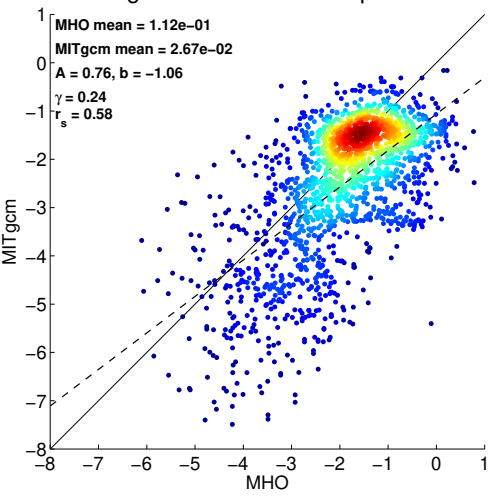


MITgcm12 Mesoscale KE

MHO mean $=6.39 \mathrm{e}-03$

MITgcm mean $=2.28 \mathrm{e}-03$

$A=0.68, b=-1.44$

$\gamma=0.36$

$-1 \frac{\gamma=0.36}{r_{s}=0.54}$

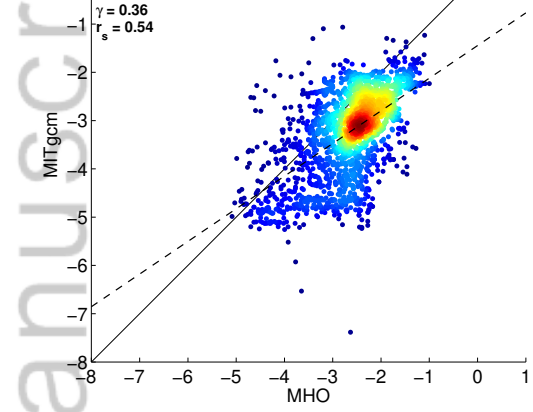

HYCOM12 Mesoscale KE

MHO mean $=6.39 \mathrm{e}-03$

HYCOM mean $=3.58 \mathrm{e}-03$

$A=0.97, b=-0.42$

$\gamma=0.56$

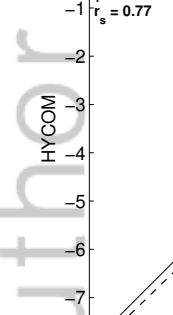

$-8$

$\begin{array}{lllll}-7 & -6 & -5 & -4 & -3 \\ & & & \end{array}$
MITgcm24 Mesoscale KE

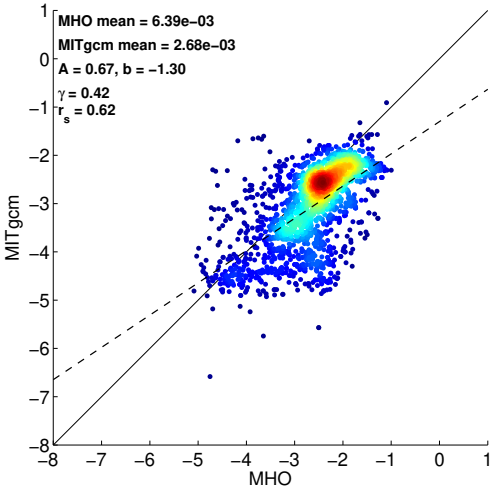

HYCOM25 Mesoscale KE

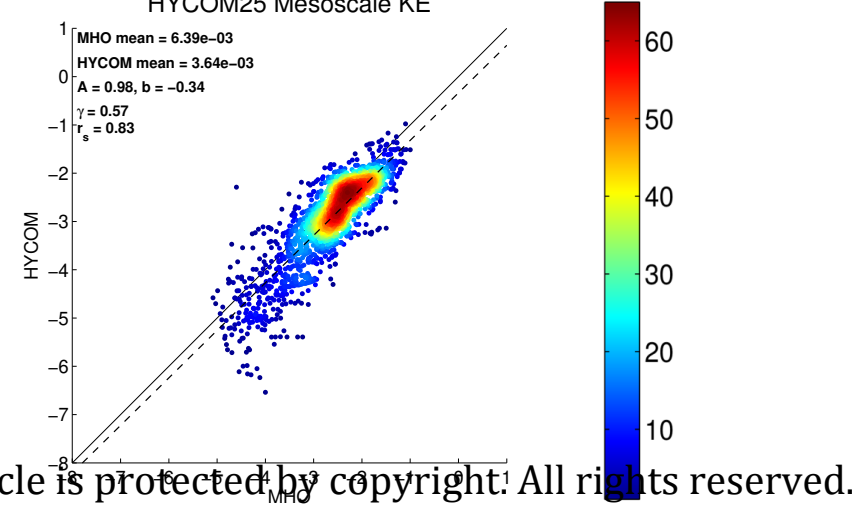

MITgcm48 Mesoscale KE

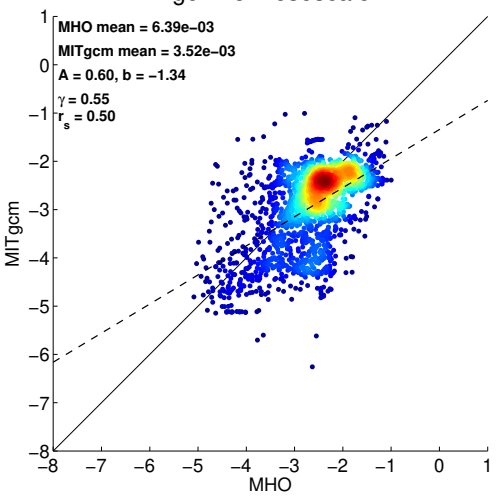

This article is protected ${ }^{-8}$ pry cơpy'right All rights reserved. 
MITgcm12 Mesoscale temperature

MHO mean $=3.69 \mathrm{e}-01$

MITgcm mean $=1.09 \mathrm{e}-01$

$A=0.74, b=-0.92$

$\gamma=0.29$

$-1 \quad \begin{aligned} & \gamma=0.29 \\ & r_{s}=0.57\end{aligned}$

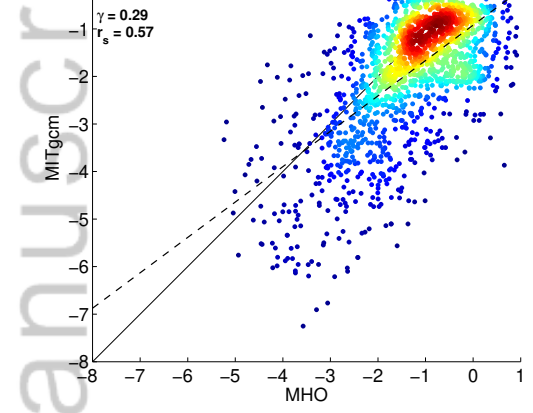

HYCOM12 Mesoscale temperature

MHO mean $=3.69 \mathrm{e}-01$

HYCOM mean $=1.70 \mathrm{e}-01$

$A=0.89, b=-0.48$

$\gamma=0.46$
$-r_{s}=0.79$

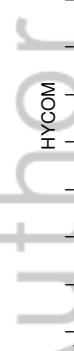

$-8$
MITgcm24 Mesoscale temperature

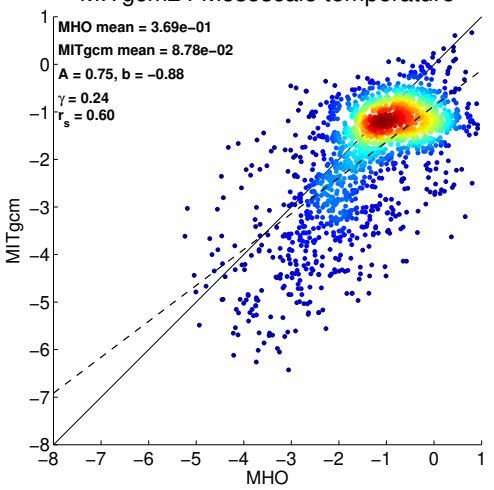

HYCOM25 Mesoscale temperature

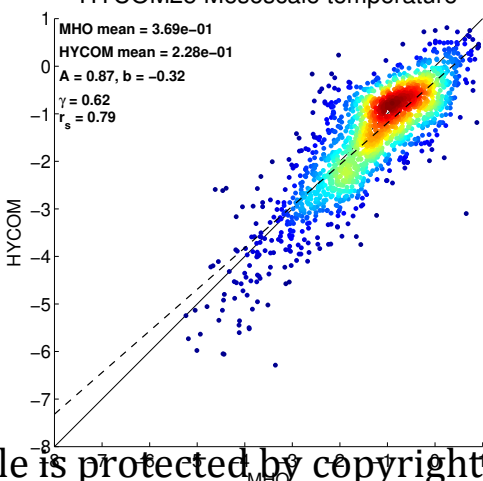

MITgcm48 Mesoscale temperature

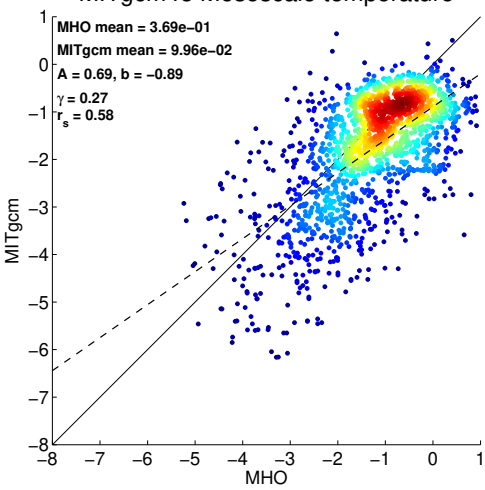

60

50

$-40$

$-30$

20

10 

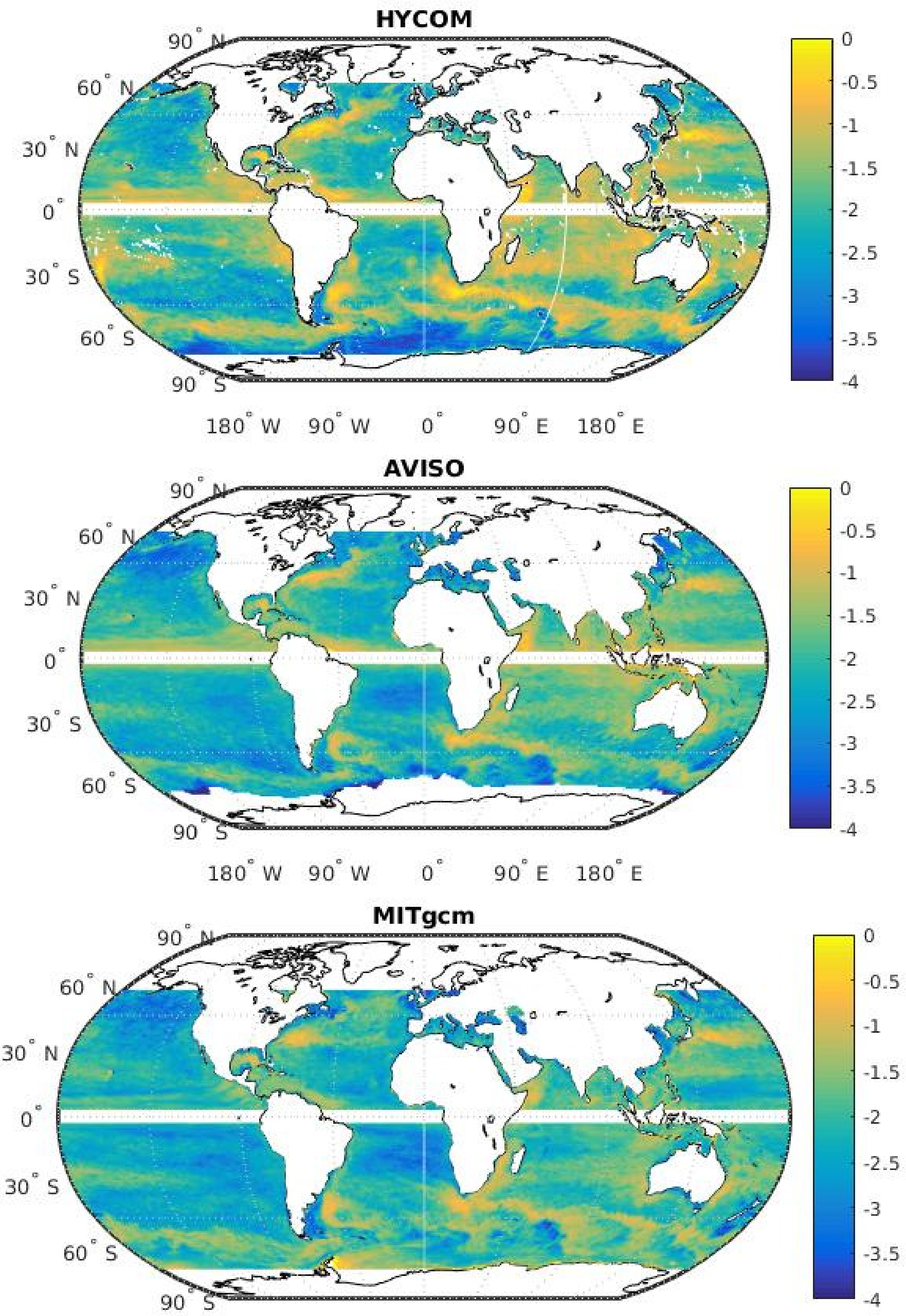

This article ais pirbtected by/ copyright. All rightsfresereed. E 
MITgcm1/48 Global Geostrophic KE

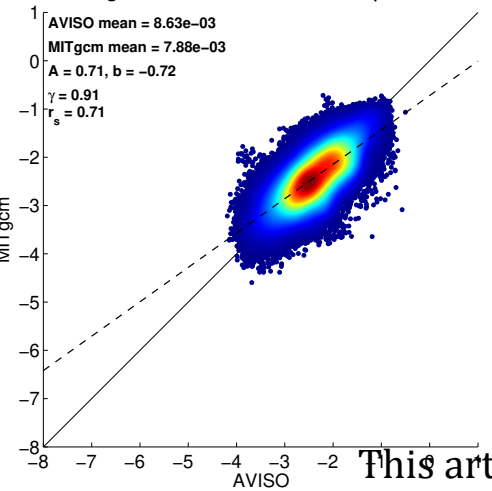

HYCOM1/25 Global Geostrophic KE

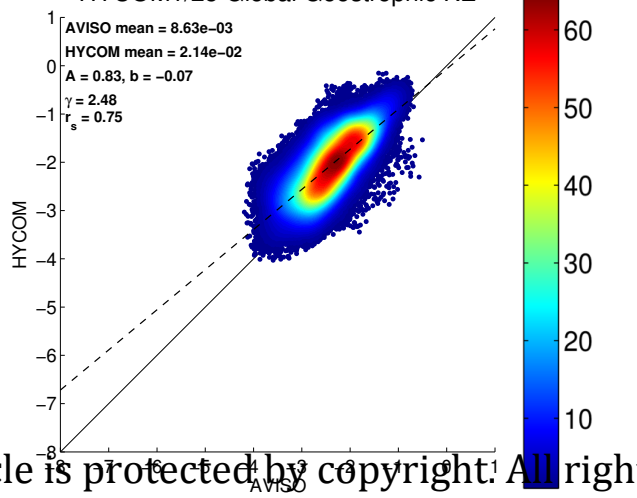


MITgcm1/48 Geostrophic KE

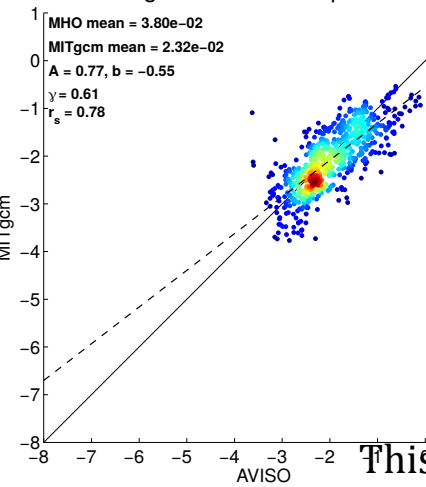

HYCOM1/25 Geostrophic KE

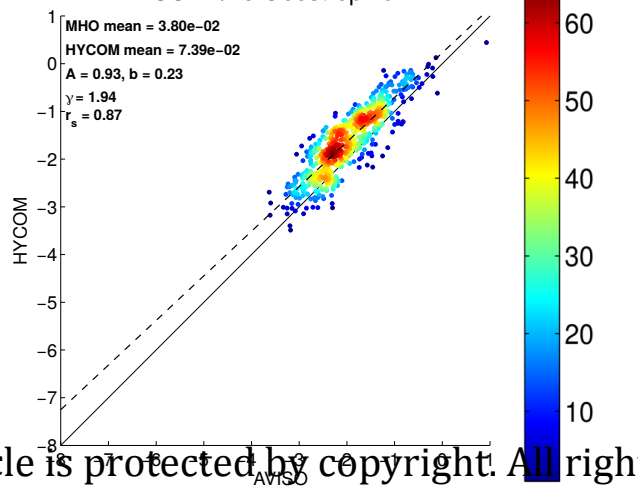




\title{
Statistical Comparisons of Temperature Variance and Kinetic Energy in Global Ocean Models and Observations: Results from Mesoscale to Internal Wave Frequencies
}

\author{
Conrad A Luecke ${ }^{1,2}$, Brian K. Arbic ${ }^{1}$, James G. Richman ${ }^{3}$, Jay F. Shriver ${ }^{4}$, Matthew H. \\ Alford $^{2}$, Joseph K. Ansong ${ }^{1,5}$, Steven L. Bassette ${ }^{6}$, Maarten C. Buijsman ${ }^{7}$, Dimitris \\ Menemenlis $^{8}$, Robert B. Scott ${ }^{9}$, Patrick G. Timko ${ }^{1}$, Gunnar Voet ${ }^{2}$, Alan J. Wallcraft ${ }^{3}$, Luis \\ Zamudio $^{3}$ \\ ${ }^{1}$ Department of Earth and Environmental Sciences, University of Michigan, Ann Arbor, Michigan, USA. \\ ${ }^{2}$ Scripps Institution of Oceanography, University of California, San Diego, La Jolla, USA \\ ${ }^{3}$ Center for Ocean-Atmospheric Prediction Studies, Florida State University, Tallahassee, Florida, USA. \\ ${ }^{4}$ Oceanographic Division, Naval Research Laboratory, Stennis Space Center, Mississippi, USA. \\ ${ }^{5}$ Department of Mathematics, University of Ghana, Accra, Ghana. \\ ${ }^{6}$ Department of Physics, University of Michigan, Ann Arbor, Michigan, USA. \\ ${ }^{7}$ Department of Marine Sciences, University of Southern Mississippi, Stennis Space Center, Mississippi, USA. \\ ${ }^{8}$ Earth Sciences Division, Jet Propulsion Laboratory, California Institute of Technology, Pasadena, California, USA. \\ ${ }^{9}$ Départment de Physique, Université de Bretagne Occidentale, Brest, France.
}

\section{Key Points:}

- Kinetic energy and temperature variance in global HYCOM and MITgem simulations are compared with moored observations

- Model resolution has large impact on the supertidal internal gravity wave continuum band

- Spatial correlations with observations are higher in HYCOM than in MITgcm 


\section{Abstract}

Temperature variance and kinetic energy (KE) from two global simulations of the HYbrid Coordinate Ocean Model (HYCOM; 1/12, 1/25 degree) and three global simulations of the Massachusetts Institute of Technology general circulation model (MITgcm; $1 / 12,1 / 24$, and $1 / 48$ degree), all of which are forced by atmospheric fields and the astronomical tidal potential, are compared with temperature variance and KE from a database of about 2,000 moored historical observations (MHO). The variances are computed across frequencies ranging from supertidal, dominated by the internal gravity wave continuum, to subtidal, dominated by currents and mesoscale eddies. The most important qualitative difference between HYCOM and MITgcm, and between simulations of different resolutions, are in the supertidal band, where the 1/48 degree MITgcm lies closest to observations. Across all frequency bands examined, the HYCOM simulations display higher spatial correlation with the MHO than do the MITgem simulations. The supertidal, semidiurnal, and diurnal velocities in the HYCOM simulations also compare more closely with observations than do the MITgcm simulations in a number of specific continental margin/marginal sea regions. To complement the model-MHO comparisons, this paper also compares the surface ocean geostrophic eddy KE in HYCOM, MITgcm, and a gridded satellite altimeter product. Consistent with the model-MHO comparisons, the HYCOM simulations have a higher spatial correlation with the altimeter product than the MITgem simulations do. On the other hand, the surface ocean geostrophic eddy $\mathrm{KE}$ is too large, relative to the altimeter product, in the HYCOM simulations.

\section{Introduction}

In this paper, we examine the ability of high-resolution global ocean models to recreate an accurate temperature variance and kinetic energy spectrum ranging from mesoscale eddies (periods of about 30-200 days) through the high-frequency (supertidal) internal gravity wave (IGW) continuum. This ability is quantified through comparison of models with both moored historical observations and satellite altimetry.

In recent years, global ocean models have been run at finer grid spacings and timesteps. Increased computer power has led to high-resolution, three-dimensional ocean models that are able to simulate mesoscale eddies on a global scale [e.g., Hecht and Hasumi, 2008; Maltrud and McClean, 2005; Chassignet et al., 2009]. The HYbrid Coordinate Ocean 
Model (HYCOM) and Massachusetts Institute of Technology general circulation model $(\mathrm{MITg} \mathrm{cm})$ simulations examined here include both astronomical tidal forcing and atmospheric forcing. High-frequency atmospheric forcing generates near-inertial waves [e.g., Silverthorne and Toole, 2009; Simmons and Alford, 2012], and barotropic tidal flow over topographic features creates internal tides [e.g., Garrett and Kunze, 2007]. In global models with sufficiently high horizontal and vertical resolution, nonlinear wave-wave interactions and simultaneous tidal and atmospheric forcing begin to fill out the oceanic internal gravity wave continuum, as first shown in Müller et al. [2015].

Tidal and atmospheric forcing were first employed simultaneously in high-resolution general circulation simulations in HYCOM [Arbic et al., 2010, 2012], and the HYCOM tidal simulations were shown to have an internal gravity wave continuum spectrum [Müller et al., 2015; Savage et al., 2017a,b]. Later, MITgcm simulations were run with higher vertical and horizontal resolutions, and were also shown to have an IGW spectrum [Rocha et al., 2016a,b; Savage et al., 2017b; Torres et al., 2018; Wang et al., 2019]. An overview of global internal tide and wave modeling in HYCOM and MITgem is given in Arbic et al. [2018], which also briefly describes two other community global high-resolution simulations with simultaneous atmospheric and tidal forcing.

Resolving a spectrum of internal gravity waves (hereafter, often referred to simply as "internal waves", or IGWs) represents a new paradigm for global ocean models. Internal waves transport substantial amounts of energy over long distances, and breaking IGWs drive most of the mixing in the open-ocean beneath the mixed layer. The threedimensional geography of mixing is important for large-scale ocean dynamics [Munk and Wunsch, 1998; Melet et al., 2016; MacKinnon et al., 2017; Kunze, 2017]. As a first step towards potentially using the simulations reported on here to better understand mixing geography, we must assess the realism of the modeled internal tide and IGW continuum fields. Model-data comparisons of the latest, high-resolution global general circulation models such as the simulations presented here have several benefits to the oceanographic community. Thorough comparisons of these simulations with observations helps to expose the faults and successes of individual changes in model configuration. Additionally, high resolution global simulations have been increasingly used to inform and supplement observational experiments. As a result, there is broad interest in the observational community in the realism of particular model solutions both geographically and with respect to different physical regimes such as the ones presented in this paper. 
High-resolution global ocean models have been compared with observations in a number of studies. For instance, low-frequency sea surface height (SSH) variance in highresolution global models has been compared with altimeter results in works such as Maltrud and McClean [2005] and Chassignet and Xu [2017], amongst others. Comparisons of low-frequency kinetic energy in high-resolution global models with mooring, surface drifter, and altimeter observations have been done in several studies [e.g., Maltrud and McClean, 2005; Penduff et al., 2006; Scott et al., 2010; Thoppil et al., 2011]. Low-frequency eddy available potential energy in global HYCOM simulations without tidal forcing was compared to mooring and Argo float observations in Luecke et al. [2017].

A number of model-data comparisons have been performed with the global HYCOM and (to a lesser extent) MITgcm tidal simulations. However these comparisons often focus on a specific frequency band, a particular geographic location, or both. For example, barotropic and internal tide sea surface height signatures in HYCOM have been compared with altimetry [Shriver et al., 2012; Stammer et al., 2014; Ansong et al., 2015; Ngodock et al., 2016]. HYCOM tidal kinetic energy and internal tide energy fluxes have been compared with moored in-situ observations in Timko et al. [2012, 2013] and Ansong et al. [2017] respectively. In Buijsman et al. [2016] the semidiurnal internal tide dissipation rates are compared with Argo inferred dissipation rates. Savage et al. [2017b] compares the dynamic height variance in both HYCOM and MITgcm to the variance computed from moored McLane profiler data, across a wide range of frequencies. The McLane profilers [Doherty et al., 1999] used in Savage et al. [2017b] were set up to study internal gravity waves, and have high vertical and temporal resolution. However Savage et al. [2017b] found only 9 such records that were useful for comparing with models in the open ocean. In Qiu et al. [2018], geostrophic surface eddy kinetic energy (EKE) in MITgcm is compared with AVISO satellite data. Rocha et al. [2016a] compared kinetic energy wavenumber spectra in the MITgcm with along-track Acoustic Doppler Current Profiler (ADCP) data in one Southern Ocean location. Wang et al. [2018] compares MITgcm and ADCP velocity for the purpose of mooring design for ground-truthing future satellite missions.

The various observational datasets that we compare our HYCOM and MITgcm solutions to all have their advantages and disadvantages. For instance, altimetry is global, but only measures the sea surface heights. The mooring archive that we use here is as extensive as we could find, in terms of global coverage, though it still does not offer the dense spatial coverage offered by, for instance, altimetry and surface drifters. On the other hand, 
in contrast to those datasets, moorings offer the ability to both look beneath the surface and to examine a broad range of frequencies, encompassing a broad range of dynamical regimes.

In this study, we compare temperature variance and $\mathrm{KE}$ in three global simulations of MITgem and two global simulations of HYCOM to moored historical observations. By examining different frequency bands, we test the ability of these simulations to model motions ranging from mesoscale eddies to the internal gravity wave continuum. Our study is quasi-global, in that about 2,000 records, distributed over the major ocean basins, are used. Our study builds upon our model-data comparison of low-frequency eddy available potential energy, in Luecke et al. [2017], to examine temperature variance over a wider range of frequencies. Both the HYCOM and MITgcm simulations are performed at different resolutions, thus allowing us to study the impact of resolution on model-data comparisons. Additionally, in order to obtain denser spatial coverage of motions in the lowfrequency band dominated by mesoscale eddies, we compare surface ocean geostrophic eddy kinetic energy from both MITgem and HYCOM to values computed from the Archiving, Validation, and Interpretation of Satellite Oceanographic data (AVISO) gridded satellite altimeter product [Ducet et al., 2000]. Our study is unique in being a quasi-global comparison of models and moored in-situ data, across five simulations of varying resolutions performed with two different models, of both temperature variance and kinetic energy (KE), across a range of frequencies running from the mesoscale eddy band to the internal gravity wave continuum.

\section{Models, Observations, and Methods}

We use temperature variance and KE spectra from HYCOM simulations of two resolutions $\left(1 / 12.5^{\circ}\right.$ and $\left.1 / 25^{\circ}\right)$, and MITgcm simulations of three resolutions $\left(1 / 12^{\circ}, 1 / 24^{\circ}\right.$, and $\left.1 / 48^{\circ}\right)$. More general information about HYCOM can be found in Chassignet et al. [2009], and more general information about MITgcm can be found in Marshall et al. [1997]. Temperature variance and KE spectra computed from the models are compared to spectra calculated from a database of moored historical observations (MHO) obtained from the Global Multi-Archive Current Meter Database [GMACMD; Wright et al. [2014]]. For our comparison of surface ocean geostrophic eddy kinetic energy in HYCOM, MITgcm, and the AVISO satellite altimeter product, we use the AVISO and MITgcm results from Figure (1) of Qiu et al. [2018]. Qiu et al. used the global SSH anomaly product created 
by Ssalto/Duacs and distributed by AVISO with support from CNES (http://marine. copernicus.eu/). The AVISO product we use here is reported on a 0.25 degree horizontal grid with a 7-day temporal increment, and is generated via the spatial-temporal interpolation of altimetric data [Ducet et al., 2000]. The surface ocean geostrophic eddy KE field in HYCOM was computed by us following the same methodology used in Qiu et al. [2018] for the MITgcm results, as confirmed in a 2018 personal communication with Bo Qiu. The HYCOM and MITgem results are both computed by differentiating the SSH field computed from spatially and temporally averaging hourly model output, from the high resolution model grid onto the AVISO grid and temporal increment. This is done so that model results are qualitatively consistent with the spatial-temporal smoothing inherent in the creation of the AVISO product.

\subsection{Moored Historical Observations}

Time-series of temperature and velocity from moored historical observations (MHO) are obtained from the GMACMD and can be found at http://stockage.univ-brest . fr/ scott/GMACMD/gmacmd.html. These records span from 1974 to 2008, and are not contemporaneous with the model runs. Only locations with seafloor depths greater than 500 meters are included. We select MHO time-series that are longer than 90 days, and exclude records containing gaps in the time-series. The remaining temperature and velocity records are then visually inspected and quality controlled for instrument errors and other problems such as severe discretization.

Our selection criteria yield a total of 1,711 instrumental records of temperature and 2,102 instrumental records of velocity, some of which are co-located, distributed around the global ocean. The geographical locations are shown in the top panel of Figure 1. The spatial coverage of both temperature and velocity is sparse and uneven, with some basins such as the North Atlantic and North Pacific having a higher density of observations than others. The bottom panel of Figure 1 shows the distribution of instruments by depth for velocity (right) and temperature (left) records. There is a clear preference for measurements in the upper $1000 \mathrm{~m}$. 


\subsection{HYCOM}

Two simulations of HYCOM are used in this comparison; HYCOM12, with a 1/12.5 degree horizontal resolution, and HYCOM25, with a 1/25 degree horizontal resolution. The spatial scales of the model grids are approximately $8 \mathrm{~km}$ and $4 \mathrm{~km}$ at the equator respectively. The HYCOM output is saved hourly, and HYCOM12 output spans October 1, 2011 through April 1, 2012, while HYCOM25 output spans January 2014 through December 2014. Both simulations contain 41 hybrid layers in the vertical direction. Atmospheric fields, such as pressure, buoyancy, and wind forcing, used in both HYCOM simulations, are taken from the U.S. Navy Global Environmental Model, NAVGEM [Hogan et al., 2014]. HYCOM12 is forced by NAVGEM on three hour intervals, while HYCOM25 is forced hourly. The HYCOM simulations are forced using a $0.5^{\circ}$ application grid interpolated from the NAVGEM primary $37 \mathrm{~km}$ grid.

The HYCOM simulations are additionally forced by the astronomical tidal potential of the two largest diurnal constituents $\left(\mathrm{K}_{1}\right.$ and $\left.\mathrm{O}_{1}\right)$ along with the three largest semidiurnal constituents $\left(\mathrm{M}_{2}, \mathrm{~S}_{2}\right.$, and $\left.\mathrm{N}_{2}\right)$ [Cartwright, 1999]. These five tidal constituents account for 97 percent of the global variance in the 10 largest tidal constituents in the Global Ocean Tide Model [GOT99.2; Ray, 1999]. The self-attraction and loading (SAL) [Hendershott, 1972] term is taken from the altimeter-constrained TPXO model of Egbert et al. [1994] and Egbert and Erofeeva [2002]. An Augmented State Ensemble Kalman Filter is implemented in both simulations to reduce the global RMS error of $\mathrm{M}_{2}$ barotropic tidal elevations with respect to TPXO, in waters deeper than $1 \mathrm{~km}$, to approximately $2.6 \mathrm{~cm}$ [Ngodock et al., 2016].

A Smagorinsky scheme is employed for horizontal viscosity and a Laplacian scheme is utilized for horizontal diffusivity, while a KPP scheme [Large et al., 1994] is used for both vertical diffusivity and viscosity. The parameterized topographic wave drag field taken from Jayne and St. Laurent [2001] is tuned to minimize barotropic tidal errors with respect to TPXO [Egbert et al., 1994; Egbert and Erofeeva, 2002]. The wave drag strength employed in HYCOM25 was half the strength of the drag used in HYCOM12. A description of the wave drag tuning can be found in Buijsman et al. [2015], and more information on the impact of the wave drag on barotropic and baroclinic tides can be found in Ansong et al. [2015] and Buijsman et al. [2016]. 


\subsection{MITgem}

Three global ocean simulations of MITgcm [Marshall et al., 1997], at horizontal resolutions of $1 / 12,1 / 24$, and $1 / 48$ degree, are used in this comparison and are referred to as MITgcm12, MITgcm24, and MITgcm48 respectively. All three MITgcm simulations have $90 \mathrm{z}$-levels in the vertical, with level thicknesses varying from $1 \mathrm{~m}$ at the surface to 480 $\mathrm{m}$ near the bottom at the maximum model depth of $7 \mathrm{~km}$. Bathymetry is taken from the Smith and Sandwell [1997] Version 14.1 and IBCAO Version 2.23 Jakobsson et al. [2008]. MITgcm is forced at the surface with atmospheric fields from the $0.14^{\circ}$ European Center for Medium-Range Weather Forecasts (ECMWF) atmospheric operational model analysis at six-hour intervals. Starting in 2011, atmospheric forcing is converted to surface fluxes using the bulk formulae of Large and Yeager [2004]. In regions of ice coverage, ocean surface fluxes are computed using the sea ice model of Losch et al. [2010].

The MITgcm runs employ the full luni-solar tidal potential of Weis et al. [2008], which is applied to MITgcm as additional atmospheric pressure forcing [Ponte et al., 2015]. No parameterized topographic wave drag was applied to the MITgcm simulations.

A Leith scheme is used for horizontal diffusivity and a KPP scheme is used for vertical diffusivity. The MITgem12 simulation is initialized on 1 January 2010 from a dataconstrained $1 / 6^{\circ}$ simulation provided by the Estimating the Circulation and Climate of the Ocean, Phase II project (ECCO2) [Menemenlis et al., 2008] and integrated for 1 year without tides with ERA-Interim [Dee et al., 2011] surface boundary conditions. Tidal forcing and atmospheric boundary conditions from the $0.14^{\circ}$ ECMWF analysis are applied starting on 1 January 2011. The MITgcm24 simulation is initialized from MITgcm12 fields on 17 January 2011. The MITgem48 simulation is initialized from MITgem24 fields on 10 September 2011.

We use $\sim 7$ months of hourly model output from the three MITgcm simulations for the following periods: 1 January 2012 through 20 July 2012 for MITgcm12, 2 October 2012 through 22 April 2013 for MITgcm24, and 28 January 2012 through 22 August 2012 for MITgcm48. The MITgcm records are only 7 months in length due to the fact that, at the time we extracted the model output, it had only been run for this long (after a suitable spinup period). 


\subsection{Methods}

In order to compute frequency spectra, a linear trend and mean are removed from each time series of temperature $T(t)$, zonal velocity $U(t)$ and meridional velocity $V(t)$, where $t$ denotes time. Each detrended time series is multiplied by a Tukey window having a taper to constant ratio of 0.2 . Approximately $10-15$ percent of the total variance is lost as a result of the application of the Tukey window.

The frequency spectra are computed from each time series for each MHO instrument, and from the output of the corresponding nearest horizontal neighbor model grid points interpolated to the depth of the MHO instrument. A discrete Fourier Transform is defined as:

$$
\widehat{\operatorname{Field}(\omega)}=\sum_{t=0}^{N-1} \operatorname{Field}(t) e^{-i \omega t},
$$

where 'Field' denotes either temperature or velocity, $\omega$ denotes frequency, and $N$ denotes the total number of points in the time series. In the case of temperature, variance is calculated as

$$
\text { Temperature variance }=\frac{2 \delta t}{N} \int_{\omega_{\min }}^{\omega_{\max }}|\widehat{T(\omega)}|^{2} d \omega
$$
and for kinetic energy, half the total velocity variance,

$$
\mathrm{KE}=\frac{\delta t}{N} \int_{\omega_{\min }}^{\omega_{\max }}\left|(\widehat{U(\omega)})^{2}+(\widehat{V(\omega)})^{2}\right| d \omega
$$

where $\delta t$ is the temporal sampling interval, and $\omega_{\min }$ and $\omega_{\max }$ represent the lower and upper bounds of the frequency band of interest. We integrate over five bands, supertidal (12-2.06 cpd), semidiurnal (2.05-1.86 cpd), diurnal (1.05-0.87 cpd), subtidal (0.7-0.1 cpd) and mesoscale $(0.09-0.01 \mathrm{cpd})$. In the case of MHO records shorter than 100 days in length, the mesoscale band is integrated to the lowest possible frequency. Additionally, for KE only, we integrate over the near-inertial band defined as $0.9-1.1 f$, where $f$ is the local Coriolis frequency. This represents a 'double counting' of KE in regions where $f$ and the diurnal tidal frequencies overlap.

We employ several statistical metrics to quantify differences between temperature variance and kinetic energy in the models and observations. A linear regression in the form $\log _{10}($ model $)=A * \log _{10}($ data $)+b$, for both temperature variance and kinetic energy 
is calculated. A ratio $\gamma$ between the mean of the model variances and the mean of the observational variances is defined as:

$$
\gamma=\frac{\sum_{i=1}^{n} \text { Variance }_{\text {model }}}{\sum_{i=1}^{n} \text { Variance }_{\text {observed }}}
$$

where $i$ is an instrument index and $n$ is the total number of instruments used in the calculation. In cases where a horizontal location contains MHO instruments at multiple depths, the instruments at each depth are counted as separate instruments. Finally, a Spearman correlation coefficient $r_{s}$ [Kokoska and Zwillinger, 2000] is calculated between model and data variance across the MHO locations. The Spearman correlation has an advantage of being less impacted by individual strong outliers in the data. Additionally, because Spearman is a rank correlation, it provides an understanding of how the models perform from low to high energetics, even when the relationship between model bias and variance is not linear. The ideal values expressing a perfect comparison are equal to one for all of the metrics $A, \gamma$, and $r_{s}$, and zero for $b$.

In order to calculate our AVISO-derived eddy kinetic energy (EKE) values from model output, we average the modeled SSH data into a weekly time series on a 0.25 degree longitude Mercator grid and compute the EKE from the geostrophic velocity field as in Qiu et al. [2018] where:

$$
u=-\frac{g}{f} \frac{\partial \eta}{\partial y}, \quad \text { and } \quad v=\frac{g}{f} \frac{\partial \eta}{\partial x} .
$$

Here $g$ is the local acceleration due to gravity, $f$ is the Coriolus frequency, and $x$ and $y$ are the zonal and meridional spatial coordinates. Equation (5) gives the geostrophic velocities for $u$ and $v$ respectively, and $\mathrm{EKE}=\frac{1}{2}\left(u^{2}+v^{2}\right)$. 

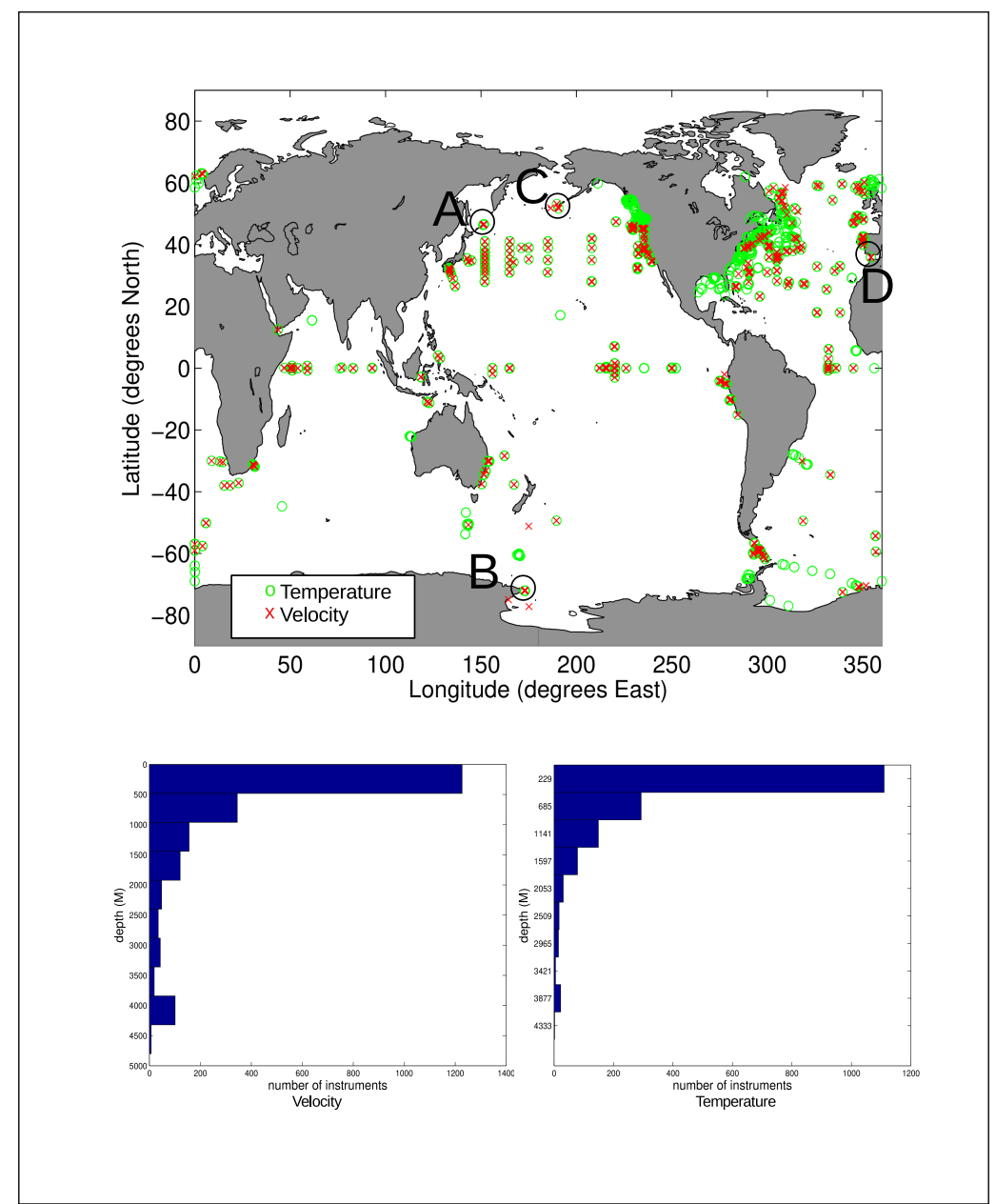

Figure 1. Geographical locations and depths of MHO records used in the model-MHO comparison. Temperature observations are shown with green circles, while velocity observations are denoted by red x's. The bottom panels show the depth distribution for velocity (left) and temperature (right) instrument record locations. The labels "A", "B", "C", and "D" will be referred to later in the text.

\section{Model-MHO comparisons}

In this section, we present global model-MHO comparisons of temperature variance and KE. Results for temperature variance and KE have been grouped into the six frequency bands defined above: supertidal, semi-diurnal, diurnal, near-inertial, subtidal, and mesoscale, where again the near-inertial band is defined only for KE, not for temperature variance. Before we summarize and discuss the model vs. MHO comparisons in each frequency band, we present sample frequency spectra of the temperature variance and KE, for four individual instrument locations shown in Figure 2. The left two panels in Figure 2 depict typical temperature variance spectra, while the right two panels show typical 

of lower-frequency motions into subtidal and mesoscale.
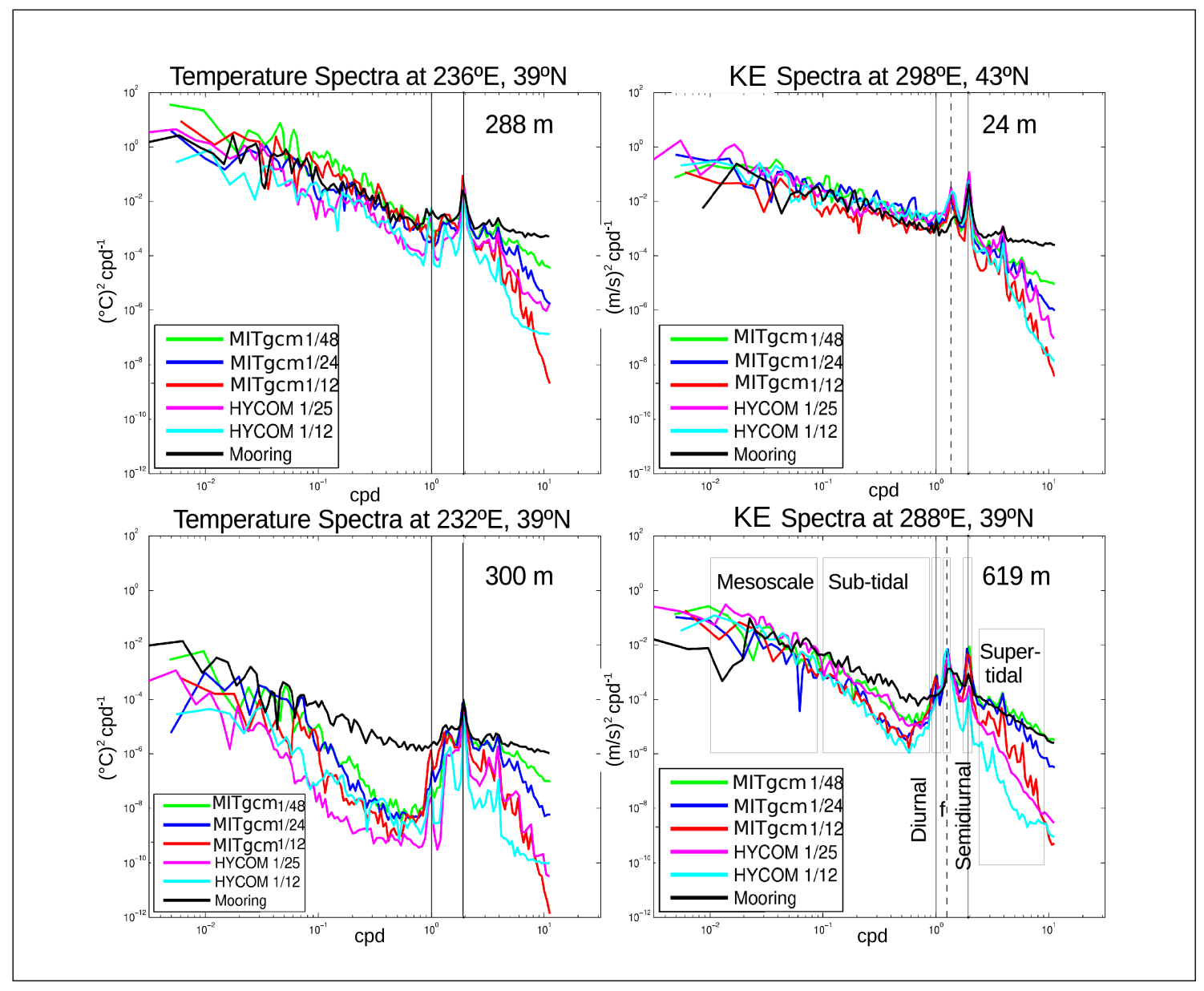

KE spectra. At supertidal frequencies, the highest resolution model (MITgcm48) clearly has more variance, and matches the observations more closely than the lower resolution models. The lowest resolution simulations (MITgcm12 and HYCOM12) have the least variance at supertidal frequencies. Also of note is a model deficiency in both KE (bottom right panel) and temperature variance (bottom left panel) that occurs in between 0.1 and 1 cpd. The lack of model energy in this band for some instruments has been noted in other model-data comparisons, for instance in Savage et al. [2017b], and prompted our division

Figure 2. Sample spectra of temperature variance (in the Eastern Pacific) and KE (Northeast Atlantic) for all 5 simulations. Instrument locations and depths are given in the subplots. The solid vertical lines show the diurnal (left) and semi-diurnal (right) tidal frequencies, and the dashed vertical lines show the local Coriolis frequency. The approximate bounds of each frequency band discussed in this paper are delineated by boxes in the lower right subplot. 


\subsection{Summary of Mean Temperature Variance and KE in all Frequency Bands}

Here we summarize the model-MHO comparisons, using the statistical metrics described in Section 2.4, computed over all instruments, across all five simulations and all six frequency bands. Figure 3 shows the spatial mean KE (top) and temperature variance (bottom) within each frequency band, for all five simulations and for the MHO, computed over all instruments at the MHO locations and depths. As seen in the differences between the red and blue bars in the top panel, the spatial means are sensitive to inclusion of a small number of continental margin/marginal sea locations, denoted by "A", "B","C", and " $\mathrm{D}$ " in figure 1. We will return to this point later in the paper. In some frequency bands, within each model, increased resolution improves the comparison between models and data. However, this does not hold universally across all simulations and frequency bands. 


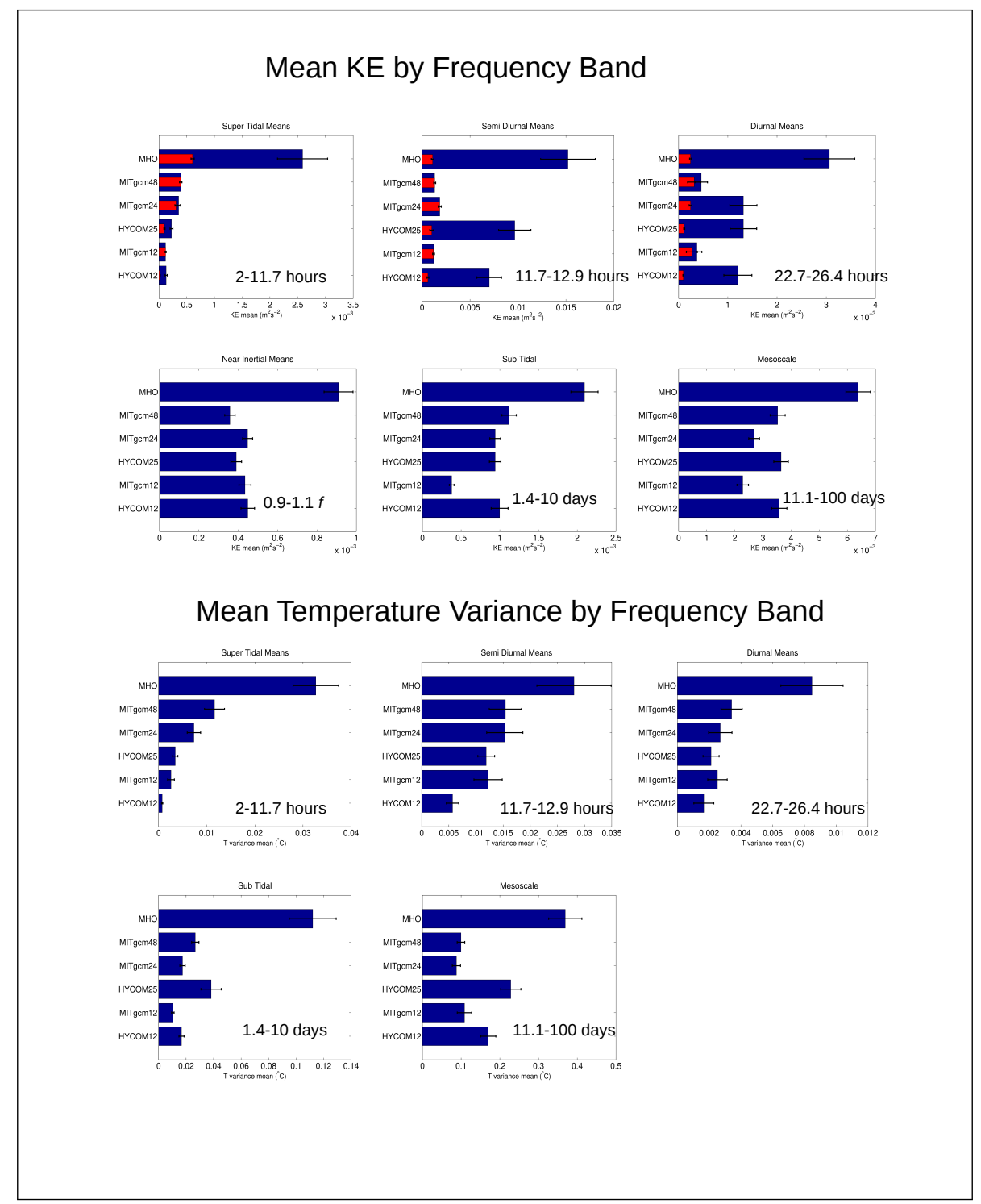

Figure 3. (top) Spatial mean $\mathrm{KE}\left(\mathrm{m}^{2} \mathrm{~s}^{-2}\right)$, computed over the MHO instrument locations and depths, across the frequency bands defined in the text. (Bottom) Spatial mean temperature variance $\left({ }^{\circ} \mathrm{C}^{2}\right)$ separated by frequency band. The red bars denote averages for which results at a small number of continental margin/marginal sea locations (denoted by "A", "B"," $\mathrm{C}$ ", and "D" in figure 1) have been removed. Note that the near-inertial band is only computed and displayed for KE.

Model improvement with increased resolution is particularly noticeable in the case of both supertidal KE and temperature variance, where increased model resolution leads to more total variance, and closer comparisons with MHO results for both MITgcm and HYCOM. Increased resolution also appears to improve temperature variance in both MITgcm and HYCOM within both the semidiurnal and diurnal bands, but not the KE within 
these bands. Within the near-inertial band, changes in resolution appear to make little difference, possibly because of the relatively large horizontal length scales associated with low-mode near-inertial waves [Simmons and Alford, 2012]. Within the sub-tidal frequency band, both MITgcm KE and HYCOM temperature variance show closer agreement in model-MHO comparisons as model resolution is increased. Within the mesoscale band, both models improve with resolution with respect to KE, but only HYCOM improves with respect to temperature.

Figure 4 shows the statistical comparison metrics for all model runs across all frequency bands and across all instruments, without any removal of anomalous results at continental margin/marginal sea locations. Across all frequency bands, for both KE and temperature variance, HYCOM has a universally higher spatial correlation $r_{s}$ with the MHO data than does MITgcm. The linear regressions tend to be closer to their ideal values within the HYCOM simulations than in MITgcm, likely as a result of the smaller amount of scatter in HYCOM. As is seen in Figure 3, increases in model resolution tend to increase $\gamma$ for both temperature variance and kinetic energy, with the tidal and supertidal temperature variance showing the largest changes with model resolution, and with the near-inertial band KE being a notable exception. The dramatic increase in both KE and temperature variance within the supertidal frequency band suggests that the increase in resolution in both HYCOM and MITgem is resulting in a large increase in energy within the IGW continuum. Within the semi-diurnal and diurnal frequency bands, it appears as if differences between HYCOM and MITgcm, such as the presence or absence of parameterized topographic wave drag, make a larger difference than resolution with respect to model-data agreement. As will be described shortly, due to the wide range of KE and temperature variance in the MHO instruments, the overall means and statistics are sensitive to extreme values. More nuanced details concerning the model-MHO comparisons in individual frequency bands will be discussed below. 


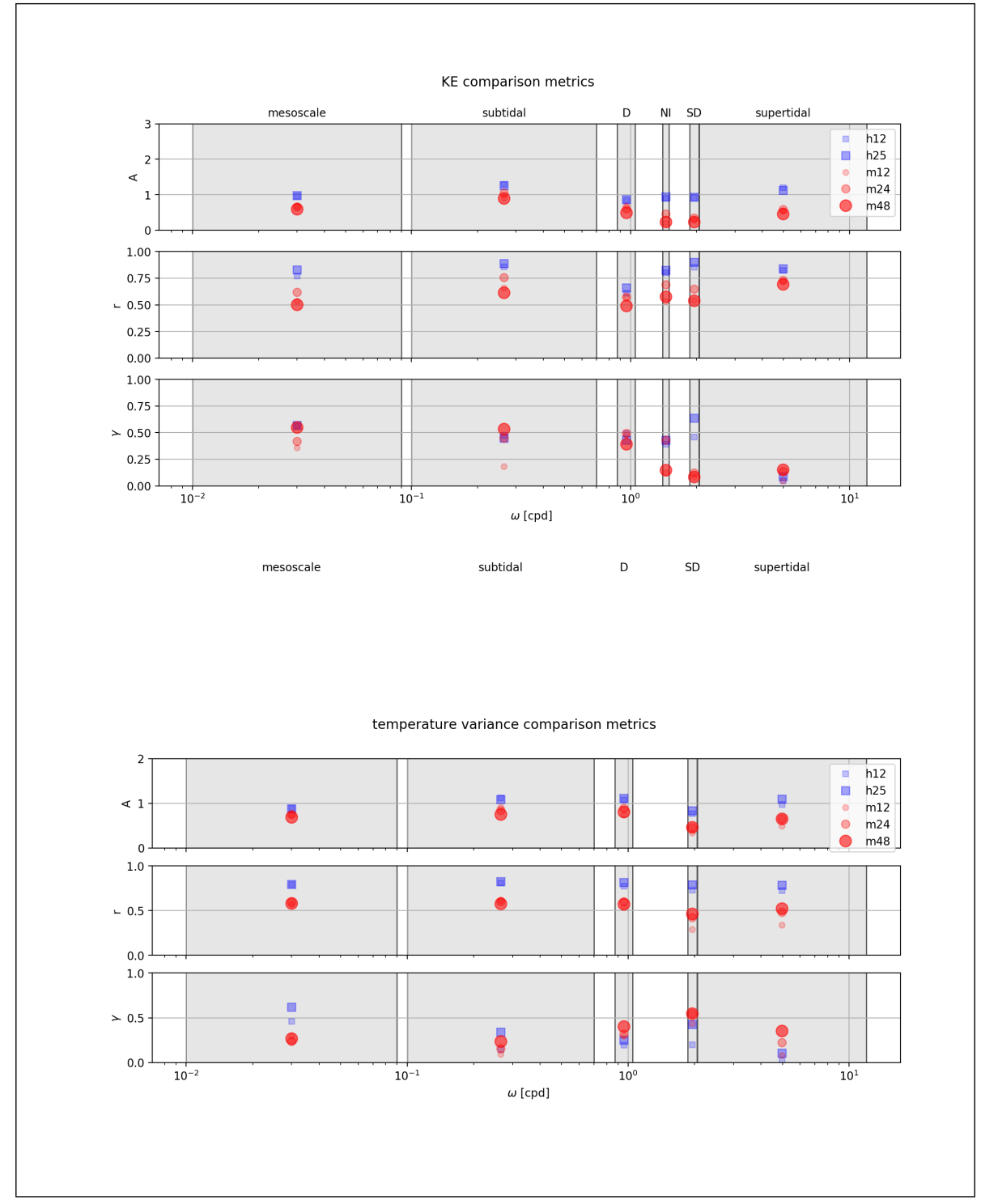

Figure 4. (top) Statistical comparison metrics, computed over all instrument locations and depths, for KE in all five simulations, and separated by the frequency bands defined in the text. (bottom) Same but for temperature variance, with the near-inertial band excluded. Note that for this Figure only, we use "D" and "SD" to denote diurnal and semidiurnal bands respectively, "h12" and "h25" to denote HYCOM12 and HYCOM25, respectively, and "m12", "m24”, and “m48” to denote MITgcm12, MITgcm24, and MITgcm48, respectively. Note that in reality, the near-inertial frequency varies with latitude, and is plotted here at a fixed frequency for visualization purposes. 


\subsection{Supertidal Frequency Band}

Figure 5 shows scatterplots of band-integrated MITgem and HYCOM supertidal KE values against $\mathrm{MHO}$ values. Comparisons are shown for varying model resolutions at the same MHO locations and depths given in Figure 1. As noted previously, for the supertidal band especially, increased model resolution yields increased KE in both MITgem and HYCOM. From visual inspection, HYCOM12 (bottom left) is biased lowest compared to MHO, while MITgcm48 (upper right), although still somewhat lower than observations, lies closest to the one-to-one line. The comparison metrics, which are given on each individual subplot of Figure 5, confirm this, as HYCOM12 has both the lowest ratio of the means, $\gamma$, while MITgcm 48 has the highest values. The closer model-MHO comparison for MITgcm48 relative to HYCOM25 in the supertidal band is likely due in part to the higher horizontal and vertical resolutions in MITgem48, but may also partly result from the overly energetic internal tides in the MITgcm simulations, which will be discussed in section 3.3. The correlation coefficients are slightly higher for HYCOM than for MITgcm, implying that the supertidal KE has a geographical distribution that is slightly more accurate in HYCOM than in MITgcm, even if the HYCOM values are generally too low.

There is a distinct group of points representing energies around $\left(10^{-1} \mathrm{~m}^{2} s^{-2}\right)$ in the MHO data. The anomalous nature of this group of points is clearly visible in all five subplots of Figure 5. The group has been enclosed with an ellipse in the HYCOM25 panel of Figure 5, and enclosed with a box in the MITgcm24 panel. The geographical locations of these anomalous points correspond to the locations in circles labeled "A", "B", "C" and "D" in Figure 1, all lying in continental margin/marginal sea areas. At these locations, MITgcm is systematically under-energetic with respect to the MHO results, while HYCOM lies closer to the observations. The statistical metrics computed upon removal of the "A", "B", "C" and "D" values are also given and are marked with an asterisk in the subplots of Figure 5 (note that these locations were also removed in the calculation of the results marked in red in the upper panel of Figure 3). The metric values change quantitatively, sometimes significantly, when the anomalies are removed; the spatial correlation $r_{s}$ becomes slightly lower for HYCOM and slightly higher for MITgcm, with MITgcm correlation values still being lower than the HYCOM values. The linear regression values fall closer to the one-to-one line, and the ratio of means $\gamma$ become larger for all of the MIT$\mathrm{gcm}$ simulations shown in Figure 5. While the linear regressions in MITgcm are more heavily dominated by scatter than in HYCOM, it is clear for both models that increased 
resolution results in closer agreement with the data, especially after the anomalies in MIT$\mathrm{gcm}$ are accounted for. The general trends in the metrics noted previously, before removal of the anomalous values- higher $\gamma$ values in MITgcm, higher $r_{s}$ values in HYCOM-still hold when the anomalies are removed.

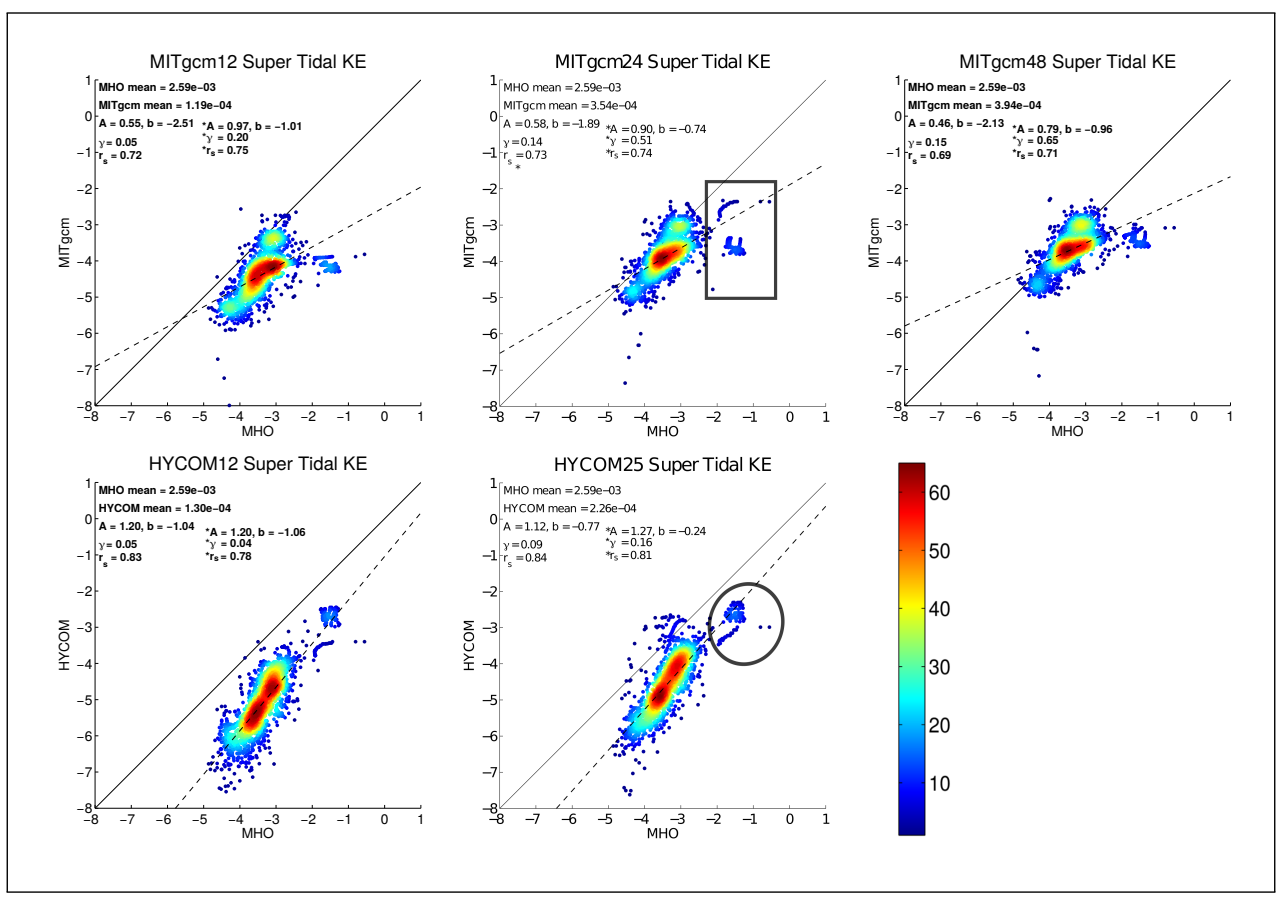

Figure 5. A point-to-point comparison of supertidal kinetic energy $\left[\log _{10}\left(\mathrm{~m}^{2} s^{-2}\right)\right]$ between model and MHO. The top panels show MITgem12, MITgem24, and MITgem48, while the bottom panels show HYCOM12 and HYCOM25. Population density is given by color, with the most tightly grouped data shown in red, and the sparsest data in blue. The one-to-one line is shown in solid black, and the linear regression is shown as a dashed line. Spatial means of MHO and model values, and statistical metrics $A, b, \gamma$, and $r_{s}$ between each model and the MHO data, are printed on the upper left of each subplot. The second,right-most, statistical values marked with an asterisk, are computed after the anomalous high-velocity values, enclosed by a box in the MITgem24 subplot and an ellipse in the HYCOM25 subplot, have been removed.

As with KE, supertidal temperature variance shows improvement with model resolution in both HYCOM and MITgcm (Figure 6). As with KE, HYCOM12 (bottom left) is biased lowest compared to MHO, while MITgcm48 (upper right), although still somewhat lower than observations, lies closest to the one-to-one line. Again, the comparison metrics confirm this, as HYCOM12 has both the lowest ratio of the means, $\gamma$, while MITgcm48 possesses the highest. In both MITgcm24 and MITgcm48, the linear regressions 
are again more dominated by the relatively large scatter in supertidal temperature variance, however both models improve with an increase in resolution. The correlation coefficients $r_{s}$ for supertidal temperature variance are higher in HYCOM than in MITgcm. There are no visually obvious anomalies in the supertidal temperature variance plots as there were on the KE plots.

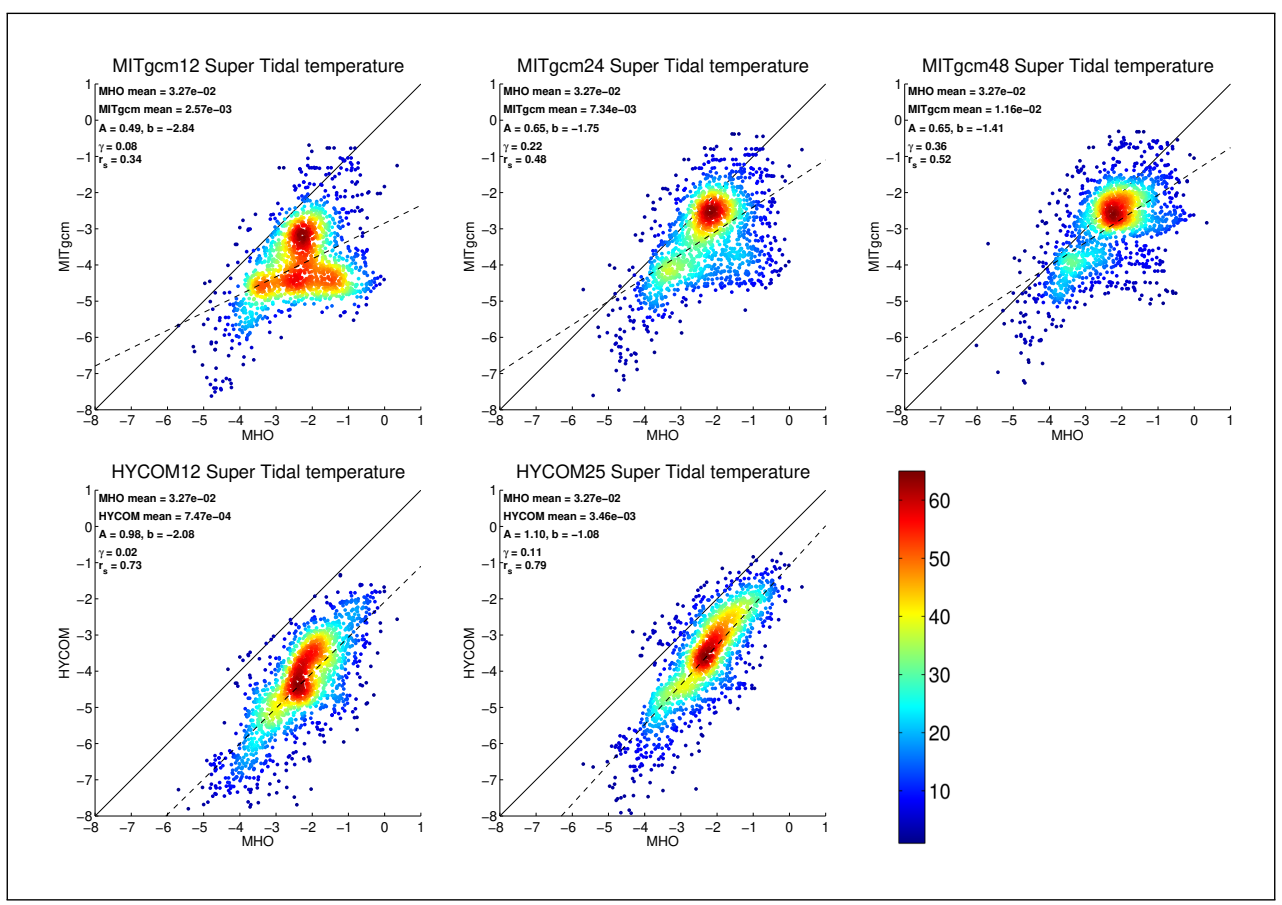

Figure 6. A point-to-point comparison of supertidal temperature variance $\left[\log _{10}\left({ }^{\circ} \mathrm{C}^{2}\right)\right]$ between model and MHO. The top panels show MITgem12, MITgem24, and MITgcm48, while the bottom panels show HYCOM12 and HYCOM25. Population density is given by color, with the most tightly grouped data shown in red, and the sparsest data in blue. The one-to-one line is shown in solid black. Spatial means of MHO and model values, and statistical metrics $A, b, \gamma$, and $r_{s}$ between each model and the MHO data, are printed on the upper left of each subplot.

\subsection{Semi-Diurnal Band}

Scatterplots of HYCOM and MITgem semi-diurnal KE values against MHO values are shown in Figure 7. From visual inspection, all three MITgem runs appear to be biased high compared to the MHO values, except for at a small number of high-velocity locations in the MHO, where, as in the supertidal KE comparison, MITgcm is biased much too low. 
As a result, $\gamma$ values computed including these high-velocity values are lower for MITgcm than for HYCOM, and the linear regressions are similarly skewed.

The high-velocity locations, representing energies around $\left(10^{-1} \mathrm{~m}^{2} \mathrm{~s}^{-2}\right)$ in the MHO data, have been highlighted in the HYCOM25 and MITgem24 panels of Figure 7 as was done in Figure 5. The high-velocity points are clearly visible in the model-data comparisons across all resolutions. These instrument locations correspond to the circle labeled "D" in Figure 1. At this location (in the Strait of Gibraltar), MITgcm is under-energetic for all three resolutions, while HYCOM lies much closer to observations. When these instruments are removed, the resulting $\gamma$ values, given in Figure 7, reveal an overall overenergetic bias in the great bulk of the MITgcm locations. In contrast, both with and without the inclusion of the high-velocity locations, the HYCOM $\gamma$ values are close to, but less than, one. The linear regressions in HYCOM are much closer to one-to-one than in MITgcm, even with the omission of the points discussed above. It is likely that the topographic wave drag employed in HYCOM plays in important role in damping HYCOM tidal KE to realistic levels. This would be consistent with discussions in Ansong et al. [2015], who showed that an extra damping, such as parameterized topographic wave drag, is needed to make modeled internal tide SSH signatures agree with altimeter observations (see Buijsman et al. [2016] for related discussions on the impact of wave drag on tidal energetics). MITgcm does not employ a wave drag, which likely explains its overly large KE outside of special regimes such as the Strait of Gibraltar. More analyses of the MITgcm results are currently underway in order to further test this hypothesis of damping sensitivity. The high sensitivity of the comparison metrics to outliers, particularly in the case of the linear regression coefficient and $\gamma$, illustrates some of the difficulties inherent in bulk model-data comparisons such as this. Finally, we note that, both with and without the inclusion of the high-velocity values, the HYCOM spatial correlation values $r_{s}$ are always higher than the MITgcm $r_{s}$ values. 


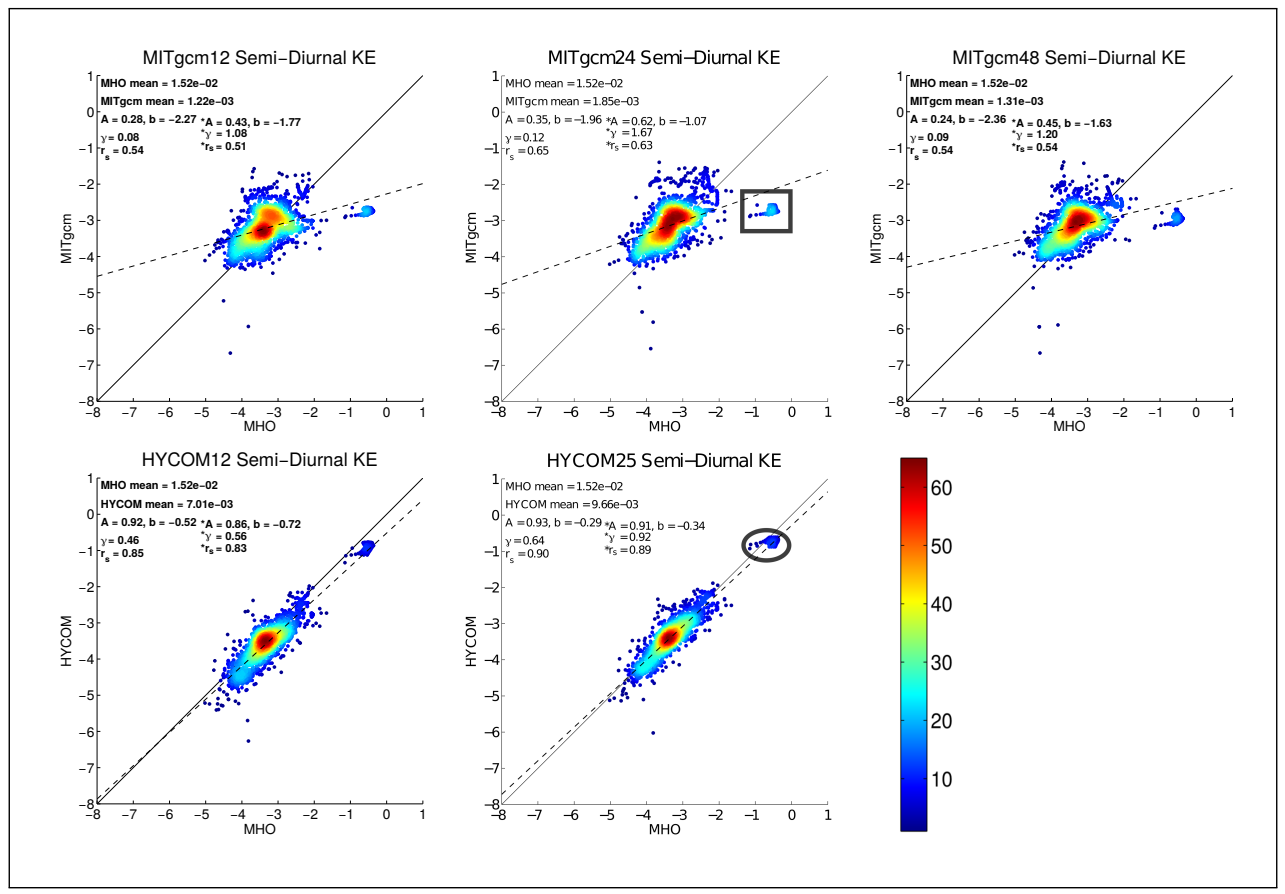

Figure 7. As in Figure 5 but for semi-diurnal KE.

Figure 8 shows scatterplots of HYCOM and MITgem semi-diurnal temperature variance values against $\mathrm{MHO}$ values. Visually, there is more improvement between MITgcm12 and MITgcm24, with the values becoming more tightly clustered around the one-to-one line, than there is between MITgcm24 and MITgcm48, as is evident in both the linear regression and correlation coefficient. Both HYCOM12 and HYCOM25 display lower variance levels than their MITgcm counterparts, although HYCOM25 is nearly centered on the one-to-one line. The ratios of the means, $\gamma$, are closer to one for MITgcm than for HYCOM. As in all previous comparisons, the correlation coefficients $r_{s}$ are higher in HY$\mathrm{COM}$ than in MITgcm, reflecting the tighter correlations seen in the scatterplots. 


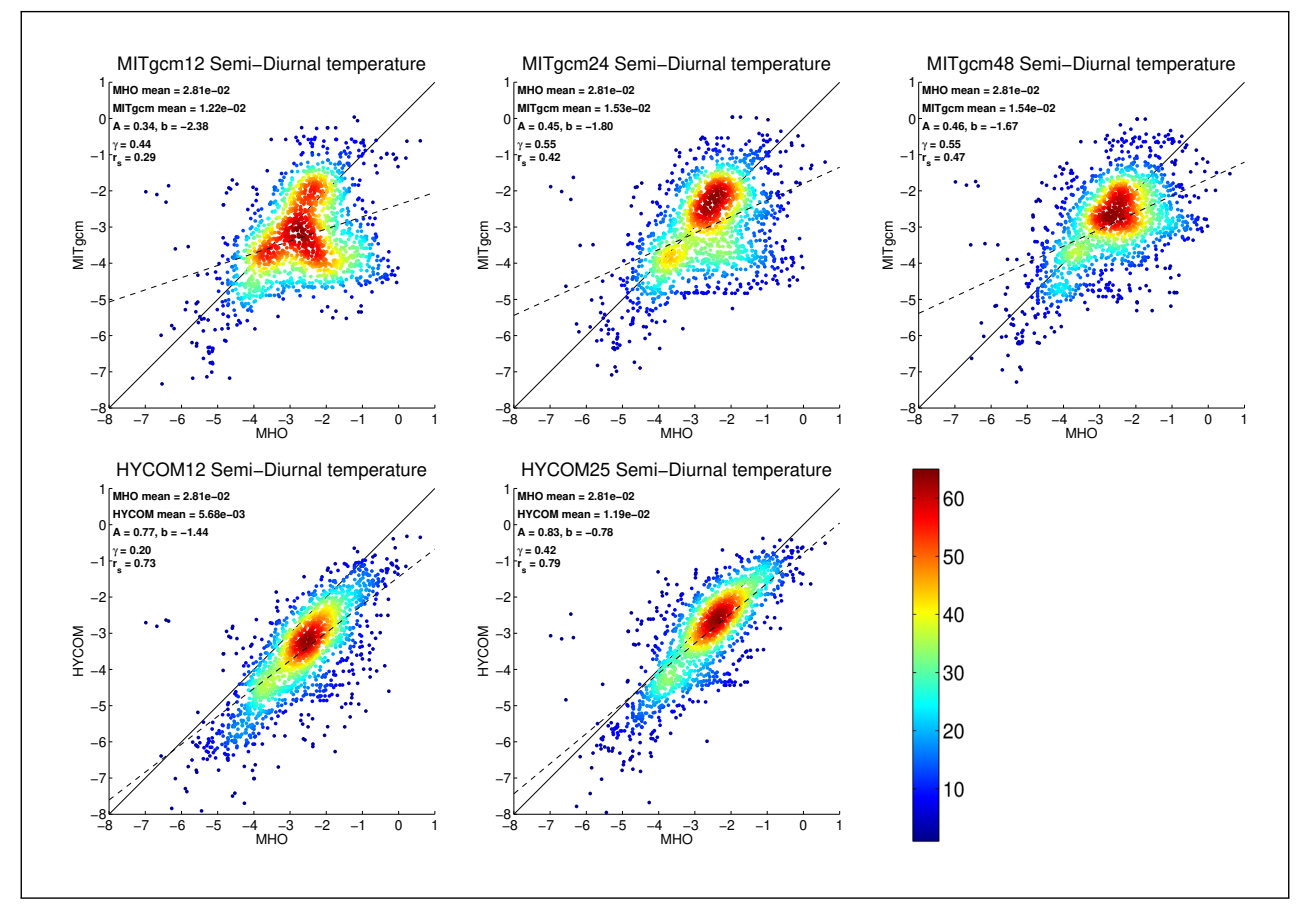

Figure 8. As in Figure 6 but for semi-diurnal temperature variance.

\subsection{Diurnal Band}

Figure 9 shows scatterplots of HYCOM and MITgem diurnal KE values against MHO values. Interestingly, it visually appears as if MITgcm24 is better performing than both MITgcm12, and MITgcm48, and this is confirmed by the statistical metrics, $A, b, \gamma$, and $r_{s}$. Because extreme values tend to dominate the statistics, as discussed below, this result should be treated with some amount of skepticism. The majority of locations visually display a similar amount of scatter in MITgem and HYCOM here compared with earlier plots, although outliers for high-velocity MHO values are again more apparent in MITgcm. The HYCOM results suggest a slight weak bias for the great bulk of values. This is likely due to over-damping of diurnal tides due to the fact that wave drag in HYCOM is optimally tuned for semidiurnal rather than diurnal tides, as discussed in Timko et al. [2013]; see also discussions in Skiba et al. [2013], a study that focused solely on diurnal tides and that employed a wave drag optimally tuned for diurnal tides. The optimal wave drag for diurnal tides is found to be weaker than the optimal drag for semidiurnal tides.

Again, there are several distinct groups of locations representing energies beyond $\left(10^{-2} \mathrm{~m}^{2} \mathrm{~s}^{-2}\right)$ in the MHO data that are anomalously under-energetic in MITgcm. The in- 
strument locations associated with these anomalous values correspond to the circles labeled "A", "B", "C", "D", as well as instruments located in regions near the coastal North West Atlantic, West Pacific, near Taiwan, East Pacific off the Californian coast, the coastal Antarctic, the Ross sea, and off the eastern extent of the Weddell sea. These locations are contained in the large rectangle in the central top panel of Figure 9, and corresponding locations have been covered with a circle and an ellipse in the HYCOM25 subplot of Figure 9. At these locations, MITgcm is systematically under-energetic, while HYCOM appears to do better in its representation of observations, many of which are located in marginal seas or continental margins. Additionally, an anomalous group of points representing energies beyond $\left(10^{-2} \mathrm{~m}^{2} \mathrm{~s}^{-2}\right)$ can be seen in the MITgcm 24 output (and analogous clusters in both MITgcm12 and MITgcm48). These locations are marked with a smaller rectangle in the central top panel of Figure 9. When the instruments enclosed in the rectangles shown in Figure 9 (central top panel) are removed, the statistical metrics change slightly for HYCOM12 and HYCOM25 and MITgcm24, while the changes are more pronounced for MITgcm12, and MITgcm48. This illustrates that even within a single model, locations of outliers can vary between simulations having different resolutions. Once again, with and without the anomalous high-velocity points included, the spatial correlation coefficients $r_{s}$ are higher for HYCOM than for MITgcm.

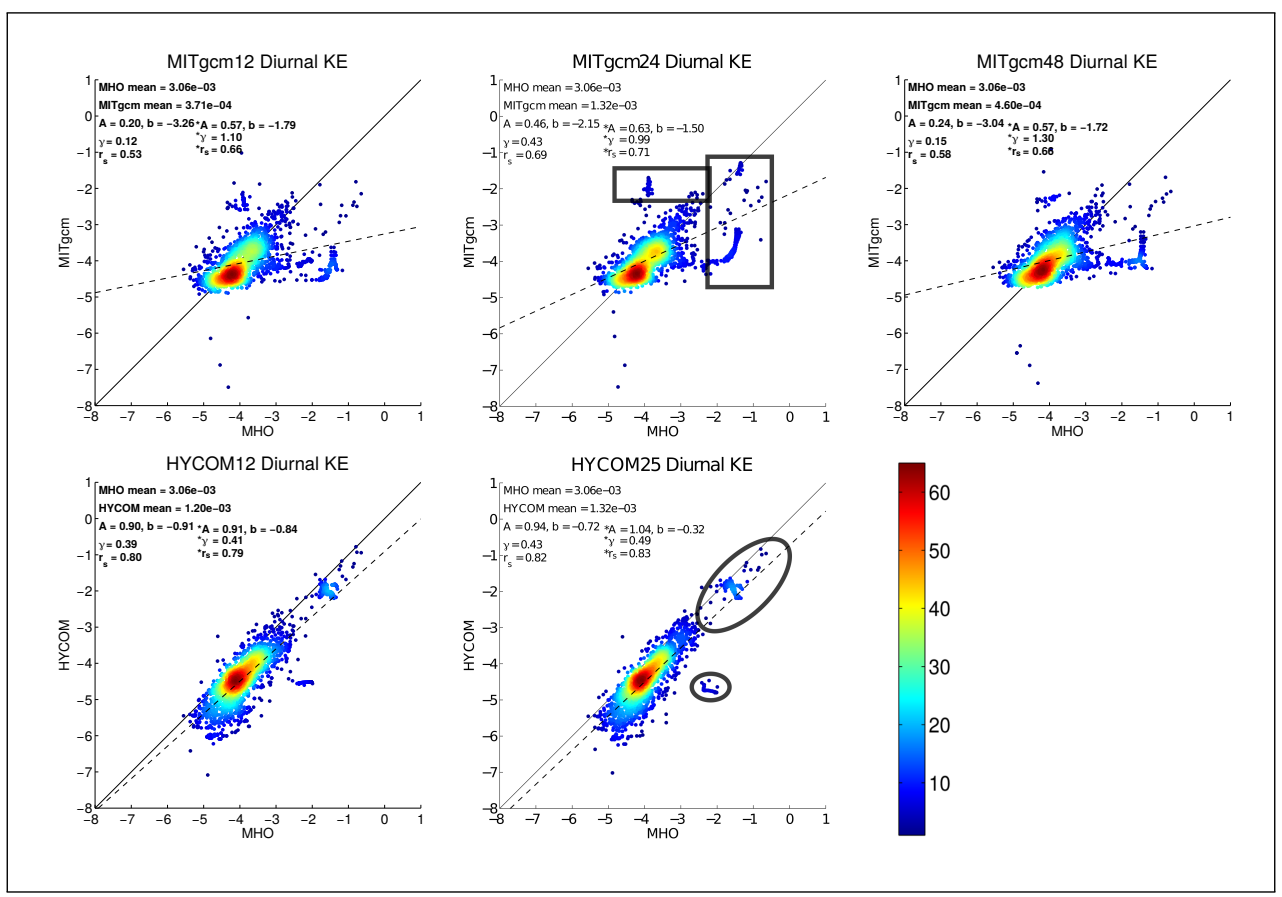

Figure 9. As in Figure 5 but for diurnal KE. 
Figure 10 shows scatterplots of HYCOM and MITgcm diurnal temperature variance values against MHO values. Both HYCOM12 and HYCOM25 are weaker on average than MITgcm, as is seen in lower values of $\gamma$, and as discussed in the previous section, we suggest that this may be due to over-damping of diurnal tides by the wave drag employed in HYCOM. Interestingly, while HYCOM and MITgem as a whole have opposite linear regression trends, both models have more or less equal performance, with each improving slightly with increased resolution. Once again, HYCOM has higher correlation values $r_{s}$ than MITgcm.

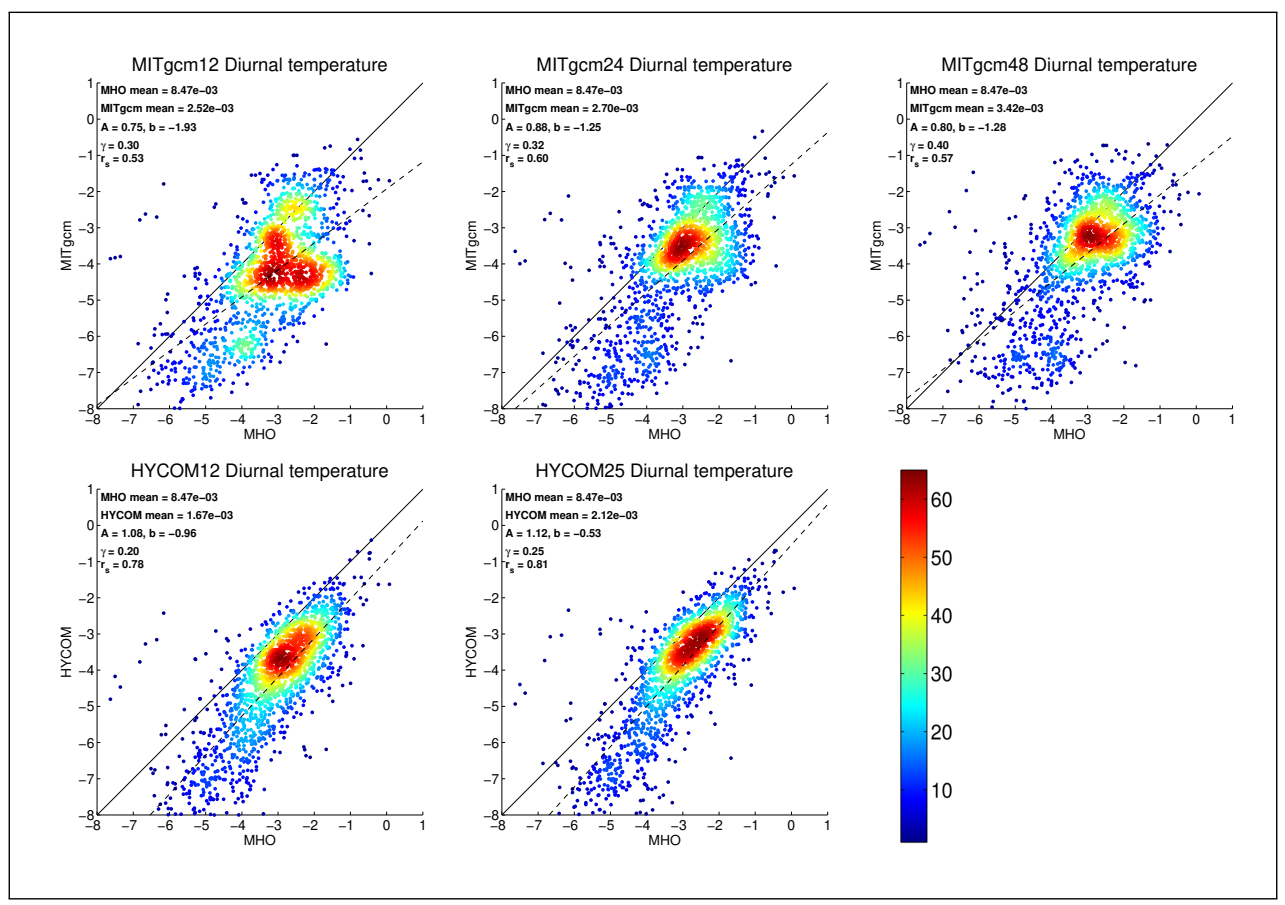

Figure 10. As in Figure 6 but for diurnal temperature variance.

\subsection{Near-Inertial Band}

As near-inertial motions do not, to first order, do not have associated vertical displacements, we do not compare temperature variances in the near-inertial band. Scatterplots of HYCOM and MITgcm near-inertial KE values against MHO values are displayed in Figure 11. Some scatter between models and observations is expected, as the mooring data spans many different years, and the atmospheric forcing such as storms that generate near-inertial motions will inherently vary from year to year. The performance of MITgcm and HYCOM is fairly similar in this band as seen in all four metrics $\left(A, b, \gamma\right.$, and $\left.r_{s}\right)$, and 
is also not greatly sensitive to horizontal resolution, consistent with the fairly large horizontal scales of near-inertial waves (e.g., Simmons and Alford [2012]). As in all bands, the HYCOM spatial correlation values $r_{s}$ are higher than in MITgcm. However, in this band the HYCOM $r_{s}$ values are only slightly higher, consistent with the visual appearance of Figure 11.

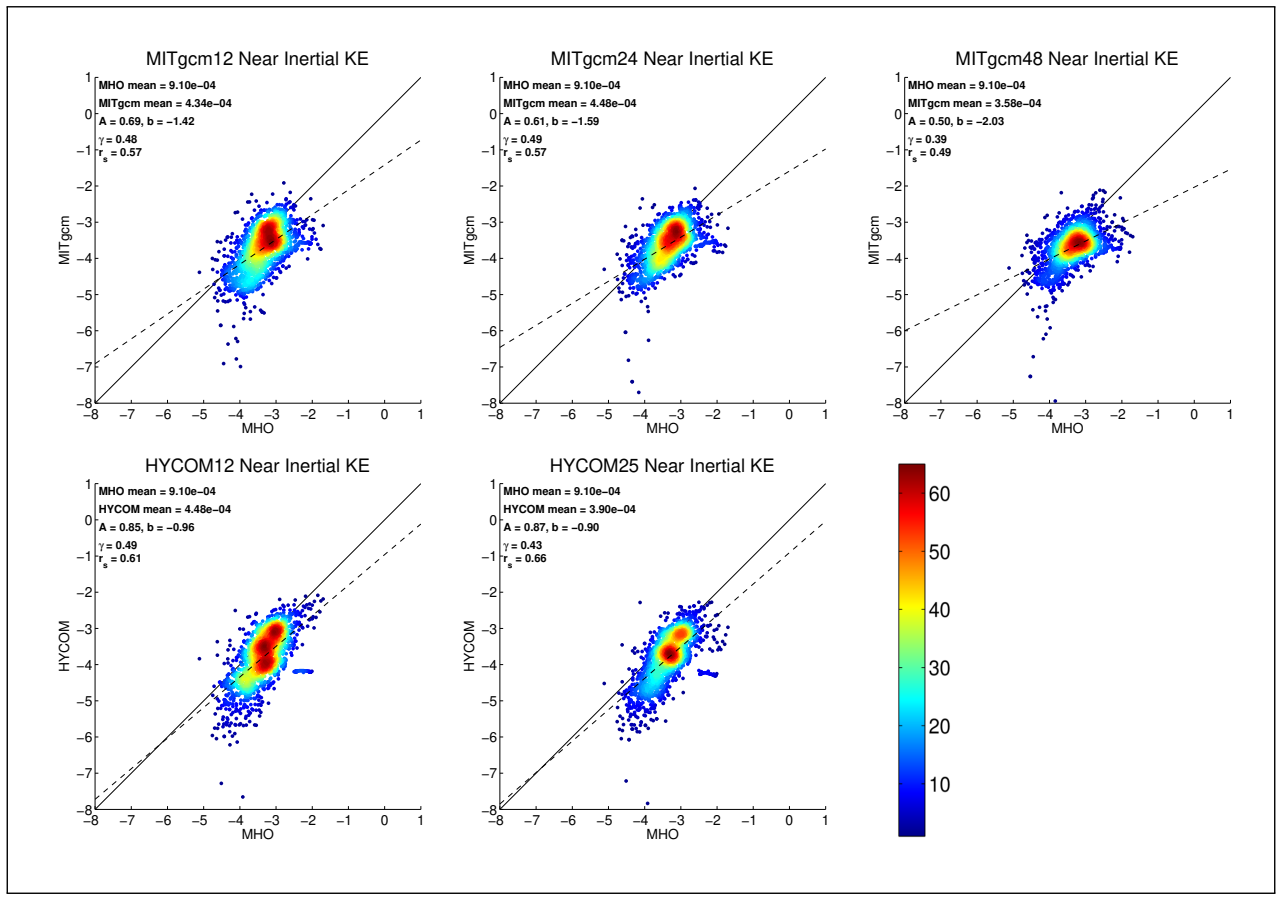

Figure 11. As in Figure 5 but for near-inertial KE.

\subsection{Subtidal Frequency Band}

The subtidal band covers frequencies from $0.7 \mathrm{cpd}$, a little less than once per day, to one cycle every 10 days, and is the frequency band most likely to contain sub-mesoscale eddy motions, which have shorter timescales and smaller spatial extent than mesoscale motions [Su et al., 2018]. One might expect an increase in model resolution to enhance the dynamics within these time scales, as higher spatial resolutions precipitate frontal instabilities and other submesoscale motions [Capet et al., 2008]. Figure 12 shows scatterplots of HYCOM and MITgem subtidal kinetic energy values against MHO values. From visual inspection, HYCOM12 and HYCOM25 behave similarly, with both runs being about a factor of 2 lower than the MHO mean $(\gamma=0.48,0.45$ for HYCOM12 and HYCOM25 respectively), and the linear regressions suggest that this bias is lowest at lower 
energies. MITgcm however shows a steady increase in variance as resolution is increased $(\gamma=0.18,0.45,0.53$ for MITgcm12, MITgcm24, and MITgcm48 respectively), and the linear regressions have slopes slightly closer to one. Although MITgcm48 has the highest variance, it is only slightly larger than the MITgem24 and HYCOM variances. Thus we cannot conclude with any confidence that better resolution of the submesoscale is responsible for the changes seen with higher resolution in Figure 12. As in other frequency bands, the HYCOM scatterplots have a tighter visual appearance, and accordingly, somewhat higher $r_{s}$ values.

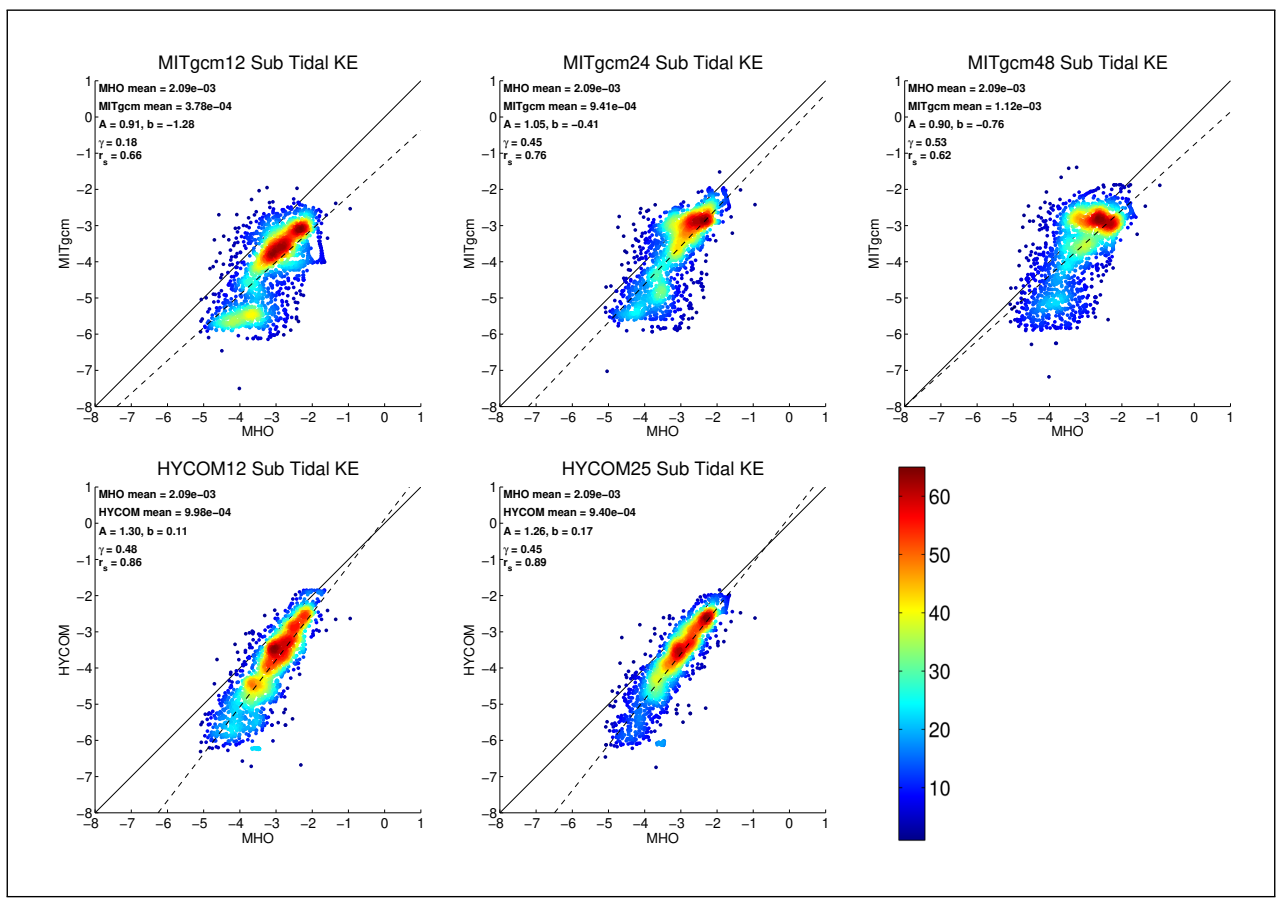

Figure 12. As in Figure 5 but for subtidal KE.

The subtidal temperature variance scatterplots are displayed in Figure 13. Visually, HYCOM12 and HYCOM25 are similar, with both runs having lower means than the MHO. There is marked improvement in some statistics with $\gamma=0.15,0.34$ for HYCOM12 and HYCOM25 respectively. Similarly, MITgcm also increases temperature variance as resolution increases $(\gamma=0.09,0.16,0.24$ for MITgcm12, MITgcm24, and MITgcm48 respectively). The linear regressions for subtidal temperature variance are very similar to $\mathrm{KE}$ within the same frequency band. However, as the submesoscale is just beginning to become evident at the $\sim 2 \mathrm{~km}$ grid spacing in MITgcm48 [Capet et al., 2008], it is again 
difficult to be confident that resolution of the submesoscales is responsible for the changes with model horizontal resolution seen in Figure 13. Once again the $r_{S}$ values for subtidal temperature variance are higher for HYCOM than for MITgcm.

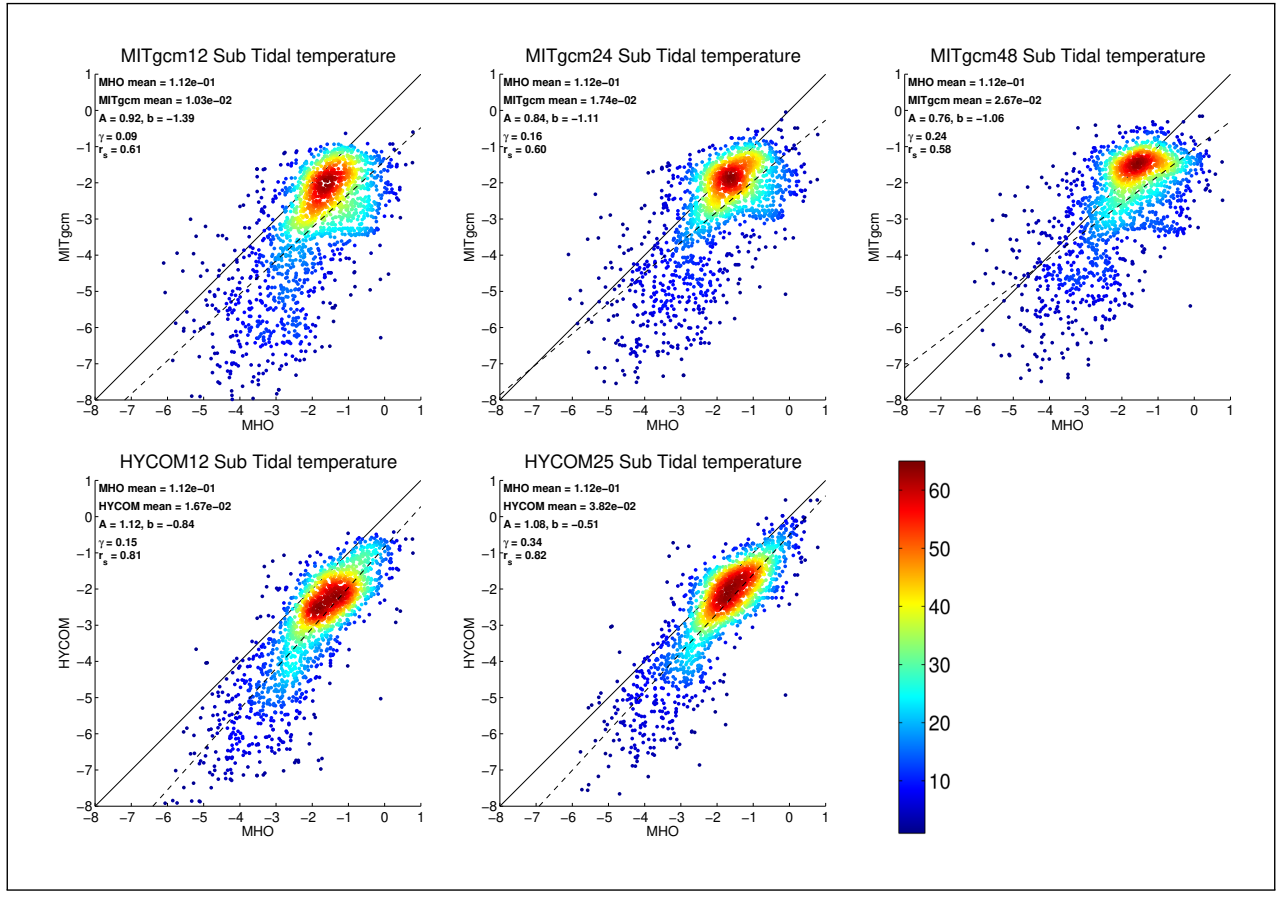

Figure 13. As in Figure 6 but for subtidal temperature variance.

\subsection{Mesoscale Frequency Band}

The mesoscale is the final, and lowest frequency, band that we examine in the model vs. MHO comparisons. Figure 14 shows scatterplots of HYCOM and MITgcm mesoscale kinetic energy values against MHO values. From visual inspection, MITgcm12 is biased lowest compared to MHO, while HYCOM25 is the closest to the one-to one line as confirmed by the linear regression, although still somewhat lower than observations. Within both models, higher resolution runs generally contain more KE variance, $(\gamma=0.36,0.42,0.55$ for MITgcm12, MITgcm24, and MITgcm48 respectively, and $\gamma=0.56,0.57$ for HYCOM12 and HYCOM25 respectively). HYCOM is more correlated than MITgcm, with $r_{s}=0.77,0.83$ for HYCOM12 and HYCOM25 versus $r_{s}=0.54,0.62,0.50$ for MITgcm12, MITgcm24, and MITgcm48.

The mesoscale temperature variance scatterplots are given in Figure 15. As in all other model-MHO comparisons presented here, the HYCOM scatterplots have a visually 
tighter appearance, and accordingly are associated with larger values of the correlation coefficient $r_{s}$. The ratios of the means, $\gamma$, are also closer to 1 in HYCOM. The $\gamma$ values move closer to one when resolution is increased in HYCOM, but less so for the MITgcm simulations. As with mesoscale KE, the HYCOM mesoscale temperature variances are larger than the MITgcm variances, and are closer to observations, as measured by the $\gamma$ values. The HYCOM $\gamma$, and $r_{s}$ values computed from the HYCOM runs used here are similar to those computed in the analysis of low-frequency eddy available potential energy in the older HYCOM runs used in Luecke et al. [2017].

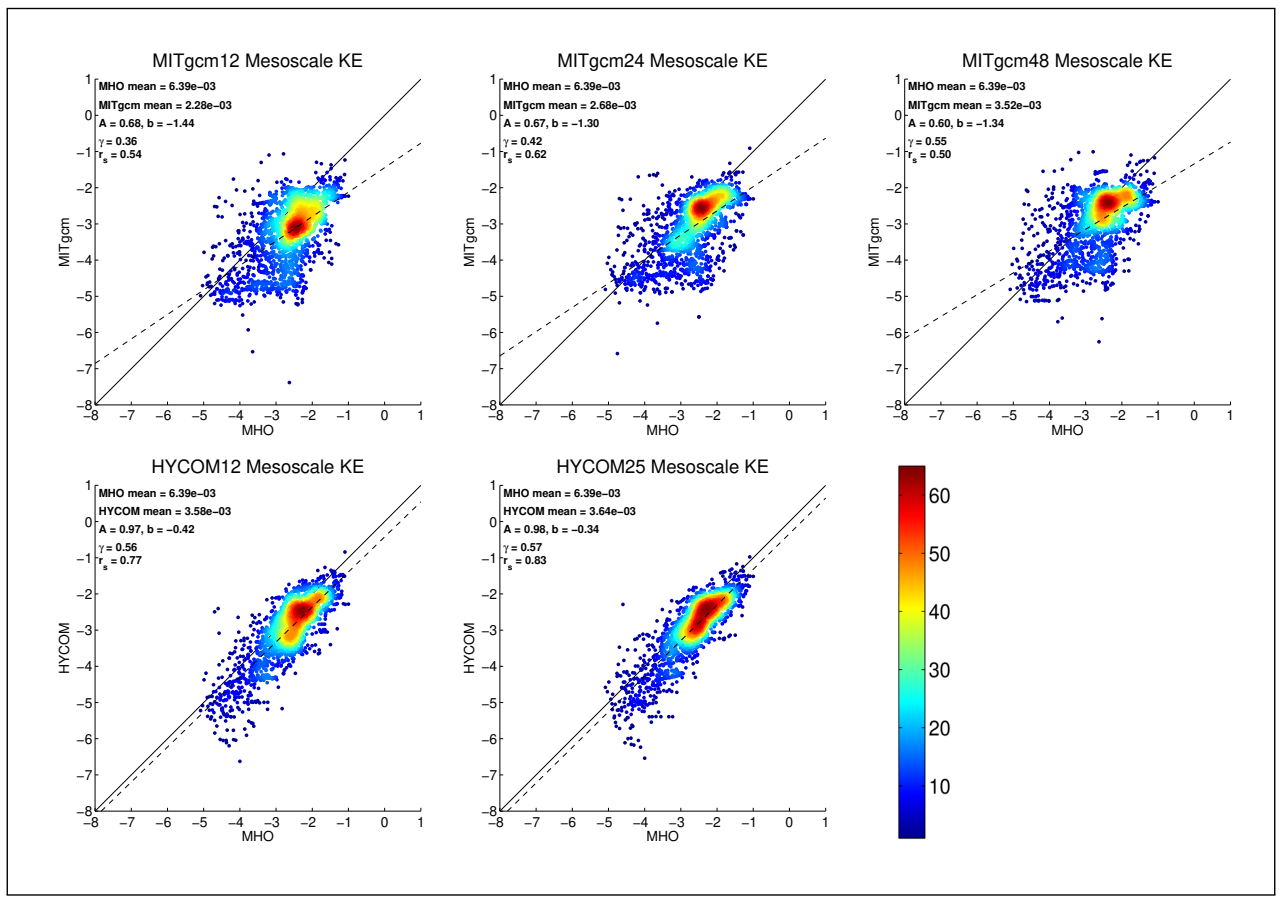

Figure 14. As in Figure 5 but for mesoscale KE. 


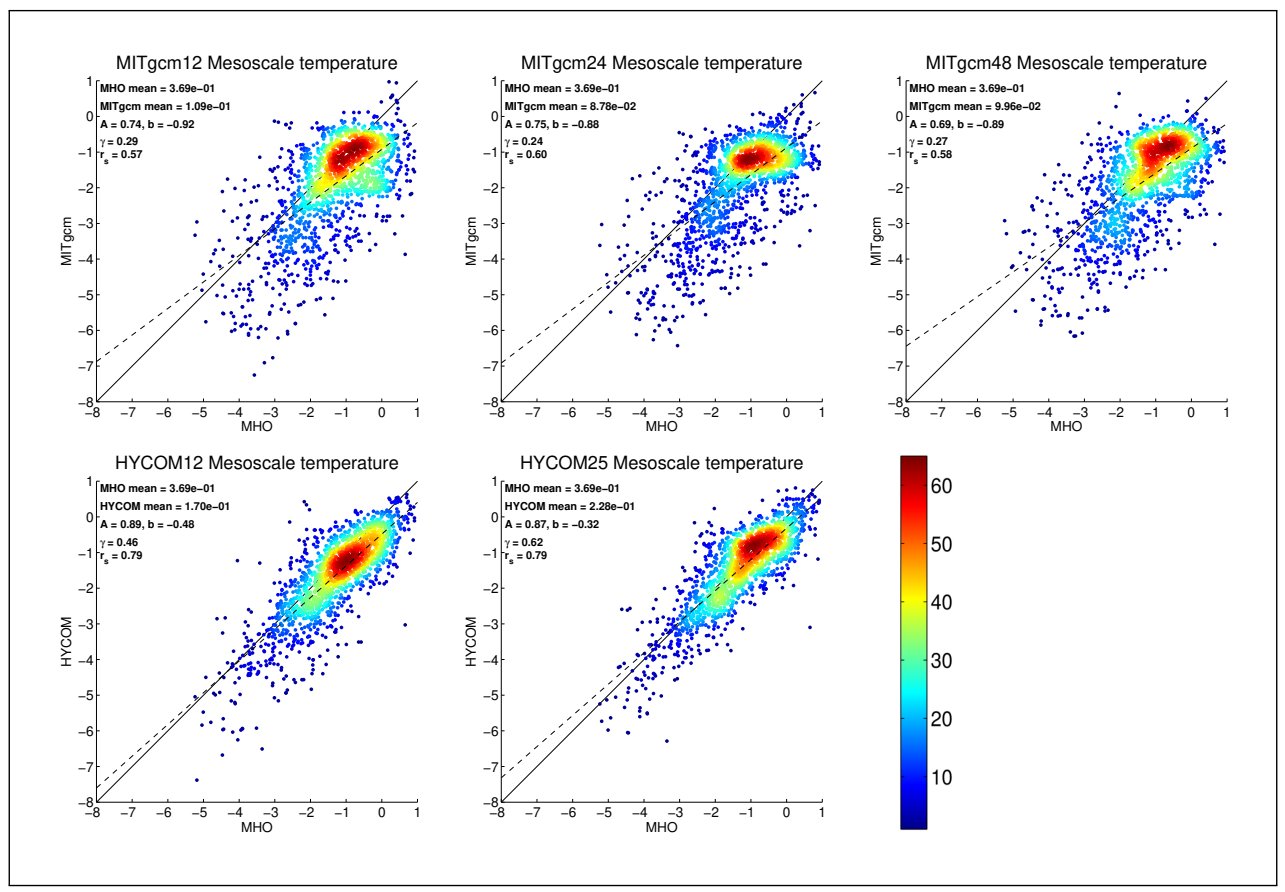

Figure 15. As in Figure 6 but for mesoscale temperature variance.

\subsection{Summary of Model-MHO Comparisons}

Our model-MHO comparisons can be summarized with a few key points:

- Increasing the horizontal resolution of the ocean models makes a larger difference in some frequency bands than it does in others, with the supertidal IGW band seeing the largest effects.

- MITgcm48 has the most realistic supertidal IGW variance levels, likely in part due to its higher vertical and horizontal resolution and perhaps due in part to an overly energetic internal tide band.

- On the other hand, in some continental margin/marginal sea regions, MITgcm has too little KE in the high-frequency bands (diurnal, semidiurnal, and supertidal), whereas HYCOM lies closer to observations in such areas.

- HYCOM has higher levels of mesoscale KE and temperature variance than MIT$\mathrm{gcm}$.

- Of all the frequency bands examined, the near-inertial band is most similar across the five simulations examined here; the lack of sensitivity to model resolution may 
reflect the relatively large horizontal scales of low-mode near-inertial motions. [Simmons and Alford, 2012].

- HYCOM displays higher spatial correlations $r_{s}$ than MITgcm across all frequency bands, with the near-inertial band showing the smallest differences between the simulations.

The comparison of the MITgem and HYCOM simulations with the MHO hints at the importance of wave drag, in that the internal tide kinetic energy in the MITgcm simulations sits higher than that of the moorings, while HYCOM is closer. This tendency for MIT$\mathrm{gcm}$ to have overly energetic internal tides is seen more clearly in comparisons with observations that have a denser spatial sampling (hence better spatial statistics) than our current meter archive-for instance, in the comparison with the global drifter dataset [ $\mathrm{Yu}$ et al., 2019]; in-preparation work led by Jonathan Brasch shows that the HYCOM internal tide kinetic energies lie closer to the drifters, primarily because of the inclusion of wave drag. An in-preparation paper by Joseph Ansong likewise shows that the internal tides in several models that are run without wave drag are overly energetic when compared to along-track altimetry; a conclusion that is consistent with Ansong et al. [2015], who considered HYCOM simulations with and without wave drag. The strength of the modelMHO comparisons lies in the ability to compare different frequency bands, which separate different classes of oceanic motions. The weakness of the model-MHO comparisons lies in the relatively sparse spatial distribution of the $\sim 2,000 \mathrm{MHO}$ instruments, which implies that statistical metrics are sensitive to a small number of extreme values, often taking place in continental margin/marginal sea locations. In the next section we compare surface ocean geostrophic KE fields in the models to AVISO, which provides a spatially dense global product. However, this product focuses on only one class of motions (lowfrequency mesoscale flows).

\section{Global Model vs. AVISO Comparisons of Surface Ocean Geostrophic Eddy Ki- netic Energy}

Prompted by differences between MITgcm and HYCOM in our MHO comparison, we present a global comparison of surface ocean geostrophic eddy KE between HYCOM, the AVISO satellite altimeter product, and MITgcm, shown in Figure 16. The spatial structure in both MITgcm48 (bottom panel) and HYCOM25 (top panel) matches the structure seen in AVISO (center) reasonably well. However, there are several regions of 
poor model-AVISO comparison. For instance, HYCOM25 appears to have more energy than AVISO in the South Atlantic, Southern Indian Ocean, South Eastern Pacific, many tropical regions, and the Antarctic Circumpolar Current, while MITgcm48 appears closer to AVISO in most regions. Conversely HYCOM25 represents the Gulf Stream more accurately than MITgcm 48 .

As was done in our comparisons at MHO locations, we can also examine the pointto-point comparisons between the models and AVISO. Figure 17 shows the point-to-point surface ocean geostrophic eddy KE between MITgcm48 and AVISO (left), and between HYCOM25 and AVISO (right), taken from the data shown in Figure 16. Because of concerns about the effect of sea ice on the comparisons, points poleward of 55 degrees have been masked out of the comparison. In addition we eliminate all AVISO for which one or more points in the local $1 / 4^{\circ}$ by $1 / 4^{\circ}$ neighborhood over which we average the model values, are land points. The elimination of points near land or sea ice results in a more restricted set of points than was used in Qiu et al. [2018]. Globally, the linear regression A is higher in HYCOM25 than in MITgem48, indicating a HYCOM bias toward higher energies. Examination of the correlation $r_{s}$ reveals that while both models correlate fairly well, HYCOM25 has a slightly larger $r_{s}$ value than MITgcm, consistent with the results of our MHO analysis.

Finally, as a test of the sampling bias in the MHO comparisons, we show, in Figure 18, scatterplots of the surface ocean geostrophic eddy KE between MITgcm48 and AVISO (left), and between HYCOM25 and AVISO (right) at the MHO locations used in this work. (For this plot, in order to duplicate the MHO analysis as closely as possible, at MHO locations with instruments at multiple depths, the model-AVISO pairs are included multiple times, once for each MHO instrument). The linear regression $A$ is higher in HYCOM25 than in MITgcm48, consistent with our other results indicating higher energies in the HYCOM surface ocean geostrophic eddy KE field. As measured by $\gamma$ values, at MHO locations MITgcm25 slightly under-predicts AVISO eddy KE, while HYCOM25 over-predicts the eddy KE by a factor of about two. Consistent with previous results of the MHO comparison, the correlation $r_{s}$ in HYCOM25 is higher than MITgem48. The results of Figure 18 indicate once again that the HYCOM simulations achieve a higher spatial correlation with respect to observational products than the MITgcm simulations. 


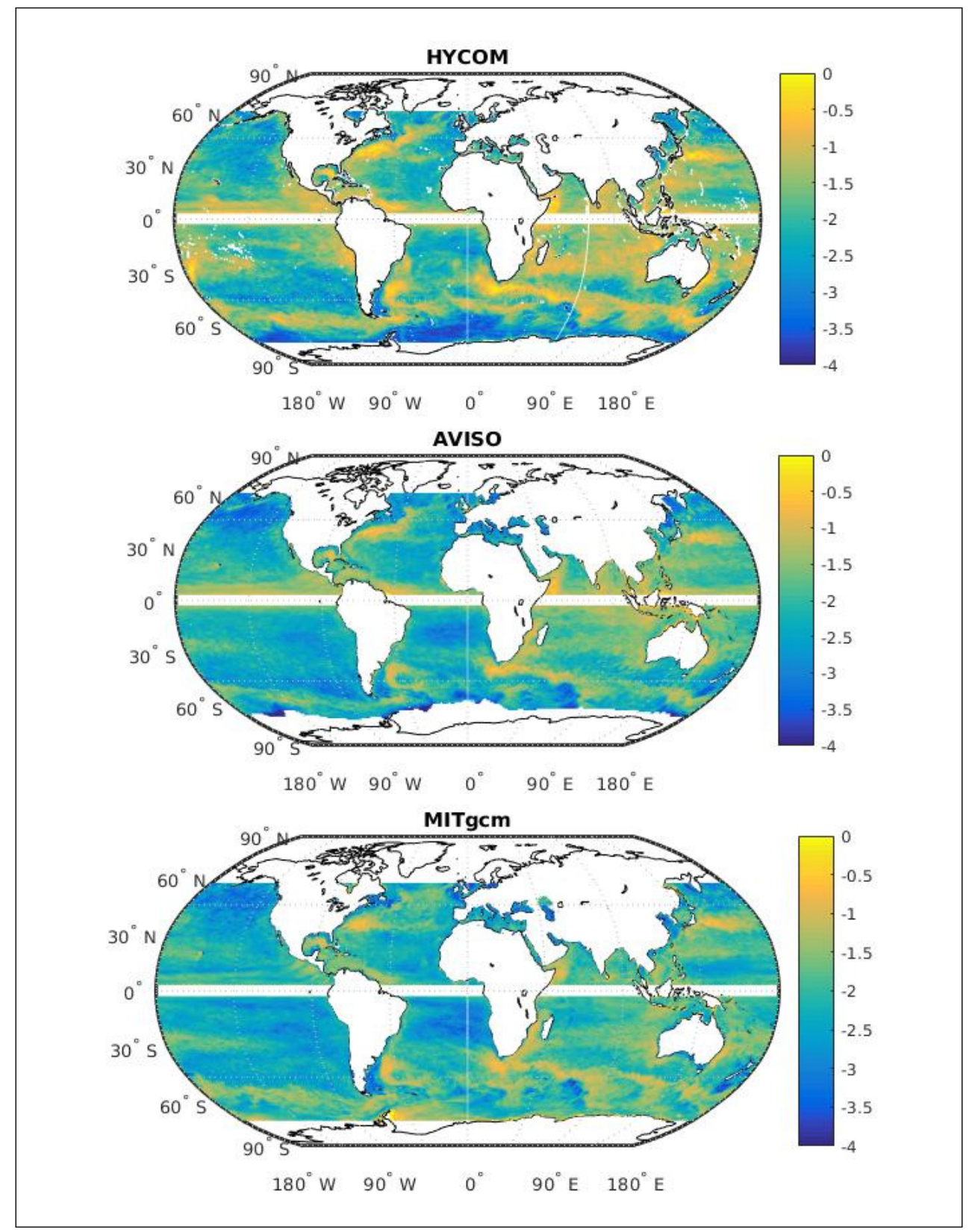

Figure 16. Global surface ocean geostrophic eddy kinetic energy $\left(\log _{10}\left(\mathrm{~m}^{2} \mathrm{~s}^{-2}\right)\right)$ in HYCOM 25 (top), AVISO (center), and MITgcm48 (bottom). Maps are given on a 0.25 degree grid. 


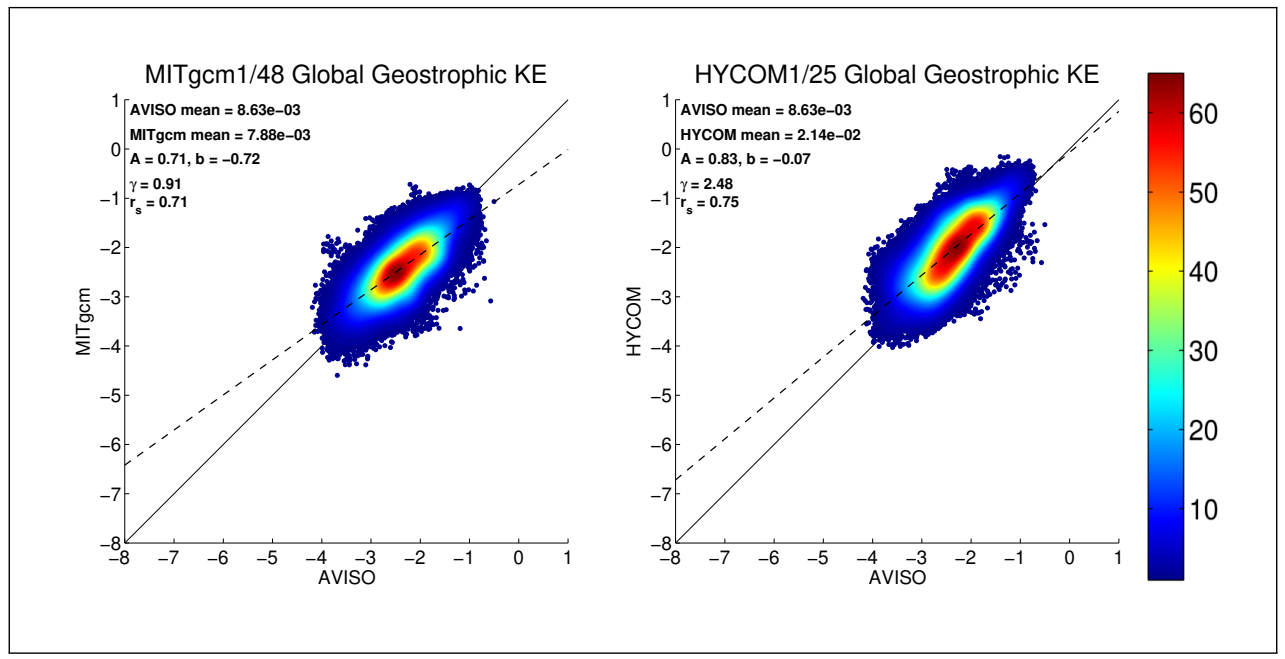

Figure 17. As in Figure 5 but for surface ocean geostrophic eddy KE between MITgcm48 and AVISO (left), and between HYCOM25 and AVISO (right), over the global values taken from the maps of Figure 16. Locations poleward of 55 degrees and near-land locations (see text for details), have been omitted.

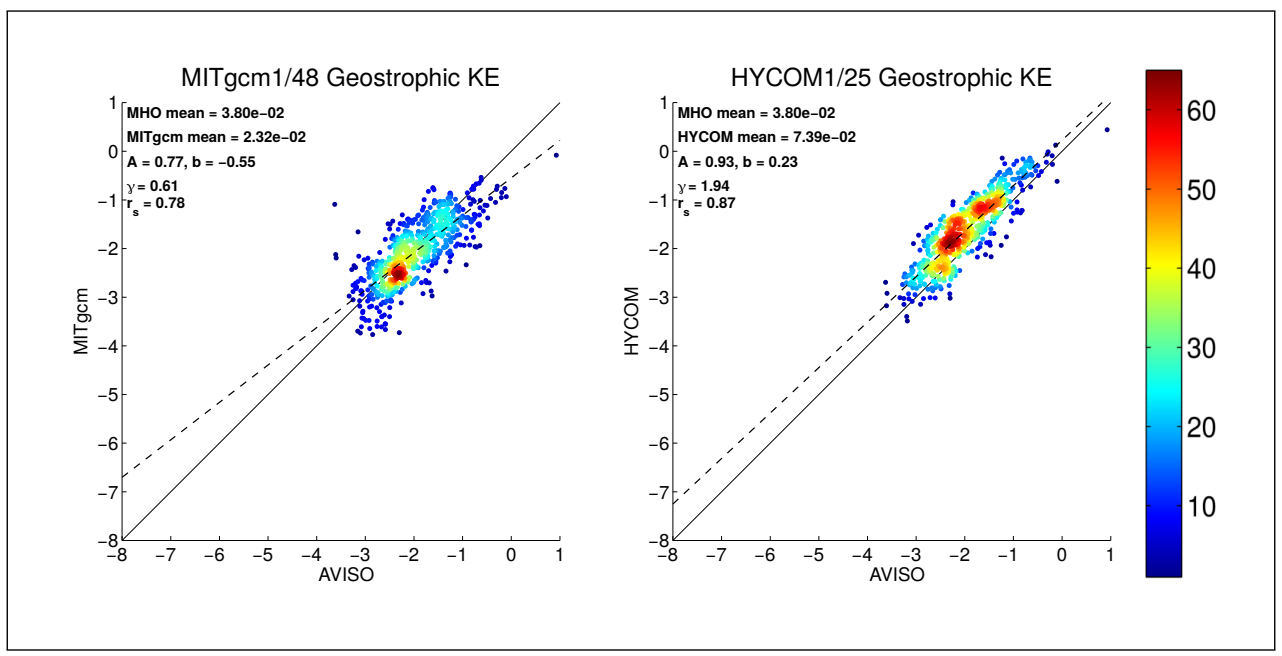

Figure 18. As in Figure 17 but for surface ocean geostrophic eddy KE between MITgcm48 and AVISO (left), and between HYCOM25 and AVISO (right), at the locations of the MHO intruments.

\section{Summary and discussion}

We have assessed the frequency content of temperature variance and kinetic energy in multiple resolutions of two global ocean general circulation models with embedded tides (MITgcm 1/12, 1/24 and 1/48 degree, and HYCOM 1/12 and 1/25 degree) using a database of moored historical observations (MHO). We also compared geostrophic sur- 
face ocean eddy kinetic energy in the models and in the AVISO satellite altimeter product. The AVISO comparisons can only be done for one class of motions, mesoscale currents and eddies, but offer much denser spatial coverage over the globe. The MHO comparisons allow a separation into different frequency bands, corresponding to different classes of oceanic motions, but for some bands the statistical metrics are highly sensitive to behaviors at a small number of locations, often in continental shelves and marginal seas. The impact of horizontal model resolution on $\mathrm{KE}$ and temperature variance differs between frequency bands. For instance, within the near-inertial band, model performance was not dramatically improved by an increase in resolution. However in the supertidal, subtidal, and mesoscale bands (and to a lesser extent semi-diurnal and diurnal bands), models more closely match the observations as resolution is increased. Particularly within the supertidal band, increasing the horizontal model resolution plays an important role in transferring energy into the IGW continuum.

Both HYCOM and MITgem simulations show good and poor agreement with observations in some respects. For instance the HYCOM simulations have higher spatial correlations with the MHO observations than the MITgcm simulations do, at all resolutions and frequency bands. The HYCOM simulations also show a higher correlation with observations in the AVISO surface ocean geostrophic eddy KE comparison. Both the MHO and AVISO comparisons display a tendency for the MITgem simulations to perform poorly in some continental margin/marginal sea locations, where the high-frequency motions in the MITgcm simulations are often under-energetic relative to observations. The HYCOM simulations do not display this tendency for under-energetic high-frequency motions in near-land locations. The MITgcm simulations, particularly the highest resolution MITgcm simulations, have more realistic energy levels in the IGW continuum. Interestingly, however, the HYCOM simulations have a more energetic mesoscale band than the MITgcm simulations.

These important caveats aside, in some respects the highest resolution runs of both MITgem and HYCOM perform well compared to both observational datasets. These new models capture some of the complexities of oceanic variability from mesoscale eddies, which have timescales of 100 days or so, down to the supertidal continuum, which has timescales of a few to several hours. As high-resolution GCMs that partially resolve an internal gravity wave continuum become increasingly used both to study dynamics, and 
as a tool for informing observational oceanography, model-data validation across a wide range of frequencies becomes increasingly important.

We end by clarifying the obvious, that this paper has reported on particular simulations of HYCOM and MITgcm. Our conclusions above apply to these simulations only, and are not meant to apply generally to these two models. It is likely that many of the statements above would change if new simulations of either model with improved parameterizations, numerics, resolution, etc. were to be developed. This being said, we are confident that many of the findings regarding resolutions and parameterizations are broadly applicable. We speculate that the higher spatial correlations of the HYCOM simulations with respect to observations may be due, at least in part, to the long history of tuning HYCOM simulations to be accurate enough for Navy operational purposes. Given time and resources, it is likely that the MITgcm simulations could be brought to a similar state. Similarly, if HYCOM simulations were to be run at higher resolution, they would likely develop a supertidal IGW continuum spectrum with energy levels closer to observations, as in the higher resolution MITgcm simulations reported on here. Introduction of a topographic wave drag into the MITgcm simulations could lead to a better agreement of the modeled internal tide with observations, as has been shown using HYCOM [Ansong et al., 2015]. Alternatively, more advanced parameterizations of internal wave energy loss might be developed, that allow us to move away from using topographic wave drag. Developing better mixing parameterizations is the subject of much present and ongoing research, e.g. MacKinnon et al. [2017]. The relatively poor performance of the particular MITgcm simulations used here in continental margin/marginal sea regions is interesting. We do not have an explanation for it, and we again caution against drawing general conclusions about MITgcm performance in such regions from the particular solutions examined here.

\section{Acknowledgments}

We acknowledge the talent and hard work of all the many principal investigators and mooring technicians, as well as the Captains and crews of many vessels, for deploying and recovering the many moorings without whose efforts, the MHO would not be possible. We thank Bo Qiu and Shuiming Chen for providing the MITgem and AVISO results for surface ocean geostrophic kinetic energy, from their analyses for Qiu et al. 2018. B.K.A., C.A.L., and J.K.A. acknowledge funding by the University of Michigan Associate Professor Support Fund supported by the Margaret and Herman Sokol Faculty Awards. C.A.L. 
and B.K.A. were also funded by the Office of Naval Research (ONR) grants N0001411-1-0487, N00014-15-1-2288, N00014-17-1-2958, and N00014-18-1-2544, the second of which also supported M.C.B. J.K.A., B.K.A., and S.L.B. acknowledge funding provided by National Science Foundation (NSF) grant OCE-0968783 as well as an NSF Research Experience for Undergraduates (REU) supplement for S.L.B. J.G.R., J.F.S., A.J.W., and L.Z. were supported by the project "Eddy resolving global ocean prediction including tides" sponsored by the Office of Naval Research. B.K.A., J.G.R., M.C.B, and J.F.S. also acknowledge funding provided by the National Aeronautics and Space Administration grants NNX13AD95G, NNX16AH79G, and NNX17AH55G. This NRL contribution NRL-JA-7320-2019-4447 has been approved for public release. Distribution is unlimited. Hourly output from the $1 / 12,1 / 24$, and $1 / 48$-degree MITgem simulations is available on the ECCO data portal: https://data.nas.nasa.gov/ecco/. A subset of MHO time series that contains the observations used in this paper, along with MITgcm and HYCOM profiles at MHO locations is available on the University of Michigan Library archival system: https://doi.org/10.7302/dbfp-s644. One year of sea surface height, and surface velocity fields, from a 1/25th degree HYCOM simulation, can also be accessed through the OSiRIS system at the University of Michigan. Co-authors Arbic and Shriver can be contacted for details on how to access the OSiRIS system.

\section{References}

Ansong, J. K., B. K. Arbic, M. C. Buijsman, J. G. Richman, J. F. Shriver, and A. J. Wallcraft (2015), Indirect evidence for substantial damping of low-mode internal tides in the open ocean, Journal of Geophysical Research: Oceans, 120(9), 6057-6071, doi: 10.1002/2015JC010998.

Ansong, J. K., B. K. Arbic, M. H. Alford, M. C. Buijsman, J. F. Shriver, Z. Zhao, J. G. Richman, H. L. Simmons, P. G. Timko, A. J. Wallcraft, and L. Zamudio (2017), Semidiurnal internal tide energy fluxes and their variability in a global ocean model and moored observations, Journal of Geophysical Research: Oceans, 122(3), 1882-1900, doi:10.1002/2016JC012184.

Arbic, B. K., A. J. Wallcraft, and E. J. Metzger (2010), Concurrent simulation of the eddying general circulation and tides in a global ocean model, Ocean Modelling, 32, 175187, doi:doi:10.1016/j.ocemod.2010.01.007. 
Arbic, B. K., J. G. Richman, J. F. Shriver, P. G. Timko, E. J. Metzger, and A. J. Wallcraft (2012), Global modeling of internal tides within an eddying ocean general circulation model, Oceanography, 25, 20-29, doi:https://doi.org/10.5670/oceanog.2012.38.

Arbic, B. K., M. H. Alford, J. K. Ansong, M. C. Buijsman, R. B. Ciotti, J. T. Farrar, R. W. Hallberg, C. E. Henze, C. N. Hill, C. A. Luecke, D. Menemenlis, E. J. Metzger, M. Müller, A. D. Nelson, B. C. Nelson, H. E. Ngodock, R. M. Ponte, J. G. Richman, A. C. Savage, R. B. Scott, J. F. Shriver, H. L. Simmons, I. Souopgui, P. G. Timko, A. J. Wallcraft, L. Zamudio, and Z. Zhao (2018), New Frontiers in Operational Oceanography, chap. 13: A primer on global internal tide and internal gravity wave continuum modeling in HYCOM and MITgcm, pp. 307-392, GODAE OceanView, doi: doi:10.17125/gov2018.ch13.

Buijsman, M., B. Arbic, J. Green, R. Helber, J. Richman, J. Shriver, P. Timko, and A. Wallcraft (2015), Optimizing internal wave drag in a forward barotropic model with semidiurnal tides, Ocean Modelling, 85, 42 - 55, doi:https://doi.org/10.1016/j.ocemod. 2014.11.003.

Buijsman, M. C., J. K. Ansong, B. K. Arbic, J. G. Richman, J. F. Shriver, P. G. Timko, A. J. Wallcraft, C. B. Whalen, and Z. Zhao (2016), Impact of parameterized internal wave drag on the semidiurnal energy balance in a global ocean circulation model, Journal of Physical Oceanography, 46(5), 1399-1419, doi:10.1175/JPO-D-15-0074.1.

Capet, X., J. C. McWilliams, M. J. Molemaker, and A. F. Shchepetkin (2008), Mesoscale to submesoscale transition in the california current system. part iii: Energy balance and flux, Journal of Physical Oceanography, 38(10), 2256-2269, doi:10.1175/2008JPO3810. 1.

Cartwright, D. E. (1999), Tides : a scientific history, 210 pp., Cambridge University Press Cambridge ; New York.

Chassignet, E. P., and X. Xu (2017), Impact of horizontal resolution (1/12 to 1/50) on gulf stream separation, penetration, and variability, Journal of Physical Oceanography, 47(8), 1999-2021, doi:10.1175/JPO-D-17-0031.1.

Chassignet, E. P., H. E. Hurlburt, E. J. Metzger, O. M. Smedstad, J. A. Cummings, G. R. Halliwell, R. Bleck, R. Baraille, A. J. Wallcraft, C. Lozano, H. L. Tolman, A. Srinivasan, S. Hankin, P. Cornillon, R. Weisberg, A. Barth, R. He, F. Werner, and J. Wilkin (2009), US GODAE: Global ocean prediction with the HYbrid Coordinate Ocean Model (HYCOM), Oceanography., 22(2), 64-75, doi:dx.doi.org/10.5670/oceanog.2009. 
39.

Dee, D. P., S. M. Uppala, A. J. Simmons, P. Berrisford, P. Poli, S. Kobayashi, U. Andrae, M. A. Balmaseda, G. Balsamo, P. Bauer, P. Bechtold, A. C. M. Beljaars, L. van de Berg, J. Bidlot, N. Bormann, C. Delsol, R. Dragani, M. Fuentes, A. J. Geer, L. Haimberger, S. B. Healy, H. Hersbach, E. V. Hólm, L. Isaksen, P. Kållberg, M. Köhler, M. Matricardi, A. P. McNally, B. M. Monge-Sanz, J.-J. Morcrette, B.-K. Park, C. Peubey, P. de Rosnay, C. Tavolato, J.-N. Thépaut, and F. Vitart (2011), The ERAinterim reanalysis: configuration and performance of the data assimilation system, Quarterly Journal of the Royal Meteorological Society, 137(656), 553-597, doi:10.1002/qj. 828.

Doherty, K. W., D. E. Frye, S. P. Liberatore, and J. M. Toole (1999), A moored profiling instrument, Journal of Atmospheric and Oceanic Technology, 16, 1816-1829.

Ducet, N. P., Y. L. Traon, and G. Reverdin (2000), global high-resolution mapping of ocean circulation from topex/poseidon and ers-1 and -2, Journal of Geophysical Research: Oceans, 105(C8), 19,477-19,498, doi:10.1029/2000JC900063.

Egbert, G. D., and S. Y. Erofeeva (2002), Efficient inverse modeling of barotropic ocean tides, Journal of Atmospheric and Oceanic Technology, 19(2), 183-204, doi:10.1175/ 1520-0426(2002)019<0183:EIMOBO>2.0.CO;2.

Egbert, G. D., A. F. Bennett, and M. G. G. Foreman (1994), TOPEX/POSEIDON tides estimated using a global inverse model, Journal of Geophysical Research: Oceans, 99(C12), 24,821-24,852, doi:10.1029/94JC01894.

Garrett, C., and E. Kunze (2007), Internal tide generation in the deep ocean, Annual Review of Fluid Mechanics, 39(1), 57-87, doi:10.1146/annurev.fluid.39.050905.110227.

Hecht, W. M., and H. Hasumi (2008), Ocean Modeling in an Eddying Regime, vol. Geophysical Monograph; 177, American Geophysical Union, 2000 Florida Avenue N. W., Washington, D.C.

Hendershott, M. C. (1972), The effects of solid earth deformation on global ocean tides, Geophysical Journal of the Royal Astronomical Society, 29(4), 389-402, doi:10.1111/j. 1365-246X.1972.tb06167.x.

Hogan, T. F., M. Liu, J. A. Ridout, M. S. Peng, T. R. Whitcomb, B. C. Ruston, C. A. Reynolds, S. D. Eckermann, J. R. MoskaitisO, N. L. Baker, P. McCormack, J, L. C. Viner, J. G. McLay, M. K. Flatau, L. Xu, C. C, and S. W. Chang (2014), The navy global environmental model, Oceanography, 27(3), 116-125. 
Jakobsson, M., R. Macnab, L. Mayer, R. Anderson, M. Edwards, J. Hatzky, H. W.

Schenke, and P. Johnson (2008), An improved bathymetric portrayal of the arctic ocean: Implications for ocean modeling and geological, geophysical and oceanographic analyses, Geophysical Research Letters, 35(7), doi:10.1029/2008GL033520, 107602.

Jayne, S. R., and L. C. St. Laurent (2001), Parameterizing tidal dissipation over rough topography, Geophysical Research Letters, 28(5), 811-814, doi:10.1029/2000GL012044.

Kokoska, S., and D. Zwillinger (2000), Standard probability and statistics tables and formulae., Boca Raton: Chapman \& Hall-CRC.

Kunze, E. (2017), The internal-wave-driven meridional overturning circulation, Journal of Physical Oceanography, 47(11), 2673-2689, doi:10.1175/JPO-D-16-0142.1.

Large, W., and S. Yeager (2004), Diurnal to Decadal Global Forcing for Ocean and Sea-ice Models: The Data Sets and Flux Climatologies, NCAR technical notes, National Center for Atmospheric Research.

Large, W. G., J. C. McWilliams, and S. C. Doney (1994), Oceanic vertical mixing: A review and a model with a nonlocal boundary layer parameterization, Reviews of Geophysics, 32(4), 363-403, doi:10.1029/94RG01872.

Losch, M., D. Menemenlis, J.-M. Campin, P. Heimbach, and C. Hill (2010), On the formulation of sea-ice models. Part 1: Effects of different solver implementations and parameterizations, Ocean Modelling, 33(1), 129 - 144, doi:https://doi.org/10.1016/j. ocemod.2009.12.008.

Luecke, C. A., B. K. Arbic, S. L. Bassette, J. G. Richman, J. F. Shriver, M. H. Alford, O. M. Smedstad, P. G. Timko, D. S. Trossman, and A. J. Wallcraft (2017), The global mesoscale eddy available potential energy field in models and observations, Journal of Geophysical Research: Oceans, 122(11), 9126-9143, doi:10.1002/2017JC013136.

MacKinnon, J. A., Z. Zhao, C. B. Whalen, A. F. Waterhouse, D. S. Trossman, O. M. Sun, L. C. St. Laurent, H. L. Simmons, K. Polzin, R. Pinkel, A. Pickering, N. J. Norton, J. D. Nash, R. Musgrave, L. M. Merchant, A. V. Melet, B. Mater, S. Legg, W. G. Large, E. Kunze, J. M. Klymak, M. Jochum, S. R. Jayne, R. W. Hallberg, S. M. Griffies, S. Diggs, G. Danabasoglu, E. P. Chassignet, M. C. Buijsman, F. O. Bryan, B. P. Briegleb, A. Barna, B. K. Arbic, J. K. Ansong, and M. H. Alford (2017), Climate process team on internal wave-driven ocean mixing, Bulletin of the American Meteorological Society, 98(11), 2429-2454, doi:10.1175/BAMS-D-16-0030.1. 
Maltrud, M. E., and J. L. McClean (2005), An eddy resolving global 1/10 ocean simulation, ocean modelling, 8(1-2), 31-54, doi:https://doi.org/10.1016/j.ocemod.2003.12.001.

Marshall, J., A. Adcroft, C. Hill, L. Perelman, and C. Heisey (1997), A finite-volume, incompressible navier stokes model for studies of the ocean on parallel computers, Journal of Geophysical Research: Oceans, 102(C3), 5753-5766, doi:10.1029/96JC02775.

Melet, A., S. Legg, and R. Hallberg (2016), Climatic impacts of parameterized local and remote tidal mixing, Journal of Climate, 29(10), 3473-3500, doi:10.1175/ JCLI-D-15-0153.1.

Menemenlis, D., J.-M. Campin, P. Heimbach, C. Hill, T. Lee, A. Nguyen, M. Schodlok, and H. Zhang (2008), Ecco2: High resolution global ocean and sea ice data synthesis, Mercator Ocean Quarterly Newsletter, 31.

Müller, M., B. K. Arbic, J. G. Richman, J. F. Shriver, E. L. Kunze, R. B. Scott, A. J. Wallcraft, and L. Zamudio (2015), Toward an internal gravity wave spectrum in global ocean models, Geophysical Research Letters, 42(9), 3474-3481, doi:10.1002/ 2015GL063365, 2015GL063365.

Munk, W., and C. Wunsch (1998), Abyssal recipes ii: Energetics of tidal and wind mixing, Deep-Sea Research I, 45.

Ngodock, H. E., I. Souopgui, A. J. Wallcraft, J. G. Richman, J. F. Shriver, and B. K. Arbic (2016), On improving the accuracy of the $\mathrm{m}_{2}$ barotropic tides embedded in a high-resolution global ocean circulation model, Ocean Modelling, 97, 16 - 26, doi: https://doi.org/10.1016/j.ocemod.2015.10.011.

Penduff, T., B. Barnier, J.-M. Molines, and G. Madec (2006), On the use of current meter data to assess the realism of ocean model simulations, Ocean Modelling, 11, 399-416.

Ponte, R. M., A. H. Chaudhuri, and S. V. Vinogradov (2015), Long-period tides in an atmospherically driven, stratified ocean, Journal of Physical Oceanography, 45(7), 19171928, doi:10.1175/JPO-D-15-0006.1.

Qiu, B., S. Chen, P. Klein, J. Wang, H. Torres, L.-L. Fu, and D. Menemenlis (2018), Seasonality in transition scale from balanced to unbalanced motions in the world ocean, Journal of Physical Oceanography, 48(3), 591-605, doi:10.1175/JPO-D-17-0169.1.

Ray, R. D. (1999), A Global Ocean Tide model from TOPEX/POSEIDON altimetry: GOT99.2, 1 v. pp., National Aeronautics and Space Administration, Goddard Space Flight Center ; National Technical Information Service, distributor Greenbelt, M, Springfield, Va. 
Rocha, C. B., T. K. Chereskin, S. T. Gille, and D. Menemenlis (2016a), Mesoscale to submesoscale wavenumber spectra in Drake Passage, Journal of Physical Oceanography, 46(2), 601-620, doi:10.1175/JPO-D-15-0087.1.

Rocha, C. B., S. T. Gille, T. K. Chereskin, and D. Menemenlis (2016b), Seasonality of submesoscale dynamics in the kuroshio extension, Geophysical Research Letters, 43(21), 11,304-11,311, doi:10.1002/2016GL071349.

Savage, A. C., B. K. Arbic, J. G. Richman, J. F. Shriver, M. H. Alford, M. C. Buijsman, J. Thomas Farrar, H. Sharma, G. Voet, A. J. Wallcraft, and L. Zamudio (2017a), Frequency content of sea surface height variability from internal gravity waves to mesoscale eddies, Journal of Geophysical Research: Oceans, 122(3), 2519-2538, doi: 10.1002/2016JC012331.

Savage, A. C., B. K. Arbic, M. H. Alford, J. K. Ansong, J. T. Farrar, D. Menemenlis, A. K. O’Rourke, J. G. Richman, J. F. Shriver, G. Voet, A. J. Wallcraft, and L. Zamudio (2017b), Spectral decomposition of internal gravity wave sea surface height in global models, Journal of Geophysical Research: Oceans, 122(10), 7803-7821, doi: 10.1002/2017JC013009.

Scott, R. B., B. K. Arbic, E. P. Chassignet, A. C. Coward, M. Maltrud, W. J. Merryfield, A. Srinivasan, and A. Varghese (2010), Total kinetic energy in four global eddying ocean circulation models and over 5000 current meter records, Ocean Modelling, 32, $157-169$.

Shriver, J. F., B. K. Arbic, J. G. Richman, R. D. Ray, E. J. Metzger, A. J. Wallcraft, and P. G. Timko (2012), An evaluation of the barotropic and internal tides in a highresolution global ocean circulation model, J. Geophys. Res., 117(C10024), doi:10.1029/ 2012JC008170.

Silverthorne, K. E., and J. M. Toole (2009), Seasonal kinetic energy variability of nearinertial motions, Journal of Physical Oceanography, 39(4), 1035-1049, doi:10.1175/ 2008JPO3920.1.

Simmons, H. L., and M. H. Alford (2012), Simulating the long-range swell of internal waves generated by ocean storms, Oceanography, 25 .

Skiba, A. W., L. Zeng, B. K. Arbic, M. Müller, and W. J. Godwin (2013), On the resonance and shelf/open-ocean coupling of the global diurnal tides, Journal of Physical Oceanography, 43(7), 1301-1324, doi:10.1175/JPO-D-12-054.1. 
Smith, W. H. F., and D. T. Sandwell (1997), Global sea floor topography from satellite altimetry and ship depth soundings, Science, 277(5334), 1956-1962, doi:10.1126/science. 277.5334.1956.

Stammer, D., R. D. Ray, O. B. Andersen, B. K. Arbic, W. Bosch, L. Carrére, Y. Cheng, D. S. Chinn, B. D. Dushaw, G. D. Egbert, S. Y. Erofeeva, H. S. Fok, J. A. M. Green, S. Griffiths, M. A. King, V. Lapin, F. G. Lemoine, S. B. Luthcke, F. Lyard, J. Morison, M. Müller, L. Padman, J. G. Richman, J. F. Shriver, C. K. Shum, E. Taguchi, and Y. Yi (2014), Accuracy assessment of global barotropic ocean tide models, Reviews of Geophysics, 52(3), 243-282, doi:10.1002/2014RG000450.

Su, Z., J. Wang, P. Klein, A. F. Thompson, and D. Menemenlis (2018), Ocean submesoscales as a key component of the global heat budget, Nature Communications, 9(1), 775, doi:10.1038/s41467-018-02983-w.

Thoppil, P. G., J. G. Richman, and P. J. Hogan (2011), Energetics of a global ocean circulation model compared to observations, Geophysical Research Letters, 38(15), doi: 10.1029/2011GL048347.

Timko, P. G., B. K. Arbic, J. G. Richman, R. B. Scott, E. J. Metzger, and A. J. Wallcraft (2012), Skill tests of three-dimensional tidal currents in a global ocean model: A look at the North Atlantic, J. Geophys. Res: Oceans, 117(C8), doi:10.1029/2011JC007617.

Timko, P. G., B. K. Arbic, J. G. Richman, R. B. Scott, E. J. Metzger, and A. J. Wallcraft (2013), Skill testing a three-dimensional global tide model to historical current meter records, J. Geophys. Res: Oceans, 118(12), 6914-6933, doi:10.1002/2013JC009071.

Torres, H. S., P. Klein, D. Menemenlis, B. Qiu, Z. Su, J. Wang, S. Chen, and L.-L. Fu (2018), Partitioning ocean motions into balanced motions and internal gravity waves: A modeling study in anticipation of future space missions, Journal of Geophysical Research: Oceans, 123(11), 8084-8105, doi:10.1029/2018JC014438.

Wang, J., L.-L. Fu, B. Qiu, D. Menemenlis, J. T. Farrar, Y. Chao, A. F. Thompson, and M. M. Flexas (2018), An observing system simulation experiment for the calibration and validation of the surface water ocean topography sea surface height measurement using in situ platforms, Journal of Atmospheric and Oceanic Technology, 35(2), 281297, doi:10.1175/JTECH-D-17-0076.1.

Wang, J., L.-L. Fu, H. S. Torres, S. Chen, B. Qiu, and D. Menemenlis (2019), On the spatial scales to be resolved by the surface water and ocean topography ka-band radar interferometer, Journal of Atmospheric and Oceanic Technology, 36(1), 87-99, doi: 
10.1175/JTECH-D-18-0119.1.

Weis, P., M. Thomas, and J. Sündermann (2008), Broad frequency tidal dynamics simulated by a high-resolution global ocean tide model forced by ephemerides, Journal of Geophysical Research: Oceans, 113(C10), doi:10.1029/2007JC004556.

Wright, C. J., R. B. Scott, P. Ailliot, and D. Furnival (2014), Lee wave generation rates in the deep ocean, Geophysical Research Letters, 41(7), 2434-2440, doi:10.1002/ 2013 GL059087.

Yu, X., A. L. Ponte, S. Elipot, D. Menemenlis, E. D. Zaron, and R. Abernathey (2019), Surface kinetic energy distributions in the global oceans from a high-resolution numerical model and surface drifter observations, Geophysical Research Letters, 46(16), 97579766, doi:10.1029/2019GL083074. 

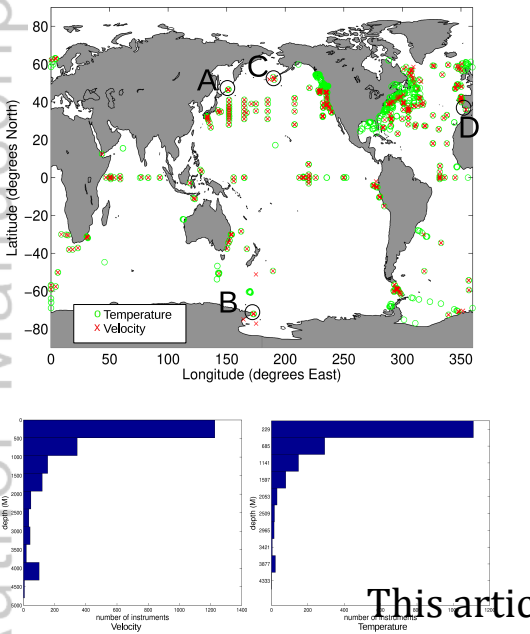
Temperature Spectra at $236^{\circ} \mathrm{E}, 39^{\circ} \mathrm{N}$

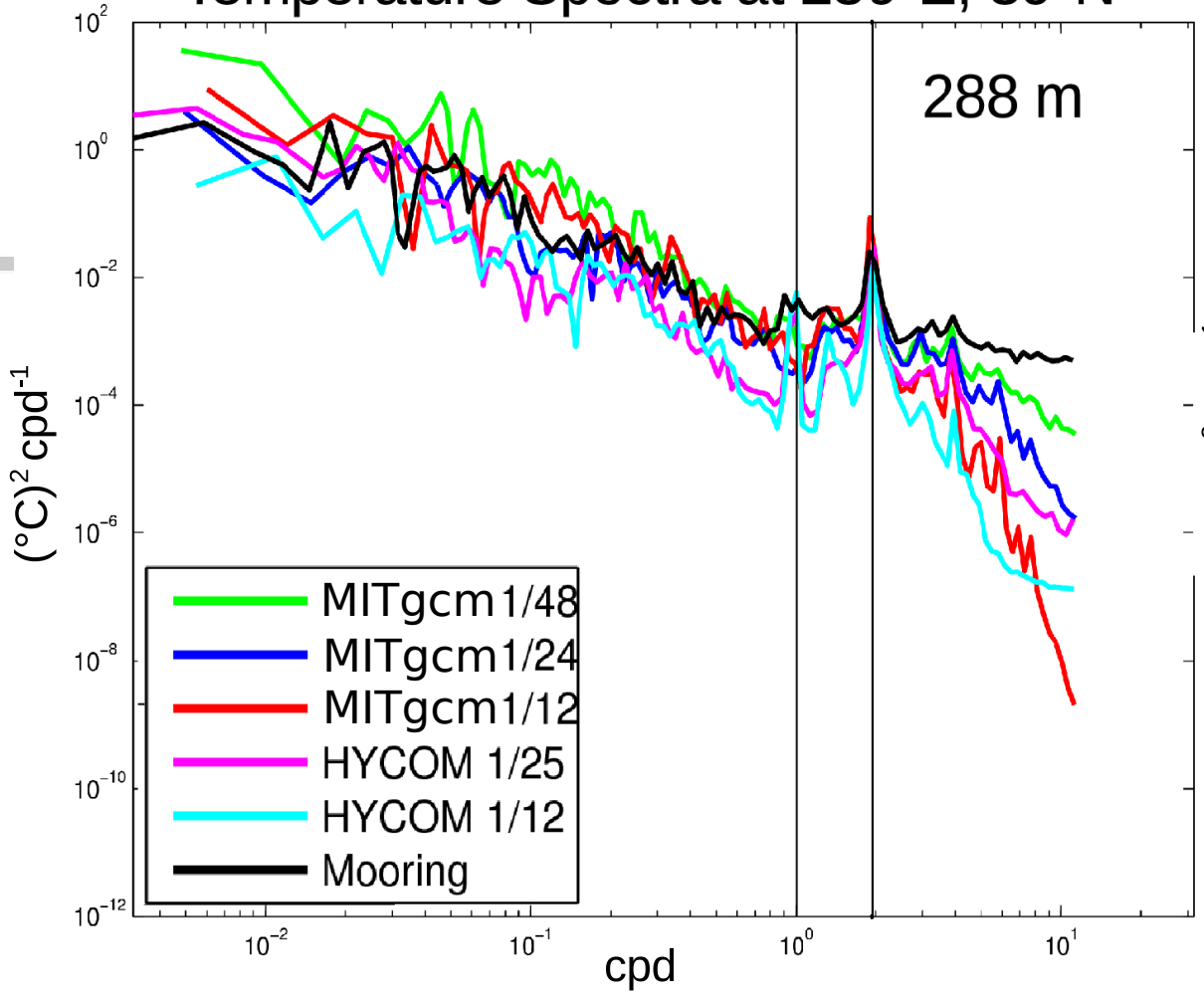

Temperature Spectra at $232^{\circ} \mathrm{E}, 39^{\circ} \mathrm{N}$

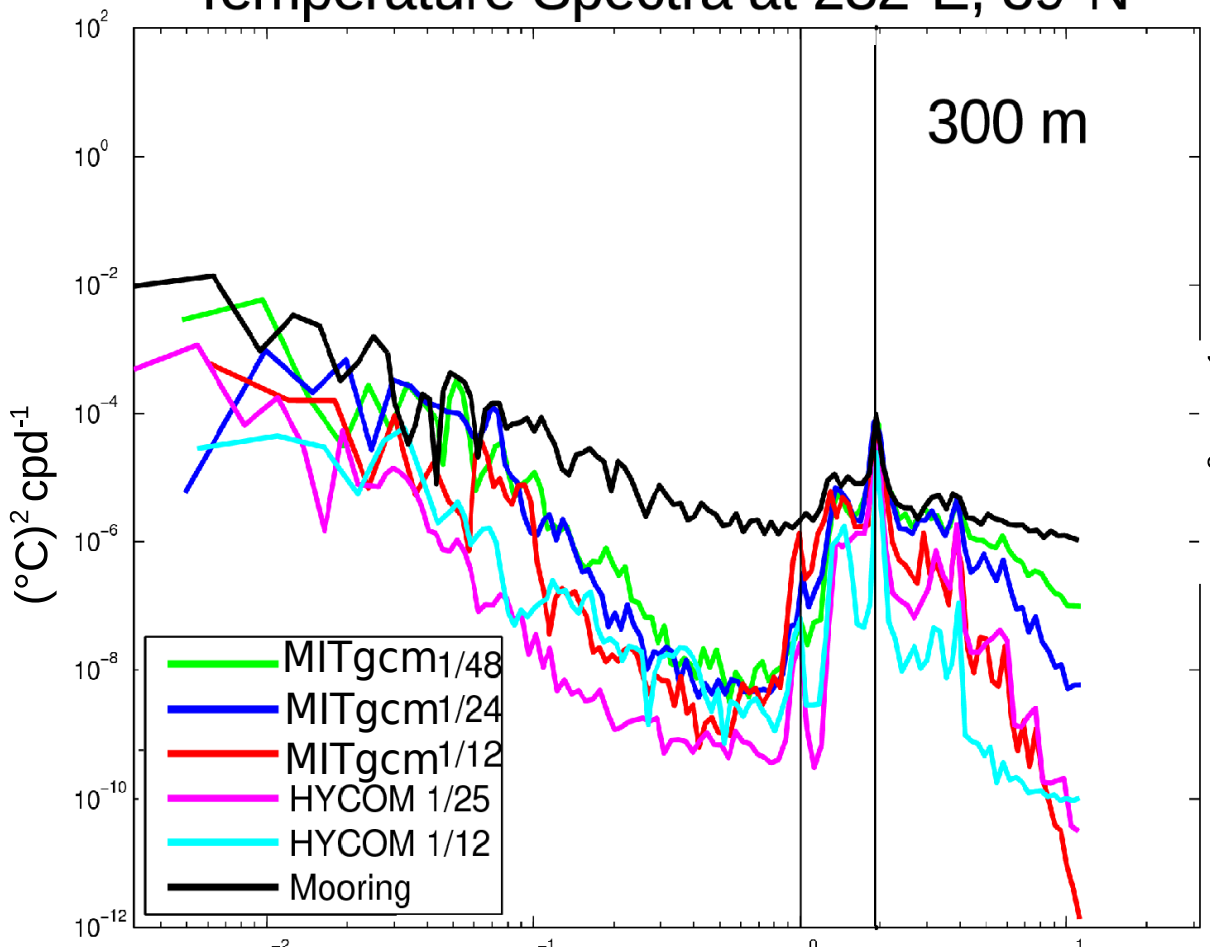

$\mathrm{KE}$ Spectra at $298^{\circ} \mathrm{E}, 43^{\circ} \mathrm{N}$

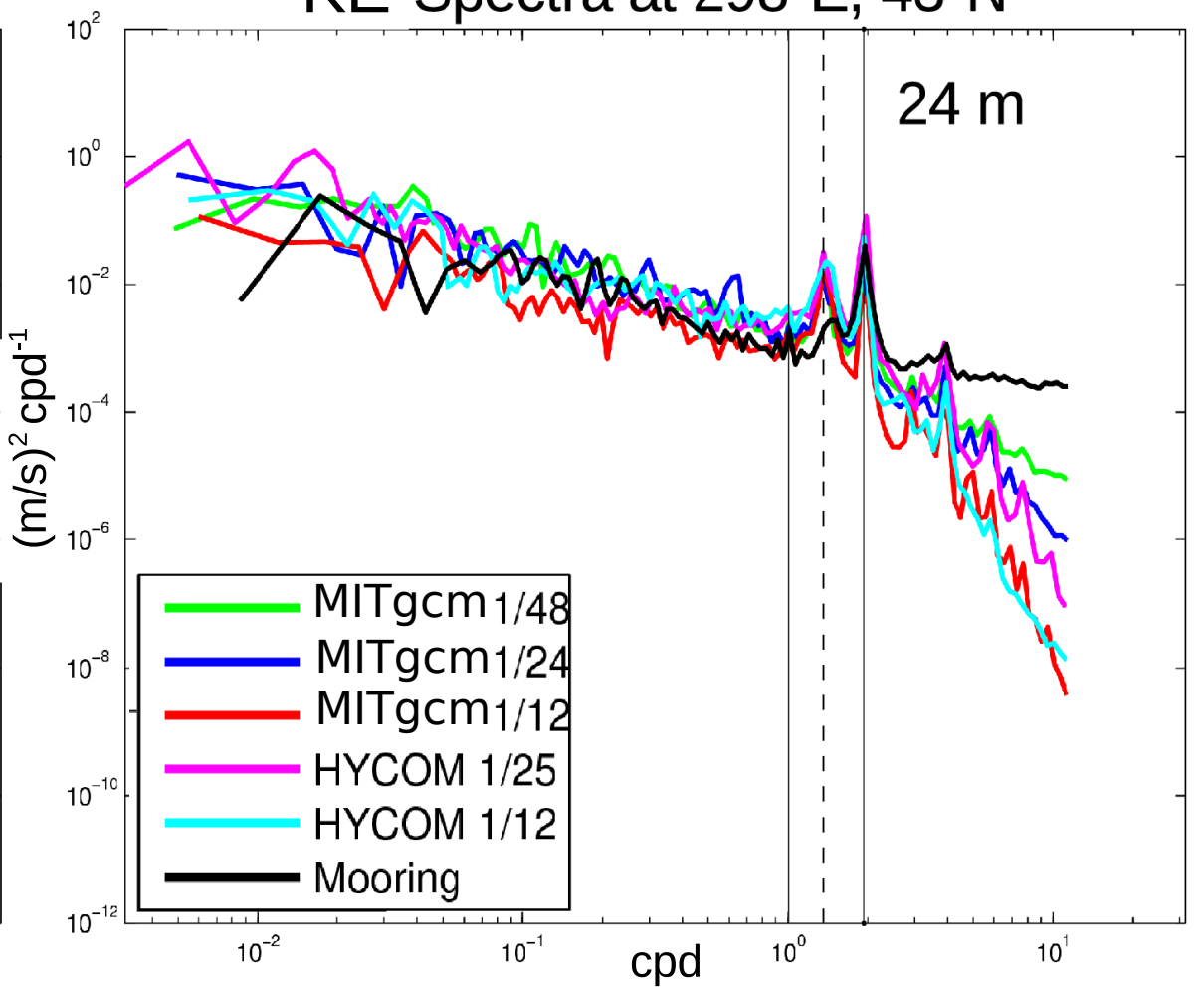

KE Spectra at $288^{\circ} \mathrm{E}, 39^{\circ} \mathrm{N}$

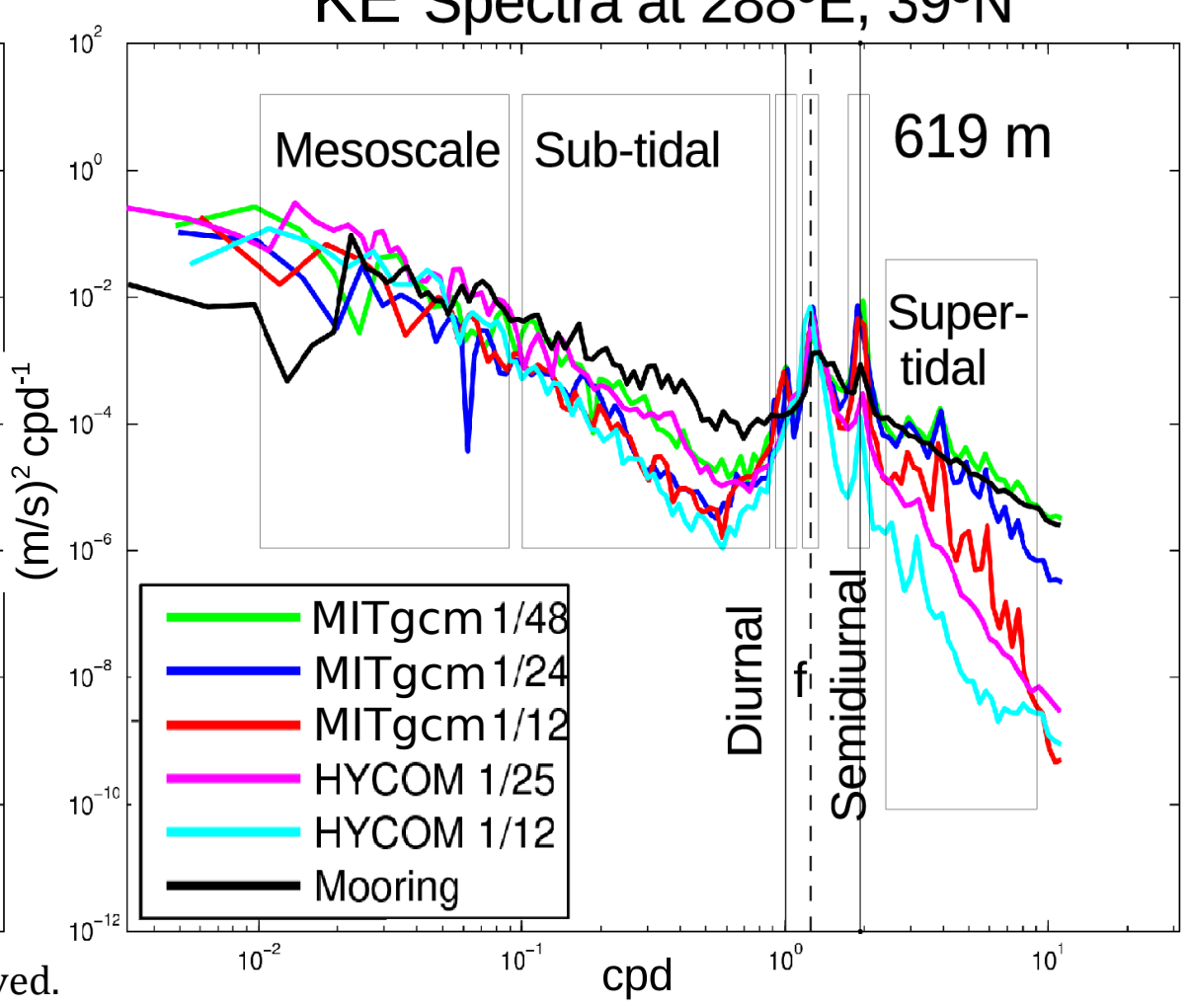




\section{Mean KE by Frequency Band}
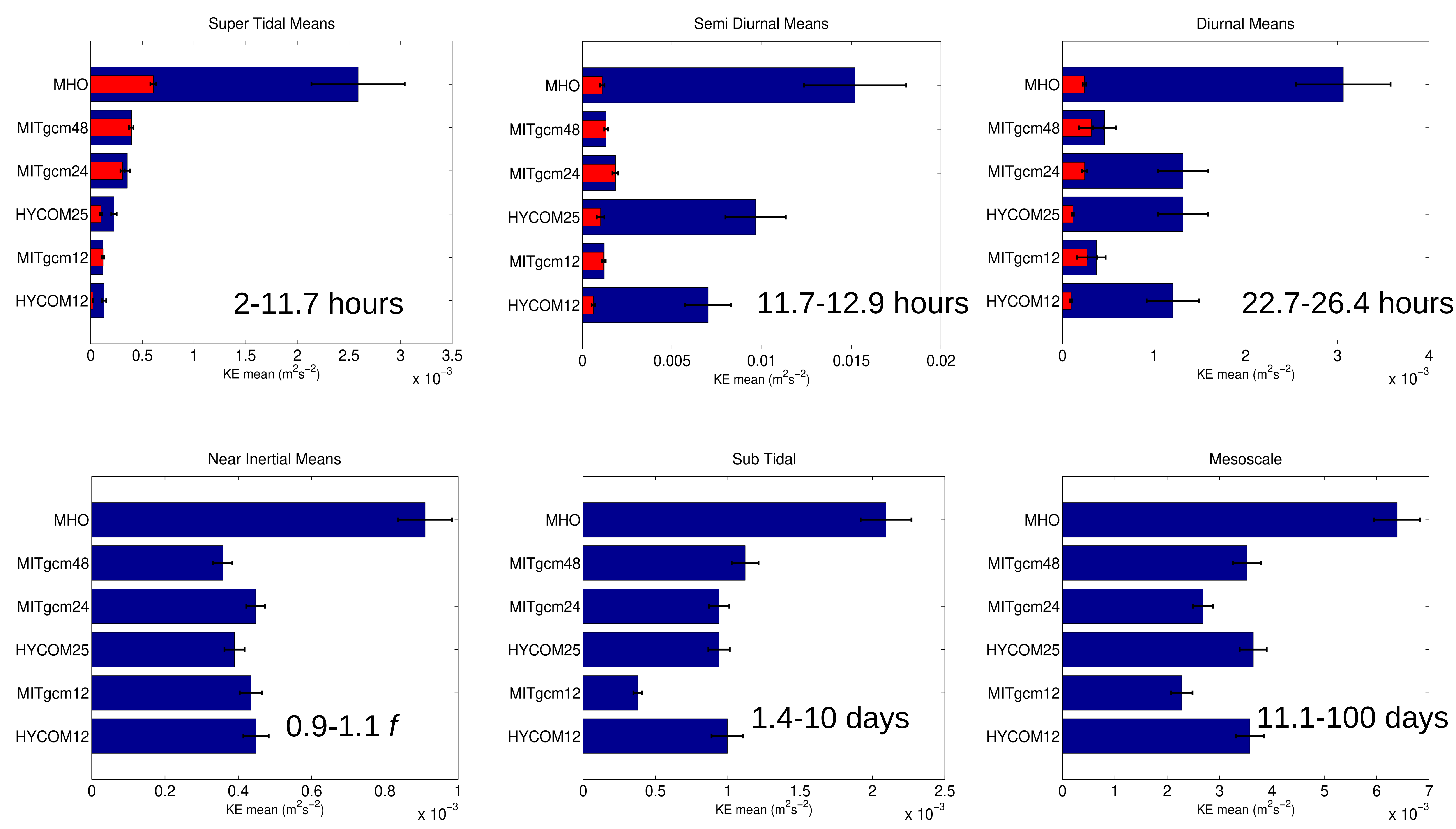

\section{Mean Temperature Variance by Frequency Band}
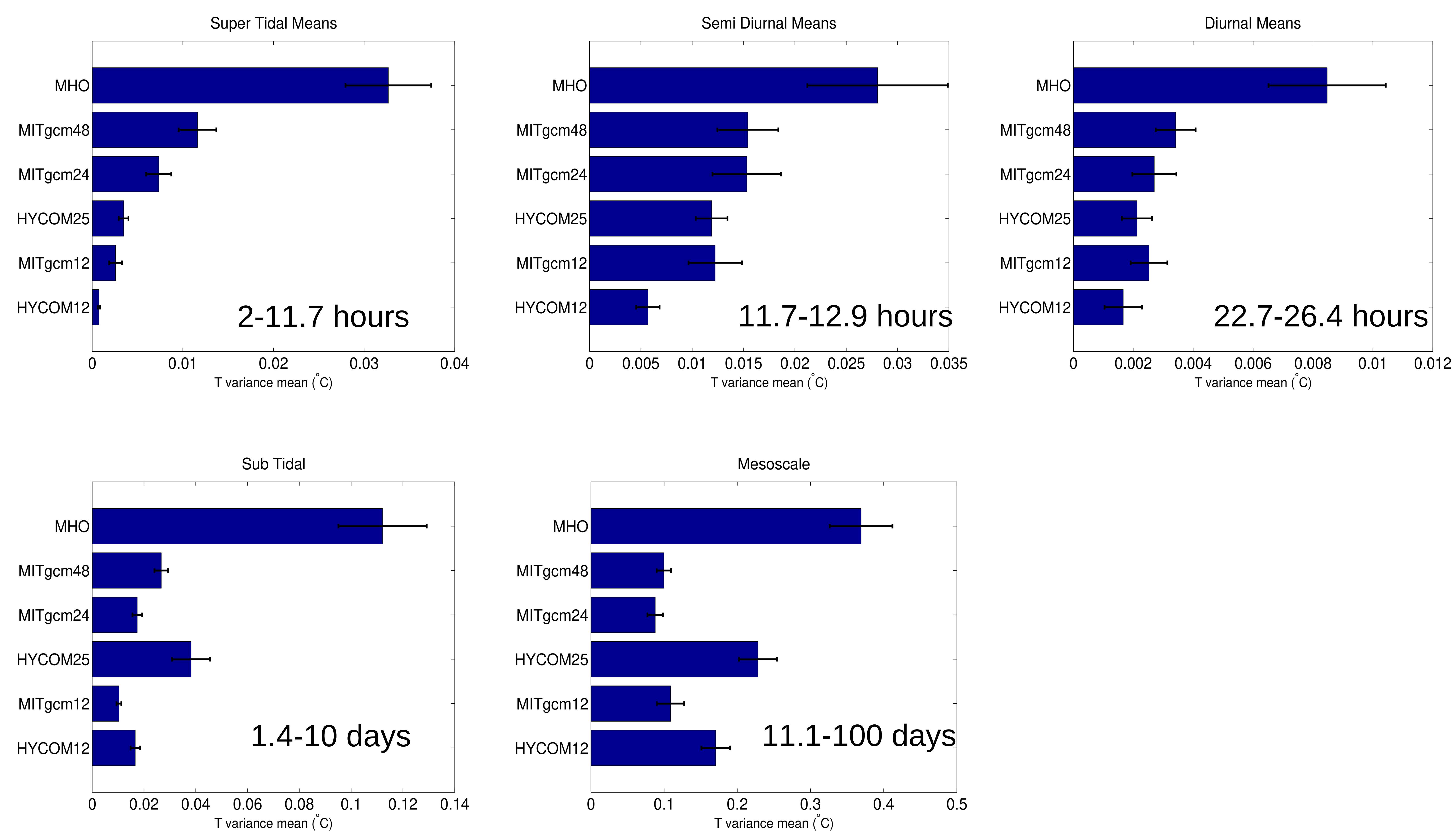
KE comparison metrics
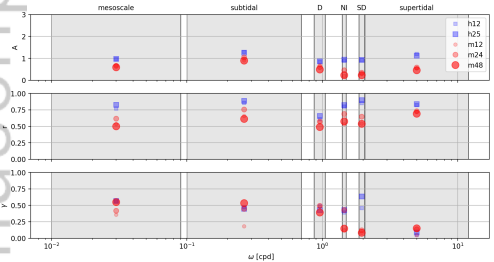

mesoscale

subtidal

D

5D

supertidal

temperature variance comparison metrics
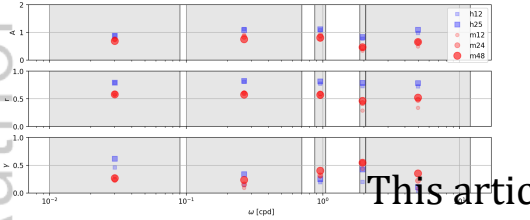
MITgcm12 Super Tidal KE

MHO mean $=2.59 \mathrm{e}-03$

MITgcm mean $=1.19 \mathrm{e}-04$

$A=0.55, b=-2.51 * A=0.97, b=-1.01$

$\begin{array}{ll}A=0.05 & { }^{*} \gamma=0.20 \\ \gamma=0.72 & { }^{*} r_{s}=0.75\end{array}$

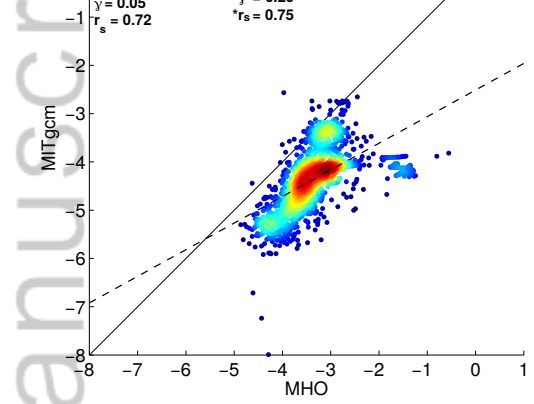

HYCOM12 Super Tidal KE

MHO mean $=2.59 \mathrm{e}-03$

HYCOM mean $=1.30 \mathrm{e}-04$

O $A=1.20, b=-1.04 * A=1.20, b=-1.06$

$\begin{array}{lll}A=0.05 & { }^{*} A=0.04 \\ \gamma & \gamma=0.83 & { }^{*} r_{s}=0.78\end{array}$
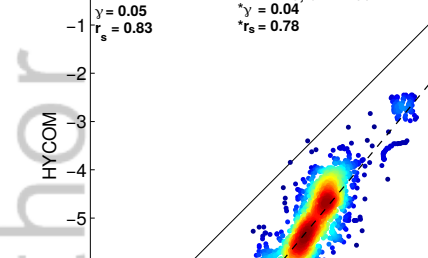

-5
-6

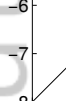

$-8$

then

(3)

$-5 \quad-4 \mathrm{MHO}^{-3}$
MITgcm24 Super Tidal KE

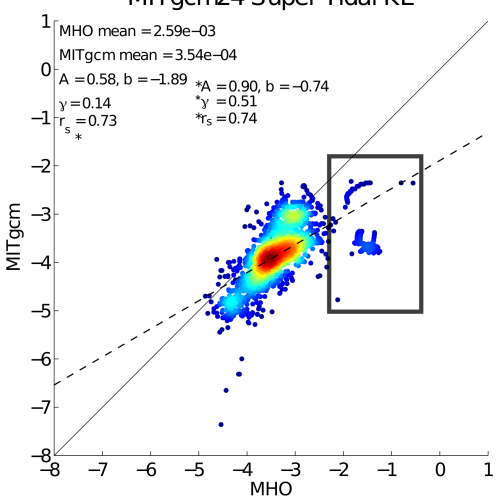

HYCOM25 Super Tidal KE

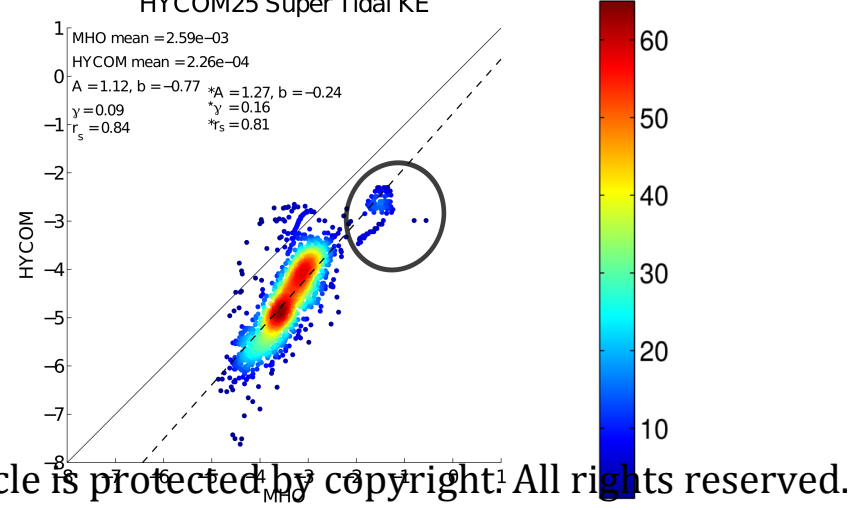

60

50

$-40$

$-30$

$-20$

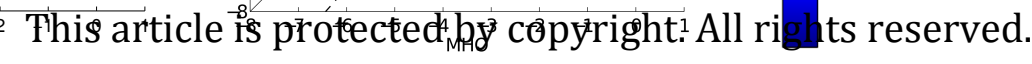

MITgcm48 Super Tidal KE

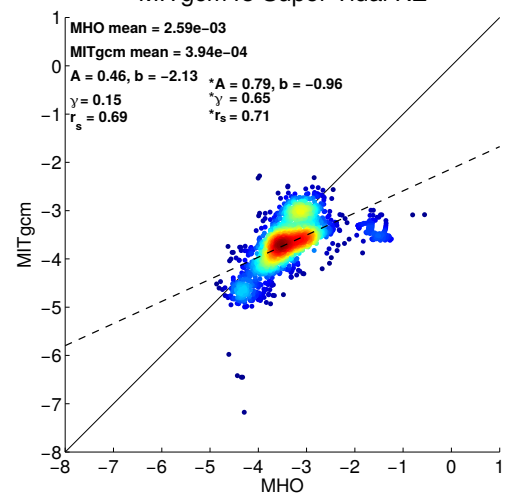


MITgcm12 Super Tidal temperature

MHO mean $=3.27 \mathrm{e}-02$

MITgcm mean $=2.57 \mathrm{e}-03$

$A=0.49, b=-2.84$

$\gamma=0.08$

$-1 \frac{\gamma=0.08}{r_{s}=0.34}$

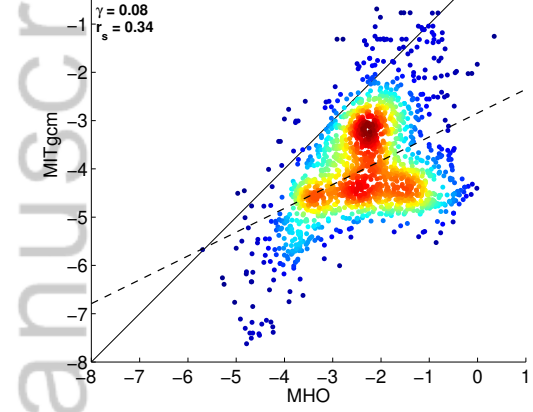

HYCOM12 Super Tidal temperature

MHO mean $=3.27 \mathrm{e}-02$

HYCOM mean $=7.47 \mathrm{e}-04$

$A=0.98, b=-2.08$

$-1 \mid \begin{aligned} & \gamma=0.02 \\ & r_{s}=0.73\end{aligned}$

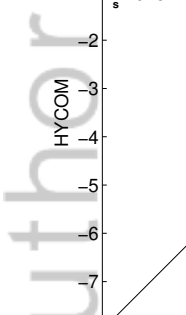

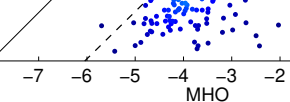

MITgcm24 Super Tidal temperature

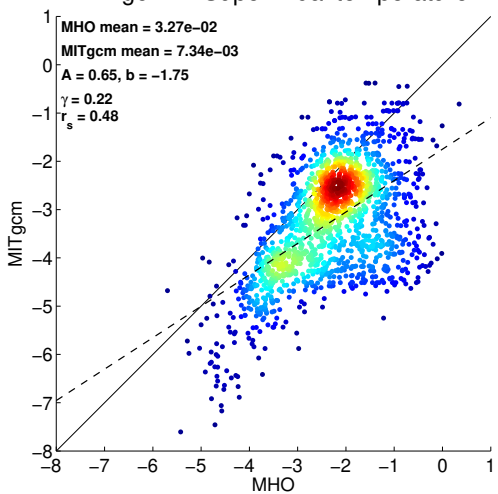

HYCOM25 Super Tidal temperature

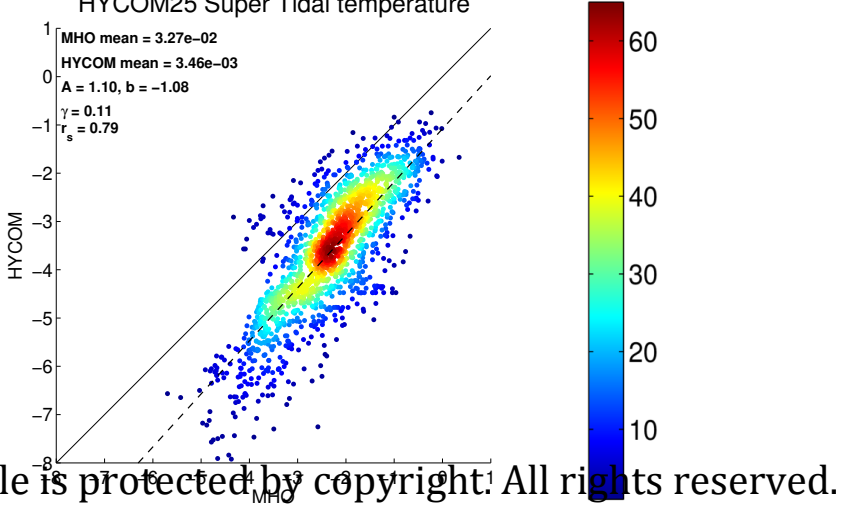

MITgcm48 Super Tidal temperature

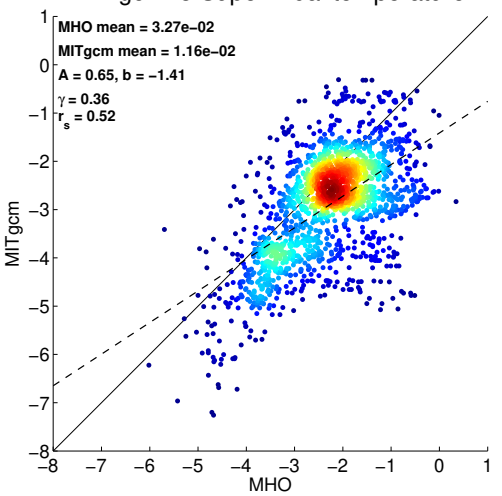

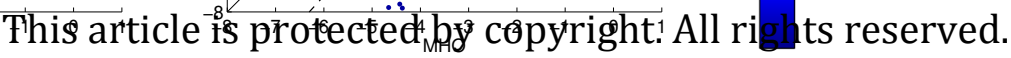


MITgcm12 Semi-Diurnal KE

MHO mean $=1.52 \mathrm{e}-02$

MITgcm mean $=1.22 \mathrm{e}-03$

$A=0.28, b=-2.27 * A=0.43, b=-1.77$

$\begin{array}{ll}\gamma=0.08 & { }^{*} \gamma=1.08 \\ r_{s}=0.54 & { }^{*} r_{s}=0.51\end{array}$

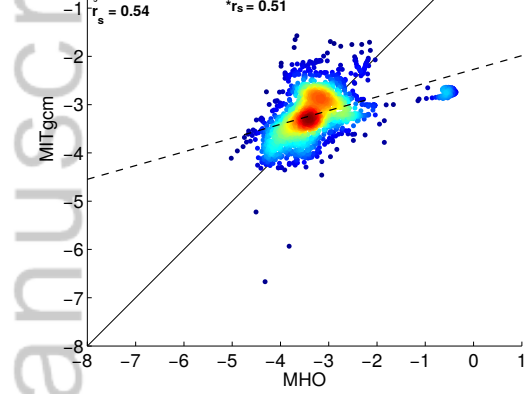

HYCOM12 Semi-Diurnal KE

MHO mean $=1.52 \mathrm{e}-02$

HYCOM mean $=7.01 \mathrm{e}-03$

$\mathrm{A}=0.92, \mathrm{~b}=-0.52 \times \mathrm{A}=0.86, \mathrm{~b}=-0.72$

\begin{tabular}{l|ll} 
& & \\
$\gamma=0.46$ & & \\
& ${ }^{*} \gamma=0.56$ \\
$r_{s}=0.85$ & ${ }^{*} r_{s}=0.83$
\end{tabular}

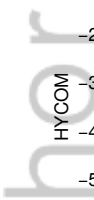

MITgcm24 Semi-Diurnal KE

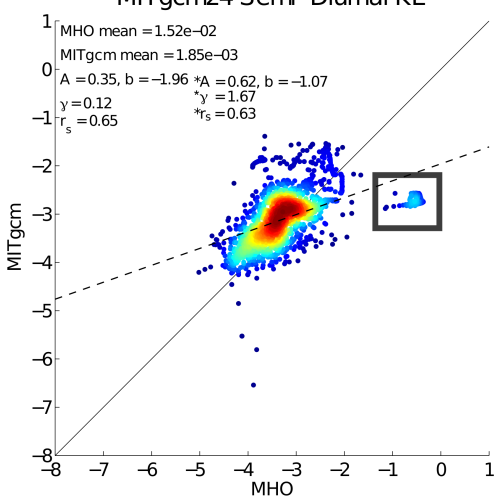

HYCOM25 Semi-Diurnal KE

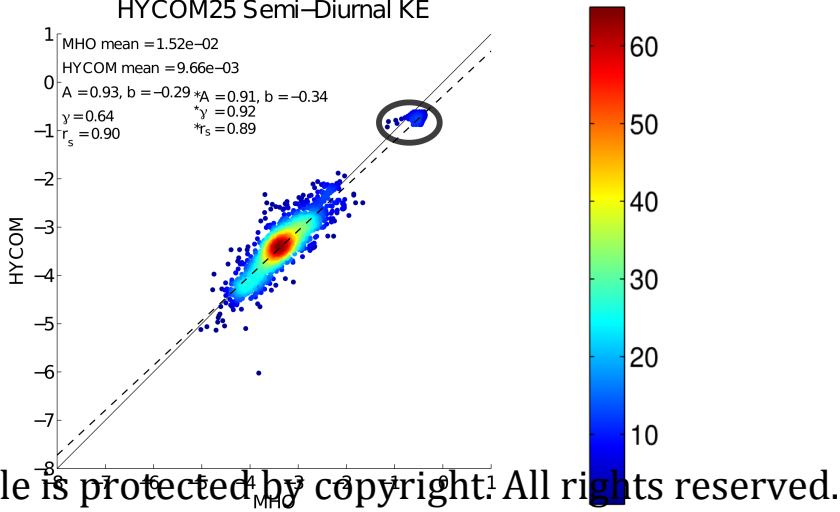

\section{MITgcm48 Semi-Diurnal KE}

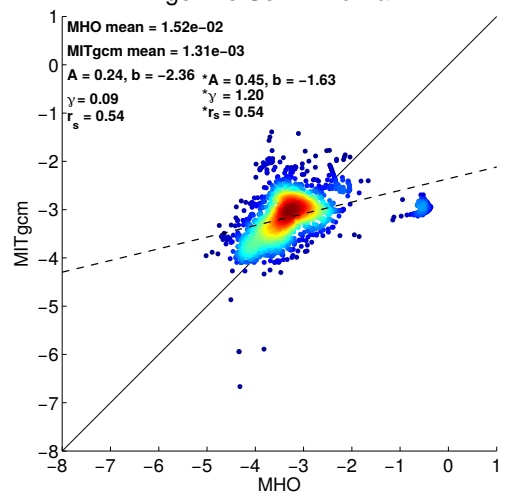

ts reserved. 
MITgcm12 Semi-Diurnal temperature

MHO mean $=2.81 \mathrm{e}-02$

MITgcm mean $=1.22 \mathrm{e}-02$

$A=0.34, b=-2.38$

$\gamma=0.44$

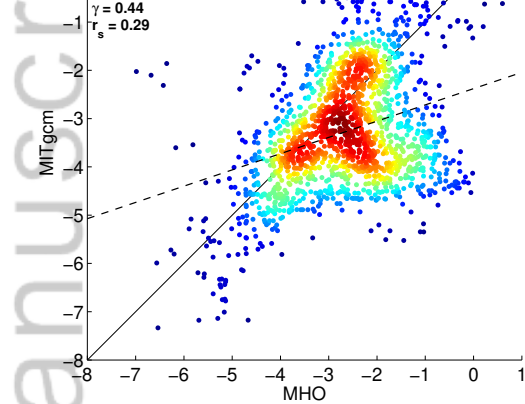

HYCOM12 Semi-Diurnal temperature

MHO mean $=2.81 \mathrm{e}-02$

HYCOM mean $=5.68 \mathrm{e}-03$

$A=0.77, b=-1.44$

$\gamma=0.20$
$\gamma=0.73$

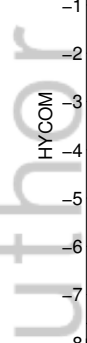
$-8$

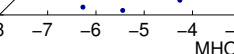

$\therefore$

$\therefore$

西

$\therefore$

or $\because \therefore$

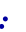

$\therefore$.

\section{T}

MITgcm24 Semi-Diurnal temperature

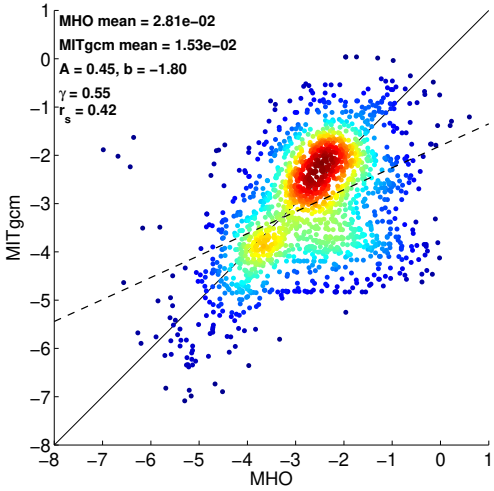

HYCOM25 Semi-Diurnal temperature

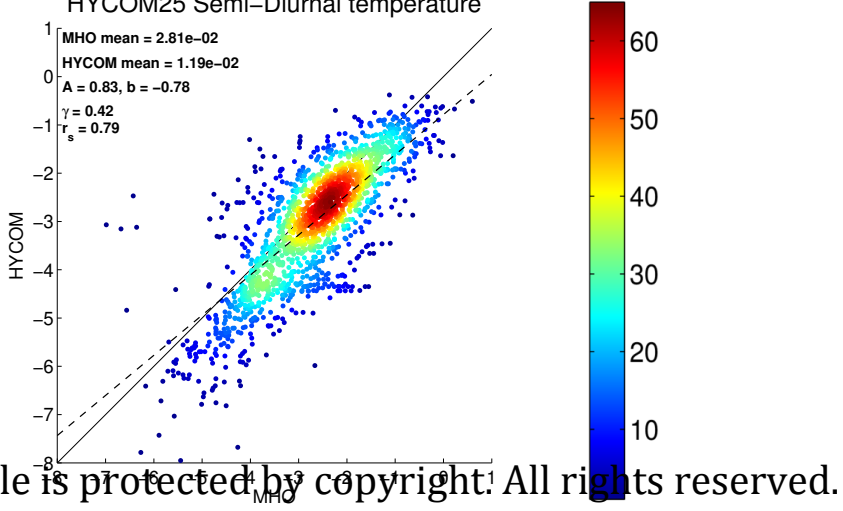

60

50
MITgcm48 Semi-Diurnal temperature

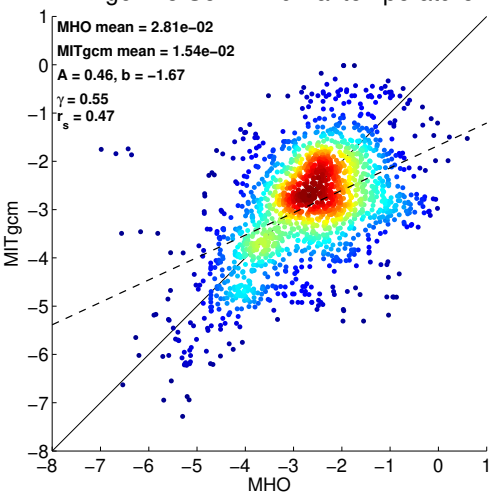

$\because \cdots$

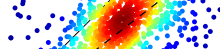

- $\therefore$,

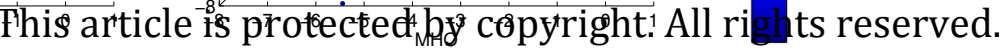


MITgcm12 Diurnal KE

MHO mean $=3.06 \mathrm{e}-03$

MITgcm mean $=3.71 \mathrm{e}-04$

$A=0.20, b=-3.26 * A=0.57, b=-1.79$

$\begin{array}{ll}\gamma=0.12 & { }^{*} \gamma=1.10 \\ r_{s}=0.53 & { }^{*} r_{s}=0.66\end{array}$

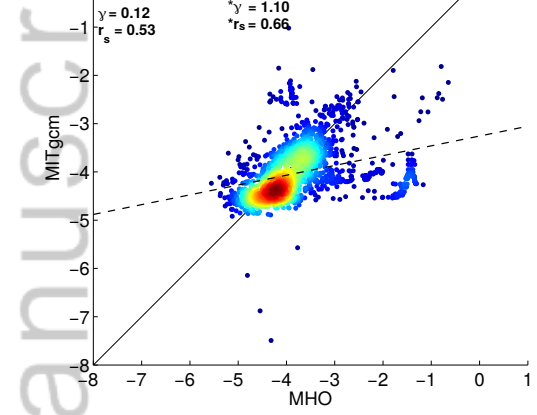

HYCOM12 Diurnal KE

MHO mean $=3.06 \mathrm{e}-03$

HYCOM mean $=1.20 \mathrm{e}-03$

0 $A=0.90, b=-0.91 * A=0.91, b=-0.84$

$-1 \quad \begin{array}{ll}A=0.39 & { }^{*} \gamma=0.41 \\ \gamma=0.80 & { }^{*} r_{s}=0.79\end{array}$
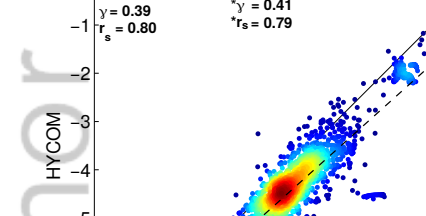

की

a

artastis.

, w.

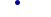

MITgcm24 Diumal KE

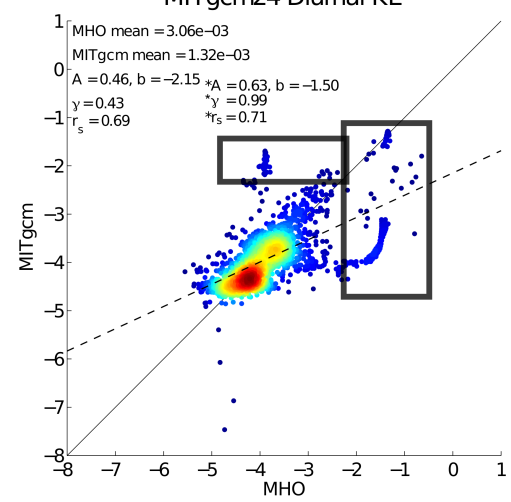

HYCOM25 Diurnal KE

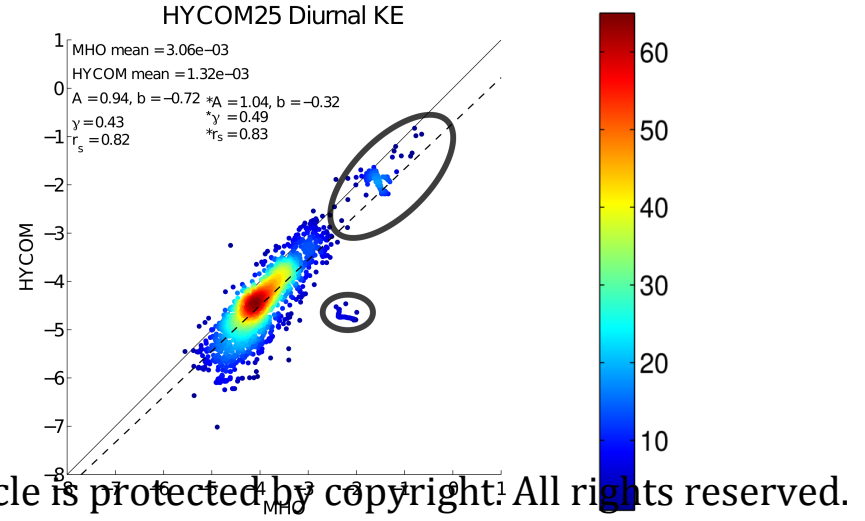


MITgcm12 Diurnal temperature

MHO mean $=8.47 \mathrm{e}-03$

MITgcm mean $=2.52 \mathrm{e}-03$

$A=0.75, b=-1.93$

\begin{tabular}{l|l}
$\gamma$ & $\gamma=0.30$ \\
$-r_{s}=0.53$
\end{tabular}

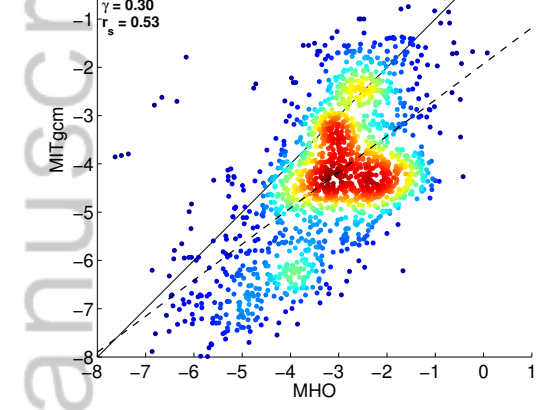

HYCOM12 Diurnal temperature

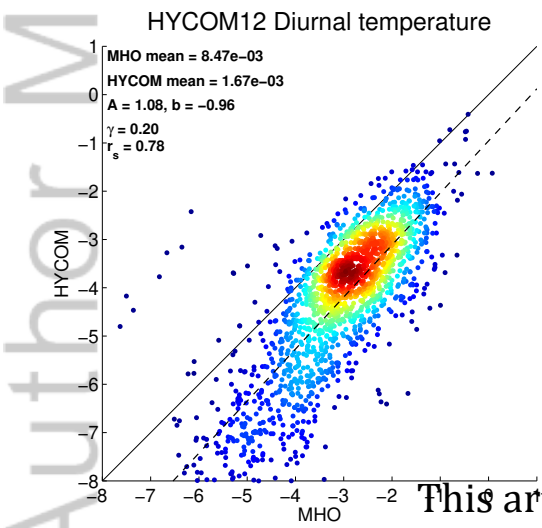

MITgcm24 Diurnal temperature

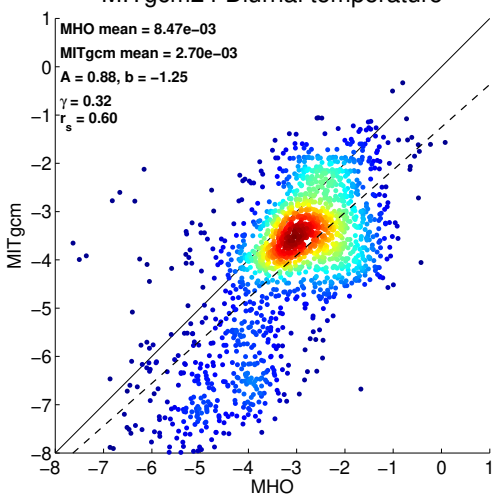

HYCOM25 Diurnal temperature

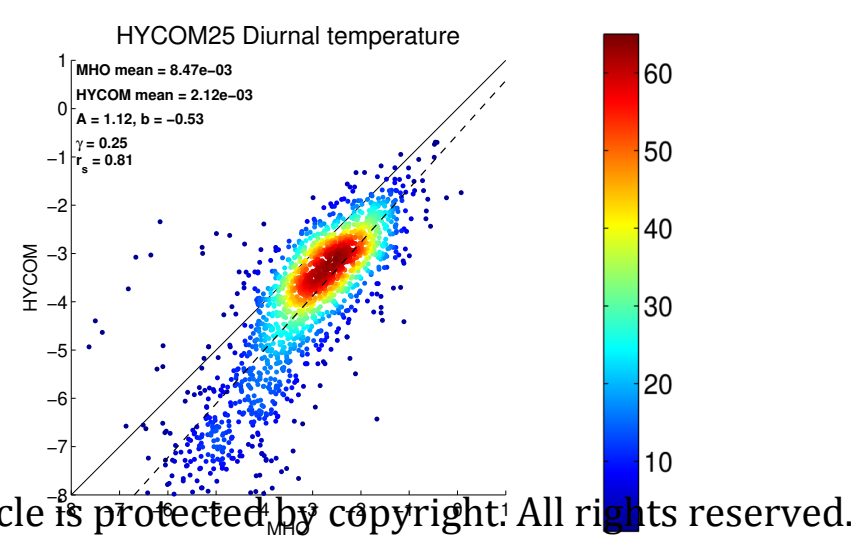

MITgcm48 Diurnal temperature

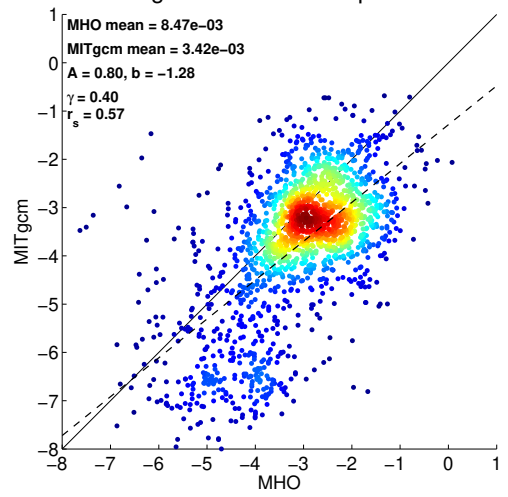


MITgcm12 Sub Tidal temperature

MHO mean $=1.12 \mathrm{e}-01$

MITgcm mean $=1.03 \mathrm{e}-02$

$A=0.92, b=-1.39$

$-1 \mid \begin{aligned} & \gamma=0.09 \\ & \gamma-r_{s}=0.61\end{aligned}$

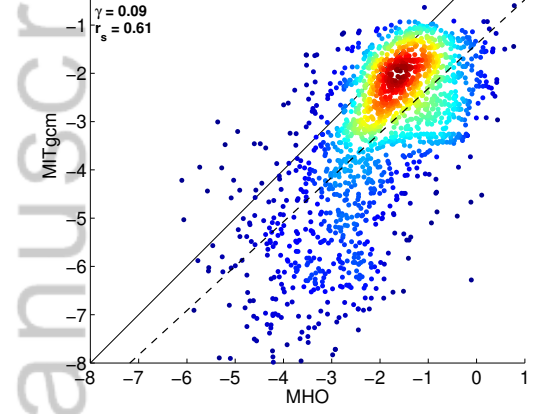

HYCOM12 Sub Tidal temperature

MHO mean $=1.12 \mathrm{e}-01$

HYCOM mean $=1.67 \mathrm{e}-02$

$A=1.12, b=-0.84$

$\gamma=0.15$

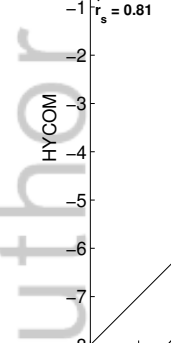

$-8$

$\begin{array}{lll}-8 & -7 & -6\end{array}$
MITgcm24 Sub Tidal temperature

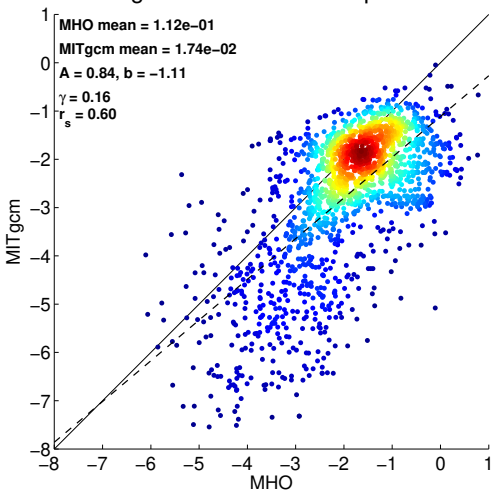

HYCOM25 Sub Tidal temperature

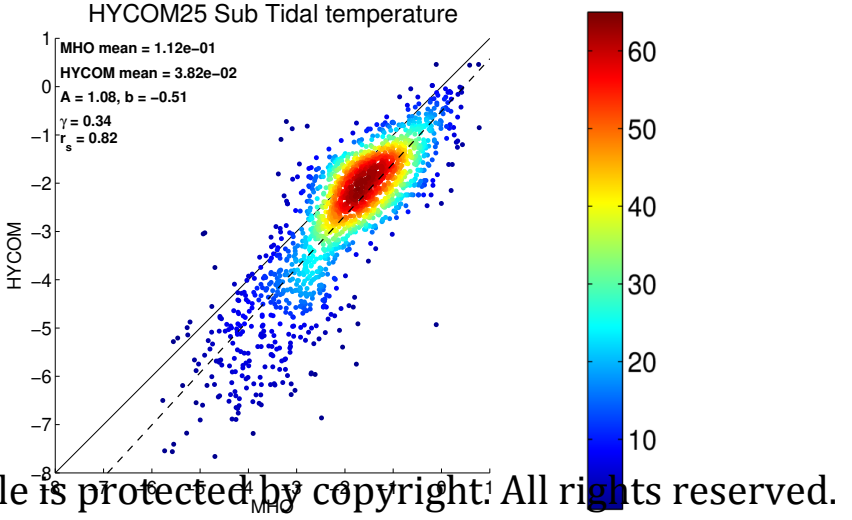

MITgcm48 Sub Tidal temperature

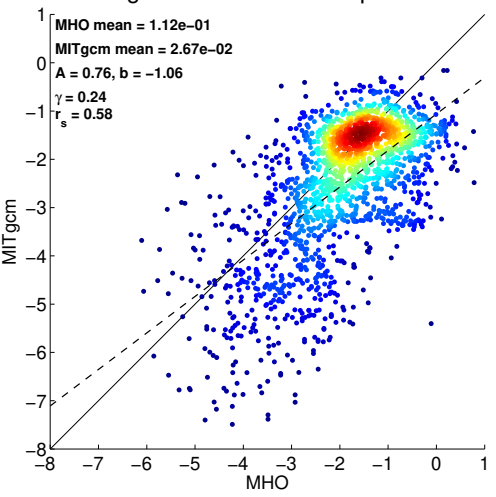


MITgcm12 Mesoscale KE

MHO mean $=6.39 \mathrm{e}-03$

MITgcm mean $=2.28 \mathrm{e}-03$

$A=0.68, b=-1.44$

$\gamma=0.36$

$-1 \frac{\gamma=0.36}{r_{s}=0.54}$

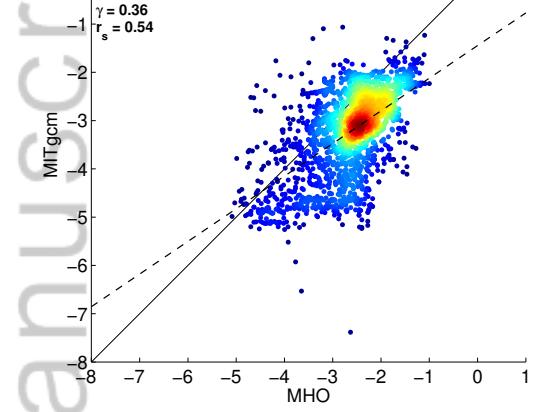

HYCOM12 Mesoscale KE

MHO mean $=6.39 \mathrm{e}-03$

HYCOM mean $=3.58 \mathrm{e}-03$

$A=0.97, b=-0.42$

$\gamma=0.56$

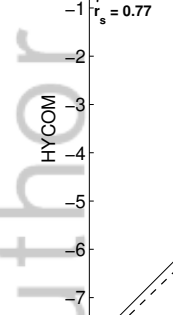

$-8$

$\begin{array}{lllll}-7 & -6 & -5 & -4 & -3 \\ & & & \end{array}$
MITgcm24 Mesoscale KE

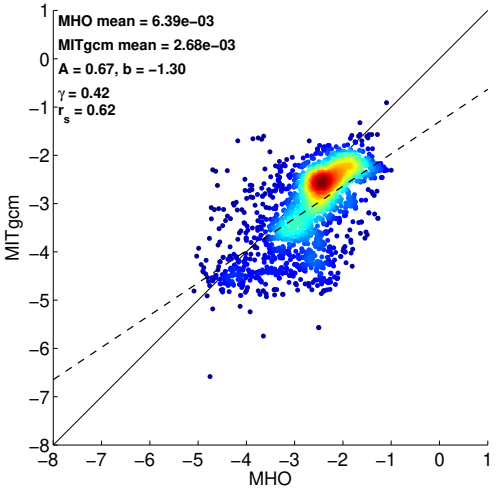

HYCOM25 Mesoscale KE

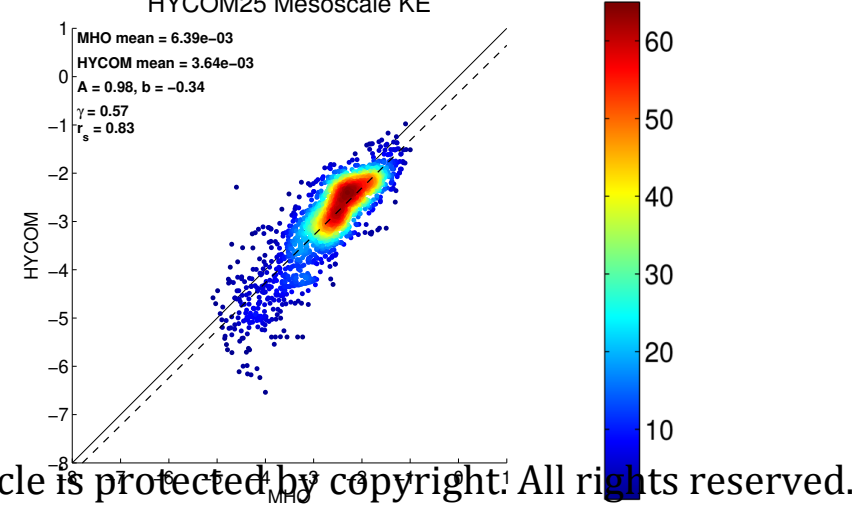

MITgcm48 Mesoscale KE

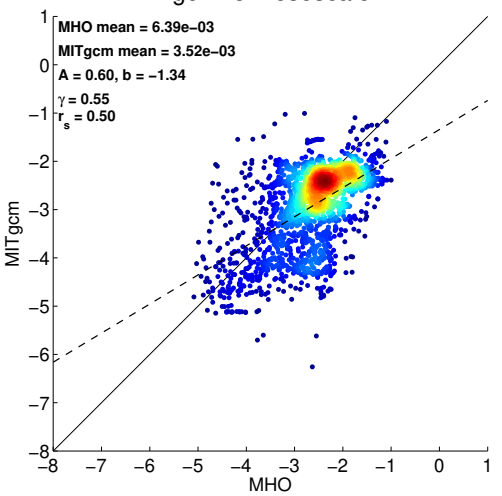

This article is protected ${ }^{-8}$ pry cơpy'right All rights reserved. 
MITgcm12 Mesoscale temperature

MHO mean $=3.69 \mathrm{e}-01$

MITgcm mean $=1.09 \mathrm{e}-01$

$A=0.74, b=-0.92$

$\gamma=0.29$

$-1 \quad \begin{aligned} & \gamma=0.29 \\ & r_{s}=0.57\end{aligned}$

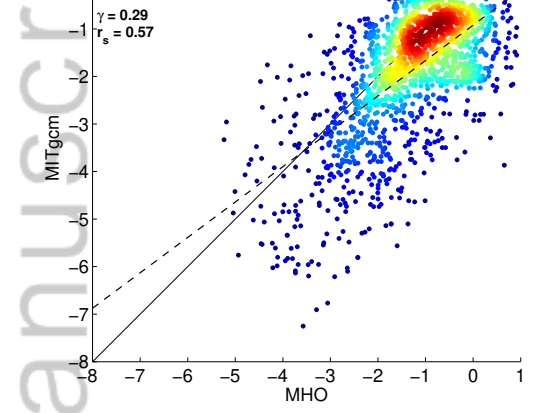

HYCOM12 Mesoscale temperature

MHO mean $=3.69 \mathrm{e}-01$

HYCOM mean $=1.70 \mathrm{e}-01$

$A=0.89, b=-0.48$

$\gamma=0.46$
$-r_{s}=0.79$

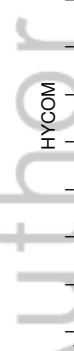

$-8$
MITgcm24 Mesoscale temperature

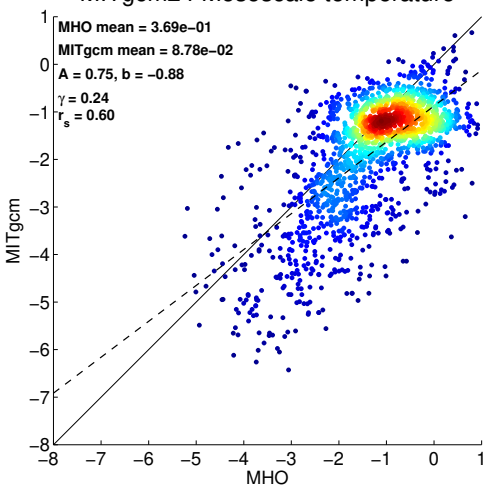

HYCOM25 Mesoscale temperature

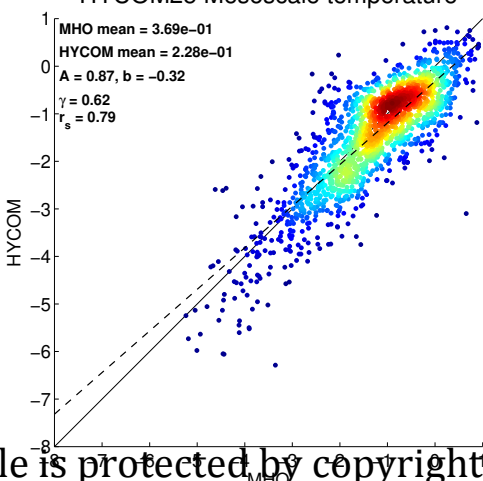

MITgcm48 Mesoscale temperature

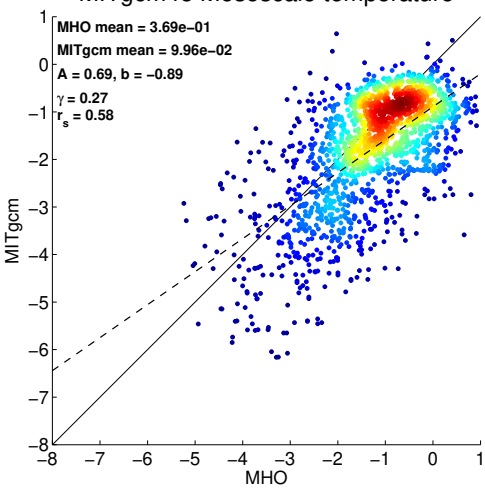

60

50

$-40$

$-30$

20

10 


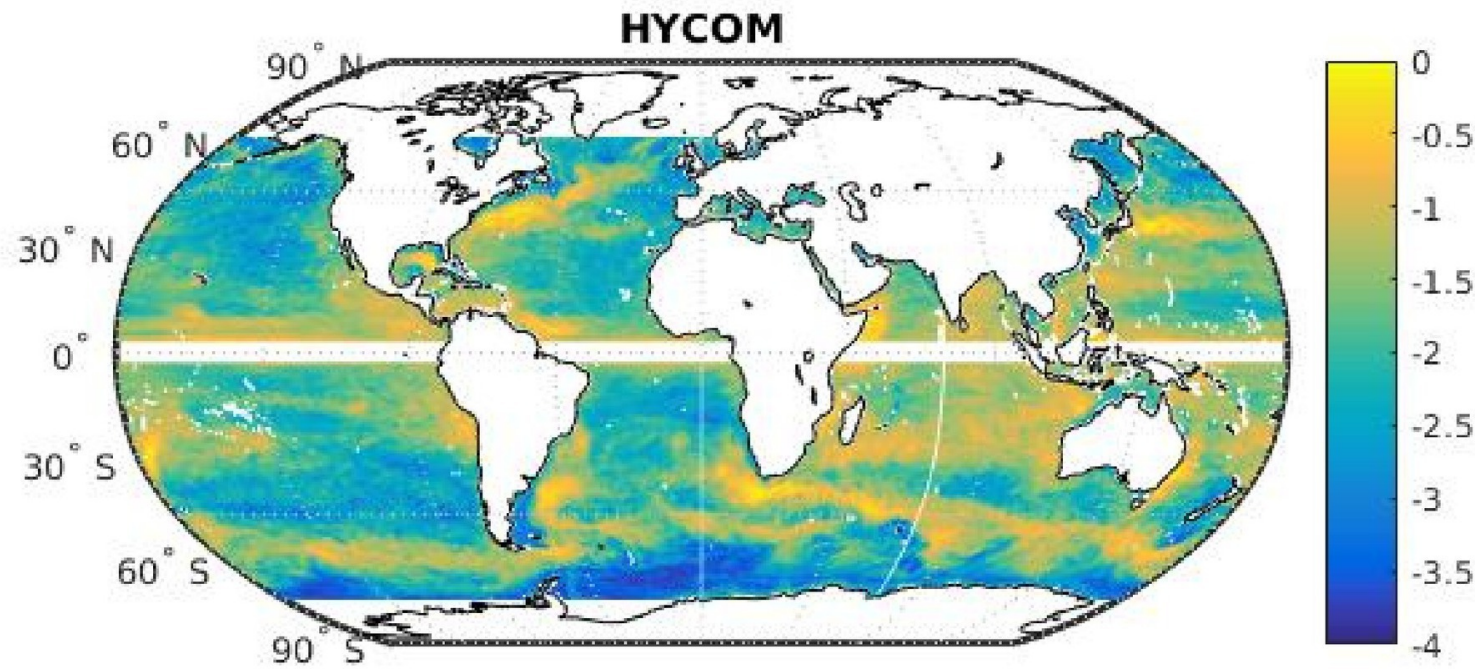

$180^{\circ} \mathrm{W} \quad 90^{\circ} \mathrm{W} \quad 0^{\circ} \quad 90^{\circ} \mathrm{E} \quad 180^{\circ} \mathrm{E}$

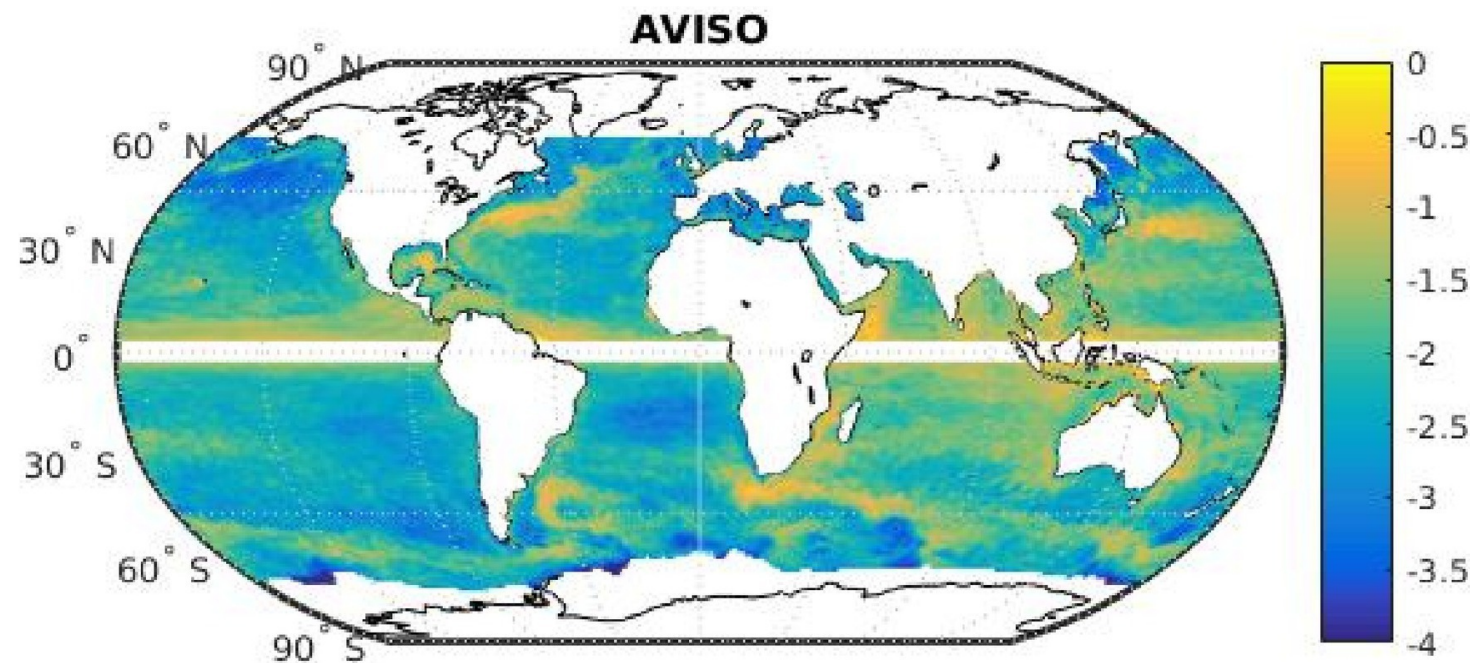

$180^{\circ} \mathrm{W} \quad 90^{\circ} \mathrm{W} \quad 0^{\circ} \quad 90^{\circ} \mathrm{E} \quad 180^{\circ} \mathrm{E}$

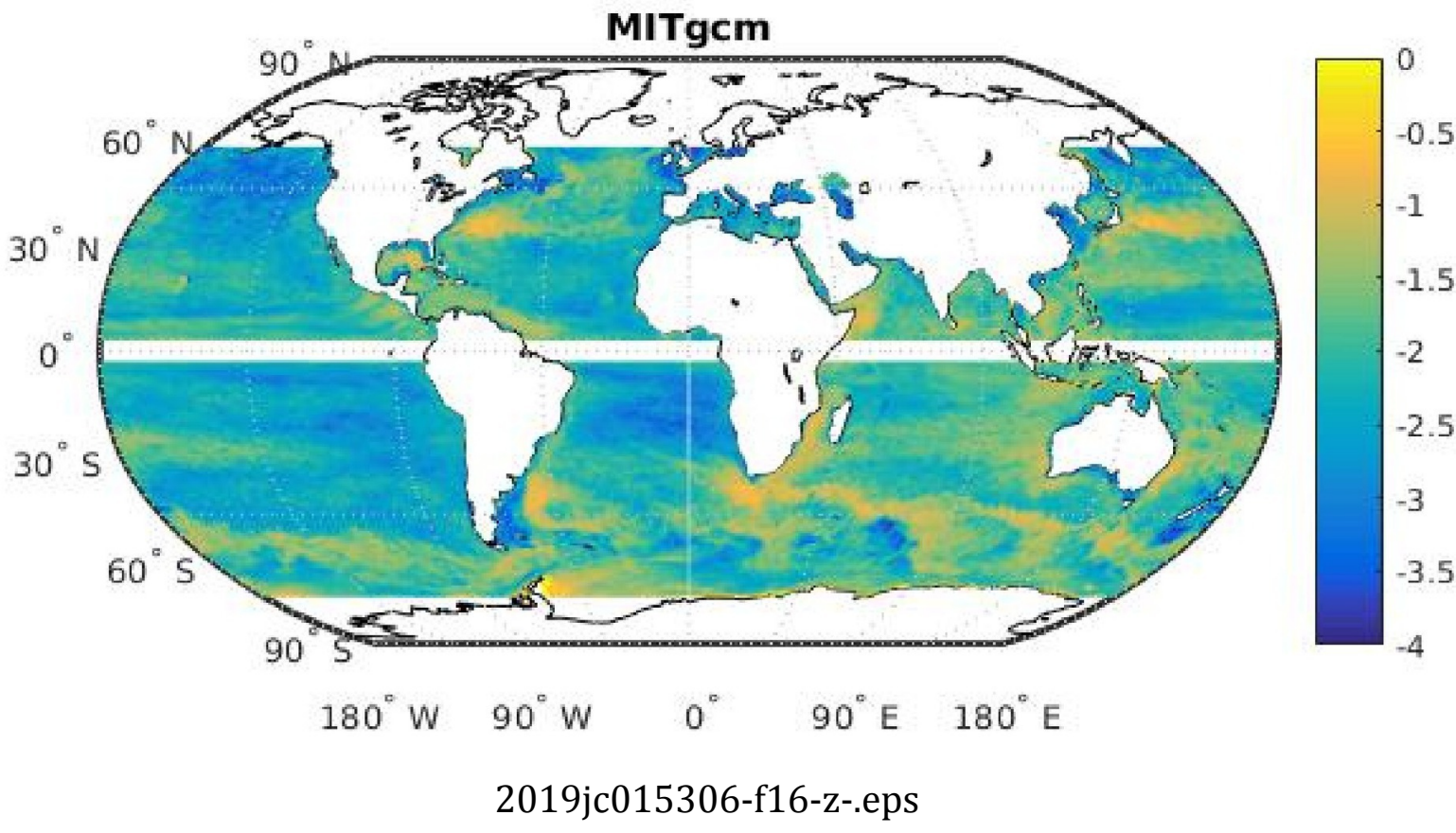

This article is protected by copyright. All rights reserved. 
MITgcm1/48 Global Geostrophic KE

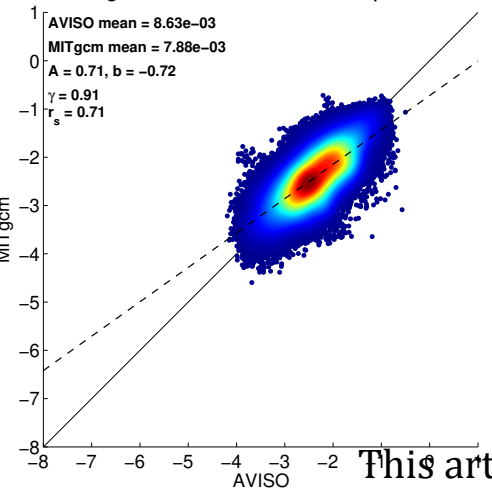

HYCOM1/25 Global Geostrophic KE

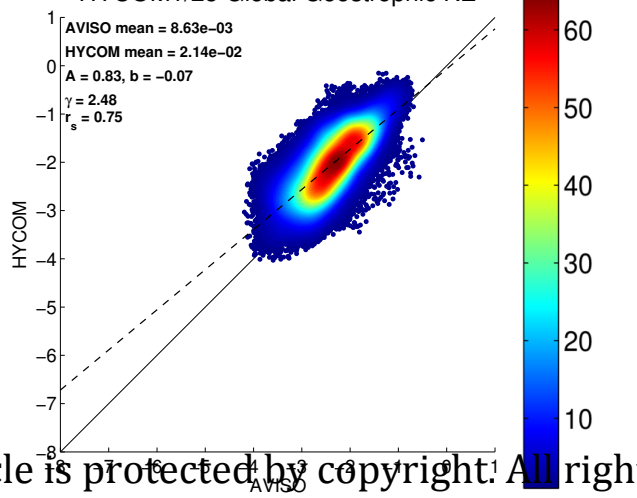


MITgcm1/48 Geostrophic KE

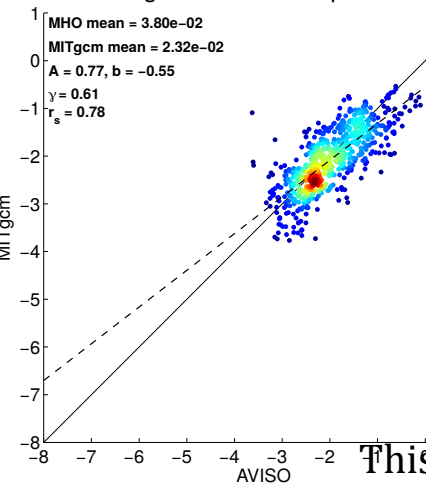

HYCOM1/25 Geostrophic KE

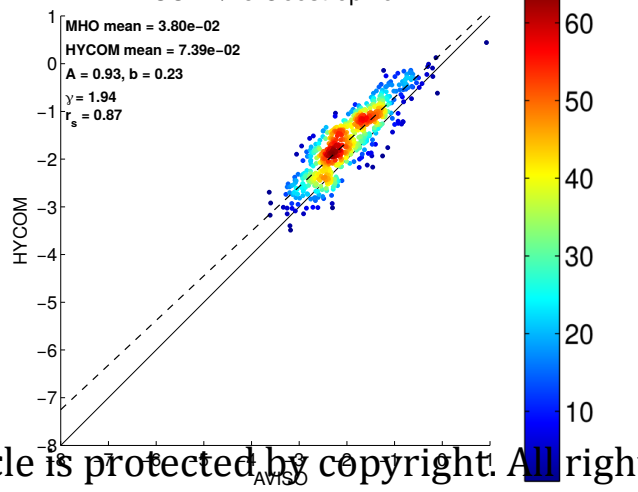

